\title{
AGGREGATING
} PHILLIPS CURVES

by Jean Imbs,

Eric Jondeau and Florian Pelgrin

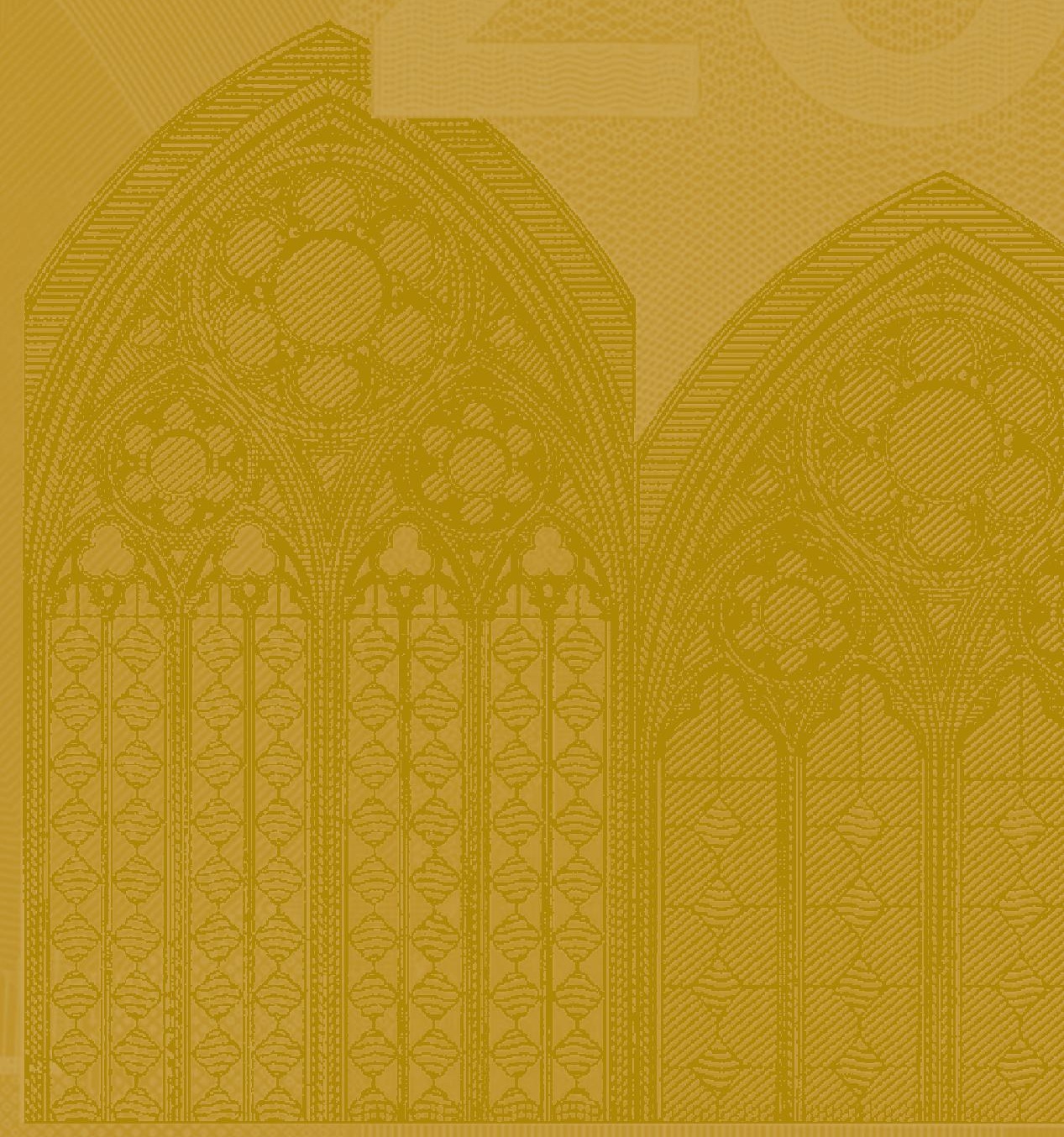




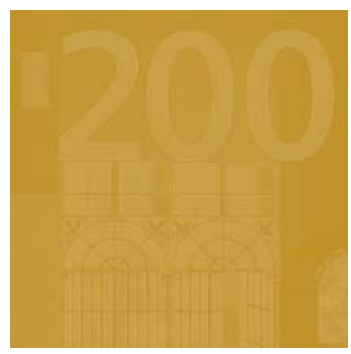

\title{
WORKING PAPER SERIES
}

NO 785 / JULY 2007

\author{
ECB/CEPR LABOUR \\ MARKET WORKSHOP ON \\ WAGE AND LABOUR \\ COST DYNAMICS

\section{AGGREGATING PHILLIPS CURVES I}
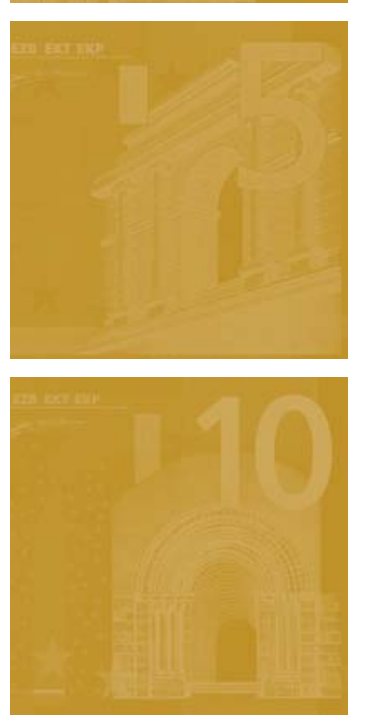

by Jean Imbs ${ }^{2}$,

Eric Jondeau ${ }^{3}$

and Florian Pelgrin ${ }^{4}$

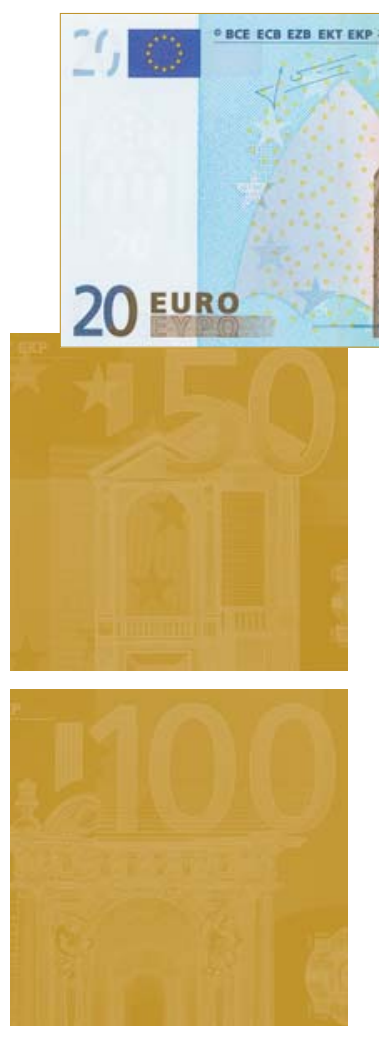

This paper can be downloaded without charge from

I We are grateful to audiences at the European Central Bank / CEPR conference on Wage and Labour Cost Dynamics held in December 2006, the European Summer Symposium in International Macroeconomics, held in May 2006, the 2006 meetings of the Society of Computational Economics, the 2006 meetings of the Society for Economic Dynamics, the 2006 Dynare conference, the joint seminar of the National Bank of Belgium, Université Catholique de Louvain, Université Libre de Bruxelles and Katholieke Universiteit Leuven, and especially to Klaus Adams, Carlos Carvalho, Marco Del Negro, David López-Salido and Rafael Wouters for insightful discussions. We also thank Stephane Gregoir for kindly supplying us with the French data used in the paper. The paper was partly written while Imbs was a Resident Scholar at the Research Department of the International Monetary Fund. Financial support from the National Center of Competence in Research "Financial Valuation and Risk Management" is gratefully acknowledged. The National Centers of Competence in Research (NCCR) are a research instrument of the Swiss National Science Foundation. All errors are our own.

2 Corresponding author: Department of Economics, Institute of Banking and Finance - HEC Lausanne, CH-10 I5 Lausanne, Switzerland; e-mail:jimbs@unil.ch

3 Institute of Banking and Finance, Ecole des HEC - University of Lausanne, Extranef 232, CH-10I5 Lausanne, Switzerland; e-mail: Eric.Jondeau@unil.ch

4 Enseignement et recherche - HEC, Quartier UNIL-Dorigny, Bâtiment Extranef 246, CH-1015 Lausanne, 


\section{ECB/CEPR Labour Market Workshop on "Wage and Labour Cost Dynamics"}

This paper was presented at the ECB/CEPR Labour Market Workshop on "Wage and Labour Cost Dynamics", held on 14-15 December 2006 in Frankfurt am Main, Germany. The workshop was organized by Torben M Andersen (Universitet Aarhus and CEPR), Samuel Bentolila (CEMFI and CEPR), Ana Lamo (ECB) and Jarkko Turunen (ECB). The conference programme, including papers, can be found on the ECB's web site http://www.ecb.int/events/conferences/html/wage_and_labour.en.html

The views expressed in the paper are the author's own and do not necessarily reflect those of the Eurosystem.

\footnotetext{
(C) European Central Bank, 2007

Address

Kaiserstrasse 29

60311 Frankfurt am Main, Germany

Postal address

Postfach 160319

60066 Frankfurt am Main, Germany

Telephone

+496913440

Internet

http://www.ecb.int

Fax

+496913446000

Telex

411144 ecb d

All rights reserved.

Any reproduction, publication and reprint in the form of a different publication, whether printed or produced electronically, in whole or in part, is permitted only with the explicit written authorisation of the ECB or the author(s).

The views expressed in this paper do not necessarily reflect those of the European Central Bank.

The statement of purpose for the ECB Working Paper Series is available from the ECB website, http://www.ecb.int. 


\section{CONTENTS}

Abstract

Non-technical summary

1 Introduction

2 Aggregating sectoral Phillips curves

2.1 A sectoral Phillips curve

2.2 Aggregation

2.3 A two-sector example

3 The biases

3.1 Analytics

3.2 Simulations

4 Econometric methods

4.1 Mean group

4.2 Random coefficients

4.3 Cross-industry linkages

5 Results

5.1 Data

5.2 Industry estimates

5.3 Heterogeneity bias

5.4 Correcting for cross-industry linkages

6 Robustness

7 Conclusion

Appendices

References

Tables and figures

European Central Bank Working Paper Series 


\begin{abstract}
The New Keynesian Phillips Curve is at the center of two raging empirical debates. First, how can purely forward looking pricing account for the observed persistence in aggregate inflation. Second, price-setting responds to movements in marginal costs, which should therefore be the driving force to observed inflation dynamics. This is not always the case in typical estimations. In this paper, we show how heterogeneity in pricing behavior is relevant to both questions. We detail the conditions under which imposing homogeneity results in overestimating a backward-looking component in (aggregate) inflation, and underestimating the importance of (aggregate) marginal costs for (aggregate) inflation. We provide intuition for the direction of these biases, and verify them in French data with information on prices and marginal costs at the industry level. We show that the apparent discrepancy in the estimated duration of nominal rigidities, as implied from aggregate or microeconomic data, can be fully attributable to a heterogeneity bias.
\end{abstract}

JEL Classifications: C10, C22, E31, E52.

Keywords: New Keynesian Phillips Curve, Heterogeneity, Inflation Persistence, Marginal Costs. 


\section{Non-technical summary}

Since it burst onto the scene of mainstream monetary economics, the New Keynesian Phillips Curve has been the focus of two important empirical debates. First, to what extent purely forward-looking pricing behavior can be reconciled with observed inflation persistence. Second, to what extent properly measured marginal costs affect inflation dynamics. Both issues are crucial for our ability to understand and predict movements in prices. If inflation is purely forward looking, its persistence arises only from that of shocks to marginal costs (provided they matter), and perfectly anticipated changes in inflation are costless. Second, that shocks to marginal costs affect inflation is the basis of the forward-looking pricing rule profit maximizing firms are assumed to follow, and indeed the basis of a model of inflation driven by economic fundamentals rather than mere autoregressive properties. What is more, the magnitude of the relation between marginal costs and inflation relates directly to the duration of nominal rigidities. Both issues have recently been hotly debated, and for good reason.

In this paper, we show that heterogeneity in the pricing behavior of firms matters for both empirical questions. We consider two archetypical models of a hybrid Phillips curve, amended to allow for differences in nominal rigidities and price setting behavior across industries. We provide the expressions for the inconsistencies that plague Phillips curve estimates in the presence of heterogeneity, and argue the biases do not all have the same sign, nor the same magnitude. We show analytically that an approach imposing homogeneity is likely to underestimate the role of (aggregate) marginal costs in affecting (aggregate) prices, and overestimate the apparent (aggregate) backward looking behavior in prices. Simulations suggest both inconsistencies tend to originate from differences across industries in the duration of nominal rigidities, and not from differences in the degree of indexation, or ad hoc backward looking behavior.

We investigate these analytics in French sectoral data, and verify they hold under less restrictive assumptions. In particular, we implement a battery of heterogeneous estimators, allowing for deterministic or stochastic heterogeneity, and for the possibility that prices and marginal costs be correlated across industries. Comparing our results and those implied by standard homogeneous approaches confirms our analysis. Prices respond to marginal costs and are more forward looking when firms' pricing strategies are allowed to differ across industries. The reduced form coefficient on marginal costs is up to ten times larger when heterogeneity is permitted, and the proportion of backward looking behavior is around a quarter, as compared with 0.4 to a half otherwise. Concomitantly our heterogeneous estimates imply an aggregate duration of nominal rigidities in the vicinity of two quarters, as compared with four to five when standard homogeneous approaches are implemented on our data. The difference is significant, and accounts for the discrepancy between the type of nominal rigidities documented in recent studies based on disaggregated data, and those that arise from standard aggregate estimates. The latter simply do not allow for heterogeneity. 


\section{Introduction}

Since it burst onto the scene of mainstream monetary economics, the New Keynesian Phillips Curve has been the focus of two important empirical debates. First, to what extent purely forward-looking pricing behavior can be reconciled with observed inflation persistence. Second, to what extent properly measured marginal costs affect inflation dynamics. Both issues are crucial for our ability to understand and predict movements in prices. If inflation is purely forward looking, its persistence arises only from that of shocks to marginal costs (provided they matter), and perfectly anticipated changes in inflation are costless. Second, that shocks to marginal costs affect inflation is the basis of the forward-looking pricing rule profit maximizing firms are assumed to follow, and indeed the basis of a model of inflation driven by economic fundamentals rather than mere autoregressive properties. What is more, the magnitude of the relation between marginal costs and inflation relates directly to the duration of nominal rigidities. Both issues have recently been hotly debated, and for good reason. ${ }^{1}$

In this paper, we show that heterogeneity in the pricing behavior of firms matters for both empirical questions. If pricing is heterogeneous, any estimation that ignores the issue is flawed. We show that the direction and magnitude of the bias are not the same for marginal costs or for expected inflation. We derive analytical expressions for both biases, which are helpful to garner intuition on their direction and magnitude. We use simulations to assess the sensitivity of our conclusions, which we then confirm in sectoral quarterly French data on prices and marginal costs, in two ways. We first use the data to calibrate our analytical expressions for the biases. Then we compare Phillips Curve estimates arising from standard homogeneous approaches to what is obtained when heterogeneity is allowed. The proportion of backward looking behavior falls to between a fifth and a quarter when heterogeneity is permitted, as compared with 0.4 to a half otherwise.

Inasmuch as it stresses a source of misspecification, the paper informs the empirical debate surrounding the New Keynesian Phillips Curve in a general sense. Our contribution has two further implications. First we inject heterogeneity within an archetypical model of the Phillips curve. We build on Christiano, Eichenbaum, and Evans (2005) and allow for the possibility that the extent of nominal rigidities and backward indexation both be heterogeneous. We discuss the importance of each, and stress in particular the first one. In fact, heterogeneity in nominal rigidities is the main source of a bias in aggregate estimations: if ignored, it attenuates the importance of aggregate marginal costs, and exaggerates that of lagged inflation. By contrast, heterogeneity in indexation affects lagged inflation only, and weakly so. This is reassuring, for the notion that nominal rigidities are sector or good specific finds support in the data, whereas empirical evidence that indexation should prevail at a disaggregated level

\footnotetext{
${ }^{1} \mathrm{~A}$ non exhaustive list of issues includes the model's ability to capture inflation persistence (Fuhrer and Moore, 1995, Fuhrer, 1997), the plausibility of its implied dynamics (Mankiw and Reis, 2002), and the validity of the empirical approach. For instance, Guay and Pelgrin (2004), Rudd and Whelan (2003, 2005), Nason and Smith (2005) or Lindé (2005) cast doubt on the validity of GMM estimates. Dufour, Khalaf, and Kichian (2006) and Mavroeidis (2004) stress sensitivity to the choice of an instrument set. Jondeau and Le Bihan (2007) and Kurmann (2007) argue Maximum Likelihood estimators ought to be preferred. See the special issue of the Journal of Monetary Economics (2005).
} 
has proved elusive. ${ }^{2}$ We later show sector level Phillips curves are well supported by our French data, and sector price inflation does indeed have heterogeneous autoregressive properties. But that heterogeneity, which we choose to explain within the confines of the model proposed by Christiano, Eichenbaum, and Evans (2005) - or Galí and Gertler (1999) in a robustness section - ends up having little effect in the aggregate.

Second, our approach underlines the importance of disaggregated information to improve the structural modeling of aggregate inflation. This is related to the flurry of recent empirical evidence on disaggregate price dynamics, pioneered by Bils and Klenow (2005) and the series of country specific studies implemented by the European Central Bank. A conclusion drawn from this vast body of evidence seems to be that price dynamics are heterogenous and inflation persistence could be an artefact of aggregation. More specifically, macroeconomic estimates have been widely criticized on the ground that the average duration of sticky prices is too large to make economic sense and, in particular, is inconsistent with the results observed in microeconomic data. ${ }^{3}$ Heterogeneity is key in explaining this discrepancy. Like others, we evaluate the duration of nominal rigidities at implausible levels, around one year, when the usual homogeneous estimators are used. But allowing for heterogeneity (especially in the extent of nominal rigidities across sectors) brings it back to a magnitude commensurate with estimates based on microeconomic data, closer to two quarters. We compare the performance of various approaches - homogeneous or otherwise - and show heterogeneous sectoral information improves sizably our ability to model aggregate inflation.

Our paper is closely related to Zaffaroni (2004) and Altissimo, Mojon, and Zaffaroni (2007). Both papers are also concerned with inflation dynamics, and apply insights on the effects of cross-sectional aggregation of heterogeneous processes that were first introduced by Robinson (1978) and Granger $(1980,1987) .{ }^{4}$ Unlike them however, here we ask from a structural model what heterogeneity will do empirically. This makes it possible for us to evaluate the effect heterogeneous pricing may have on the validity of a structural model of inflation, and correct the estimates accordingly. In that sense, our approach is complementary to Carvalho's (2006) or Nakamura and Steinsson's (2006), who derive a generalized New Keynesian Phillips Curve in the presence of heterogeneity in the frequency of price adjustments across industries. ${ }^{5}$ Gertler and Leahy (2006) develop a theory where individual firms price according to a (S,s) rule. Aggregate inflation displays standard dynamics, even with plausible firm-level rigidities. Rather than introducing heterogeneity in a calibrated general equilibrium model, here we

\footnotetext{
${ }^{2}$ In fact, we confirm our conclusions continue to hold in an alternative model of backward looking price setting, adapted from Galí and Gertler (1999). There as well, heterogeneity in the extent of nominal rigidities is what drives most inconsistencies in the aggregate, whereas the possibility that backward looking price setting should vary per sector has but a limited effect on aggregate estimates. These results are briefly described in a robustness section. A detailed account is available upon request.

${ }^{3}$ See Chari, Kehoe, and McGrattan (2000) or Dhyne et al. (2004) for an analysis of the issue as pertains to the Euro zone.

${ }^{4}$ For more recent discussions of the effects of aggregation under heterogeneity, see Pesaran, Pierse, and Kumar (1989), Granger (1990), Stoker (1993), Pesaran, Pierse, and Lee (1994) or Pesaran and Smith (1995). Imbs et al. (2005) applied the insights to the real exchange rate.

${ }^{5}$ In these calibrated models, monetary shocks have larger and more persistent effects than under homogeneity, and mimicking the data requires only shorter, more plausible, nominal rigidities.
} 
implement the adequate econometrics to account for heterogeneity in the data. We bring the data closer to the theoretically standard homogeneous case, rather than sophisticating the theory away from the representative firm case. ${ }^{6}$

Since our data contain information on real marginal costs at the industry level, we are also able to aggregate theory-implied Phillips curves involving marginal cost rather than output gap, which simplifies considerably the derivations. We are able to identify alternative sources of sectoral heterogeneity, and test for their relevance. Our contribution details how, armed with sector-level data on prices and marginal costs, it is possible to back out unbiased aggregate estimates of the New Keynesian Phillips Curve, that account for possible heterogeneity in pricing behavior.

The rest of the paper is organized as follows. In Section 2, we briefly review how to derive an expression for a sectoral Phillips Curve allowing for nominal rigidities and backward looking indexation that are sector specific. We aggregate sectors up and obtain the standard New Keynesian inflation dynamics, amended for heterogeneity. We analyze a simple two-sector model and explain how heterogeneity matters qualitatively. In Section 3, we present the expressions that render homogeneous estimators problematic when pricing is sector specific. We provide analytical expressions for heterogeneity biases, whose magnitude and direction depend on parameter values. Simulations results are discussed, which illustrate how heterogeneity matters. In Section 4, we describe the econometric methods used in the paper to deal with heterogeneity. In Section 5, we introduce our data and discuss the discrepancies between estimates implied by homogeneous and heterogeneous estimators. Section 6 reviews some robustness checks and Section 7 concludes.

\section{Aggregating Sectoral Phillips Curves}

We first derive an expression for a sectoral Phillips Curve, as implied by the model of Christiano, Eichenbaum, and Evans (2005). A sector is characterized by the extent of nominal rigidities and a degree of indexation to past inflation. ${ }^{7}$ We aggregate the model up to the country level, assuming away any cross-sectoral influences as for instance ones implied by input-output relations - just as most aggregate Phillips curves assume away international linkages. Price dynamics in each sector are assumed to respond only to the dynamics of

\footnotetext{
${ }^{6}$ Using scanner data, Midrigan (2006) shows the cross-sectional distribution of (non zero) price changes has fat tails. He argues the high moments properties of the heterogeneity in price adjustments are crucial when aggregating microeconomic rigidities in menu-costs models of macroeconomic fluctuations.

${ }^{7}$ That indexation should prevail at a disaggregated level is not uncontroversial. For instance, Fougère, Le Bihan, and Sevestre (2005) conclude that pure indexation is elusive in disaggregated French data. Bils and Klenow (2005) uncover similar evidence in U.S. data. Fortunately, our results suggest that this very source of heterogeneity has but a limited effect in the aggregate. In a robustness section, we show this continues to be true in the model introduced by Galí and Gertler (1999), where price setting may be purely backward looking. The importance of heterogeneous nominal rigidities does not seem to depend on the model used to justify lagged inflation in the Phillips curve: only the interpretation of reduced form coefficients does. What is more, while evidence of indexation is elusive for individual firms, little is known at the sectoral level. In reconstructed US data, Leith and Malley (2006) document the existence of Phillips curves at the 2-digit aggregation level.
} 
marginal costs there. ${ }^{8}$ We spend some time discussing the absence of relative sectoral prices in the aggregate, due to the availability of disaggregated information on real marginal costs. ${ }^{9}$

\subsection{A Sectoral Phillips Curve}

We briefly derive the New Keynesian Phillips curve for a sector $j$, where technology shocks and price rigidities are specific to $j$. In doing so, we conflate ingredients from Sbordone (2001), Woodford (2003) and Christiano, Eichenbaum, and Evans (2005). Monopolistic competition in each sector implies that the demand faced by firm $i$ writes

$$
Y_{i j, t}=\left(\frac{P_{i j, t}}{P_{j, t}}\right)^{-\eta} Y_{j, t}
$$

where $\eta>1$ denotes the elasticity of substitution across varieties. Each firm $i$ in sector $j$ uses labor $H_{i j, t}$ to produce a differentiated good according to the production function

$$
Y_{i j, t}=Z_{j, t} H_{i j, t}^{1-a_{j}}
$$

where $Z_{j, t}$ denotes (sector specific) labor productivity and $1-a_{j}$ is the share of labor in industry $j$ 's value added.

Firms maximize the expected discounted sum of real profits

$$
E_{t} \sum_{k=0}^{\infty} \frac{\beta^{k}}{P_{t+k}}\left(Y_{i j, t+k} P_{i j, t+k}-Y_{i j, t+k} S_{i j, t+k} P_{t+k}\right)
$$

where $\beta$ is the discount factor and $S_{i j, t+k}$ the real marginal cost of firm $i$ in sector $j$ at date $t+k$, deflated by the aggregate price index. Under complete markets, the discount factor $\beta$ is the same across firms and sectors. In addition, the expected stream of profits is deflated by the general price index $P_{t}$ because firms are assumed to be owned by consumers who all face identical consumption risk.

We assume price setting decisions follow a modified version of the Calvo (1983) mechanism. We follow Christiano, Christiano, and Eichenbaum (2005) and allow for the possibility that

\footnotetext{
${ }^{8}$ We later allow for industry shocks to be correlated across sectors. That is not quite the same as constructing an explicit model of technological linkages between sectors. Going that route while preserving the level of generality we endeavor would simply be intractable, both in theory and in empirical applications. Justiniano, Kumhof, and Ravenna (2006) propose a model of specifically vertical input-output relations between industries. They show appropriate linkages can account for the discrepancy between price sluggishness in the aggregate and rapid adjustment at the microeconomic level. Dupor (1999) focuses on the persistence in real quantities, and shows that, in general, input-output linkages are incapable of driving a wedge between sectoral and aggregate real output dynamics.

${ }^{9} \mathrm{We}$ are far from the first ones to take interest in heterogeneous pricing in monetary models. Erceg and Levin (2002) characterize a sector on the demand side, focusing on differences between durable and nondurables goods. Aoki (2001), Benigno (2004) and Huang and Liu (2004) analyze the implications of sectoral heterogeneity for the design of monetary policy. Dixon and Kara (2005) study the impact of heterogeneity in the context of Taylor staggered wage setting. Bouakez, Cardia, and Ruge-Murcia (2005) construct and estimate a model with heterogenous production sectors, and show substantial heterogeneity across sectors in the degree of sectoral sensitivity to monetary policy shocks. Álvarez, Burriel, and Hernando (2005) analyze the impact of heterogeneity under a variety of different assumptions on price-setting behavior.
} 
firms that do not optimally set their prices may nonetheless adjust them to keep up with the previous period increase in the general price level. In each period, firms face a constant probability $1-\alpha_{j}$ of being able to re-optimize their price. Therefore, firms set prices according to the following optimization program

$$
\max _{P_{i j, t}^{*}} E_{t} \sum_{k=0}^{\infty} \frac{\left(\beta \alpha_{j}\right)^{k}}{P_{t+k}}\left(Y_{i j, t+k} P_{i j, t}^{*} \Psi_{i j, t, t+k}-Y_{i j, t+k} S_{i j, t, t+k} P_{t+k}\right)
$$

where

$$
\Psi_{i j, t, t+k}= \begin{cases}\prod_{\nu=0}^{k-1}\left(\pi_{i j, t+v}\right)^{\xi_{j}}\left(\bar{\pi}_{j}\right)^{1-\xi_{j}} & k>0 \\ 1 & k=0\end{cases}
$$

and $\bar{\pi}_{j}$ denotes the (sector specific) exogenous trend inflation, which we later account for through detrending. The coefficient $\xi_{j} \in[0,1]$ indicates the degree of indexation to past prices in sector $j$, during the periods in which firms are not allowed to re-optimize. $\Psi_{i j, t, t+k}$ is a correcting term accounting for the fact that, if firm $i$ does not re-optimize its price, it is updated according to the rule $P_{i j, t}=\left(\bar{\pi}_{j}\right)^{1-\xi_{j}}\left(\pi_{i j, t-1}\right)^{\xi_{j}} P_{i j, t-1}$. When $\xi_{j}=0$, firms mechanically impute trend inflation when setting future prices; when $\xi_{j}=1$, realized inflation rates between $t+v-1$ and $t+v$ are used to choose prices in $t+v+1$. Finally, $S_{i j, t, t+k}$ is the real marginal cost of production at date $t+k$ for the firms that changed their price at $t$. Sbordone (2001) and Galí, Gertler, and López-Salido (2001) show it is related to the average real marginal cost in sector $j, S_{j, t}^{a v g}$, as in

$$
S_{i j, t, t+k}=\frac{W_{j, t+k}}{P_{t+k}} \frac{\partial H_{i j, t+k}}{\partial Y_{i j, t+k}}=\frac{W_{j, t+k}}{P_{t+k}} \frac{1}{a_{j}} Z_{j, t+k}^{-\frac{1}{a_{j}}} Y_{i j, t+k} \frac{1-a_{j}}{a_{j}}=\left(\frac{P_{i j, t}^{*}}{P_{j, t+k}}\right)^{-\frac{\eta\left(1-a_{j}\right)}{a_{j}}} S_{j, t+k}^{a v g}
$$

where $W_{j, t}$ are the nominal wages in sector $j$.

In the absence of any firm-specific shock, all firms that are allowed to re-optimize their price at date $t$ select the same optimal price $P_{i j, t}^{*}=P_{j, t}^{*}$, which ensures a symmetric equilibrium across firms in each sector. Staggered price setting under partial indexation implies the price index in sector $j$ is given by

$$
P_{j, t}=\left[\alpha_{j}\left[\left(\pi_{j, t-1}\right)^{\xi_{j}}\left(\bar{\pi}_{j}\right)^{1-\xi_{j}} P_{j, t-1}\right]^{1-\eta}+\left(1-\alpha_{j}\right)\left(P_{j, t}^{*}\right)^{1-\eta}\right]^{\frac{1}{1-\eta}} .
$$

Log-linearizing the definitions of aggregate prices, of marginal costs and optimal pricing yields

$$
\pi_{j, t}=\frac{\xi_{j}}{1+\beta \xi_{j}} \pi_{j, t-1}+\frac{\beta}{1+\beta \xi_{j}} E_{t} \pi_{j, t+1}+\frac{\left(1-\beta \alpha_{j}\right)\left(1-\alpha_{j}\right)}{\left(1+\beta \xi_{j}\right) \alpha_{j}} \frac{1}{1+h_{j}}\left(s_{j, t}^{a v g}+p_{t}-p_{j, t}\right)
$$

where lower case variables denote log-deviations from the steady state, $\pi_{j, t}=P_{j, t} / P_{j, t-1}$ and $h_{j}=\eta a_{j} /\left(1-a_{j}\right)$. From equation $(1)$, the term $h_{j}$ corrects for the fact that marginal costs are heterogeneous ex post across firms, as they do not all adjust their prices at the same point in time. Define a measure of real marginal costs in sector $j, s_{j, t}=\left(s_{j, t}^{a v g}+p_{t}-p_{j, t}\right) /\left(1+h_{j}\right)$, deflated by the industry price index, and corrected for staggered price setting. As we argue 
later, under relatively mild assumptions our data contain information on $s_{j, t}^{a v g}+p_{t}-p_{j, t}$, which we then amend using sector-specific measures of $h_{j}$ to obtain $s_{j, t}{ }^{10}$

To economize on notation, define $\lambda_{j}^{b}=\xi_{j} /\left(1+\beta \xi_{j}\right), \lambda_{j}^{f}=\beta /\left(1+\beta \xi_{j}\right)$ and $\theta_{j}=\frac{\left(1-\beta \alpha_{j}\right)\left(1-\alpha_{j}\right)}{\left(1+\beta \xi_{j}\right) \alpha_{j}}$ to rewrite the Phillips Curve in its well known hybrid form

$$
\pi_{j, t}=\lambda_{j}^{b} \pi_{j, t-1}+\lambda_{j}^{f} E_{t} \pi_{j, t+1}+\theta_{j} s_{j, t}+\varepsilon_{j, t}
$$

where we introduced an error term $\varepsilon_{j, t}$, which may include sectoral or aggregate shocks. In the case where the only source of sectoral heterogeneity stems from the extent of nominal rigidities $\alpha_{j}$, we have $\xi_{j}=\xi, \lambda_{j}^{b}=\lambda^{b}$, and $\lambda_{j}^{f}=\lambda^{f}$ for all $j$. The autoregressive properties of inflation ate then identical across sectors. Only the coefficient on marginal costs $\theta_{j}$ will be heterogeneous. This will also be true in the absence of any backward-looking indexing when $\xi=0$. The Phillips Curve becomes then purely forward looking, and only the coefficient on marginal costs is sector-specific.

The industry level Phillips curve we derive in equation (3) does not include any reference to an aggregate variable, nor indeed to any relative prices. At face value, this may seem a contradiction relative to the findings in Aoki (2001), Benigno (2004) or Carlstrom et al. (2006). But all these authors use versions of the New Keynesian Phillips curve that refer to the output gap as a measure of economic activity. In contrast, here we refer directly to marginal costs, which, under relatively benign assumptions on the labor market, we actually observe in our data. Relative prices are effectively subsumed in our definition of $s_{j, t}$, which we argue are observable in our data. This follows directly from Woodford (2003), who shows that a sector-level New Keynesian Phillips curve ceases to refer to any aggregate variables, or to relative sectoral prices, when it is written in terms of real marginal costs deflated by the sector-specific price index. ${ }^{11}$ This result simplifies considerably the theoretical impact of aggregation, and our econometric approach in addressing heterogeneity.

\subsection{Aggregation}

Heterogeneity enters as sector-specific deviations from a common mean. In particular, we assume

$$
\begin{aligned}
\alpha_{j} & =\alpha+\tilde{\alpha}_{j} \\
\xi_{j} & =\xi+\tilde{\xi}_{j}
\end{aligned}
$$

where $\tilde{\alpha}_{j}$ and $\tilde{\xi}_{j}$ have zero means and constant variances and covariances. ${ }^{12}$ Let $w_{j}$ denote the weight of sector $j=1 \ldots J$ in the aggregate economy. Straightforward aggregation of equation

\footnotetext{
${ }^{10}$ This follows Sbordone (2001) or Galí, Gertler, and López-Salido (2001). A complete description of the model is provided in a technical report available upon request.

${ }^{11}$ This is developed in the Appendix B.7 to Chapter 3, and in particular in equation B.33 on page 668. What is key is the price index used to deflate nominal marginal costs. Relative sectoral prices appear when aggregate prices are used, but they do not if the deflator is sector specific. We observe the latter in our data, so that no relative prices appear.

${ }^{12}$ Whether heterogeneity is random or deterministic will matter for the estimation procedure. Since this is an empirical question, we leave the discussion for later, and stick for now to the most general specification.
} 
(3) gives

$$
\pi_{t}=\sum_{j=1}^{J} w_{j} \lambda_{j}^{b} \pi_{j, t-1}+\sum_{j=1}^{J} w_{j} \lambda_{j}^{f} E_{t} \pi_{j, t+1}+\sum_{j=1}^{J} w_{j} \theta_{j} s_{j, t}+\sum_{j=1}^{J} w_{j} \varepsilon_{j, t} .
$$

Our purpose in this paper is to evaluate the validity of the standard Phillips curve at the country level in the presence of heterogeneity at a lower level of aggregation. Therefore, we seek to characterize the econometric properties of the residuals in a version of equation (4) that simplifies into

$$
\pi_{t}=\lambda^{b} \pi_{t-1}+\lambda^{f} E_{t} \pi_{t+1}+\theta s_{t}+\bar{\varepsilon}_{t}
$$

with $\lambda^{b}=\xi /(1+\beta \xi), \lambda^{f}=\beta /(1+\beta \xi)=\beta\left(1-\beta \lambda^{b}\right)$ and $\theta=\frac{(1-\beta \alpha)(1-\alpha)}{(1+\beta \xi) \alpha}$.

This simplification implies a specific structure of heterogeneity: we assume that linear heterogeneity at the level of the structural parameters $\xi_{j}$ and $\alpha_{j}$ translates into linear heterogeneity in the reduced form Phillips curve. In other words, we impose $\lambda_{j}^{b}=\lambda^{b}+\tilde{\lambda}_{j}^{b}$, $\lambda_{j}^{f}=\lambda^{f}+\tilde{\lambda}_{j}^{f}$, and $\theta_{j}=\theta+\tilde{\theta}_{j} .{ }^{13}$ This is obviously not the case in general, but ours is not a paper proposing an alternative structural form to account for aggregate inflation dynamics under sector-level heterogeneity. Rather it is one that seeks to evaluate the effects of (a specific form of) heterogeneity on the empirical validity of the standard model. We leave the alternative, more fundamental, route for further research. ${ }^{14}$

Estimates of $\lambda^{b}, \lambda^{f}$, and $\theta$ in equation (5) are the object of an enormous literature. Our key assumption is all three estimates differ linearly from their average (aggregate) values at the sectoral level because of different realizations of $\tilde{\xi}_{j}$ and $\tilde{\alpha}_{j}$. Under this assumption, the residuals in equation (5) are given by

$$
\bar{\varepsilon}_{t}=\sum_{j=1}^{J} w_{j} \varepsilon_{j, t}+\sum_{j=1}^{J} w_{j} \tilde{\lambda}_{j}^{b} \pi_{j, t-1}+\sum_{j=1}^{J} w_{j} \tilde{\lambda}_{j}^{f} E_{t} \pi_{j, t+1}+\sum_{j=1}^{J} w_{j} \tilde{\theta}_{j} s_{j, t}
$$

where

$$
\begin{aligned}
\tilde{\lambda}_{j}^{b} & =\frac{\xi_{j}}{1+\beta \xi_{j}}-\frac{\xi}{1+\beta \xi}=\frac{\tilde{\xi}_{j}}{(1+\beta \xi)\left(1+\beta \xi_{j}\right)} \\
\tilde{\lambda}_{j}^{f} & =\frac{\beta}{1+\beta \xi_{j}}-\frac{\beta}{1+\beta \xi}=\frac{-\beta^{2} \tilde{\xi}_{j}}{(1+\beta \xi)\left(1+\beta \xi_{j}\right)}=-\beta^{2} \tilde{\lambda}_{j}^{b} \\
\tilde{\theta}_{j} & =\frac{\left(1-\beta \alpha_{j}\right)\left(1-\alpha_{j}\right)}{\left(1+\beta \xi_{j}\right) \alpha_{j}}-\frac{(1-\beta \alpha)(1-\alpha)}{(1+\beta \xi) \alpha}=-\frac{\left(1-\beta \alpha \alpha_{j}\right)(1+\beta \xi) \tilde{\alpha}_{j}+\beta(1-\alpha) \alpha_{j} \tilde{\xi}_{j}}{\left(1+\beta \xi_{j}\right)(1+\beta \xi) \alpha \alpha_{j}} .
\end{aligned}
$$

As in Pesaran and Smith (1995) and Pesaran, Smith, and Im (1996), ignoring heterogeneity in equation (5) results in a residual that is unavoidably correlated with the dependent variables.

\footnotetext{
${ }^{13}$ We also assume information is perfectly common across sectors, so that pricing decisions are taken across the whole economy on the basis of exactly the same data.

${ }^{14}$ Equation (4) is hideously non linear when heterogeneity is introduced in the most general way. The linearity hypothesis we maintain is akin to what Lewbel (1992) suggested, and amounts to a mean scaling transformation. The model in Carvalho (2006) is solved in the aggregate under general heterogeneity at the industry level. But it is a model - not an econometric correction of the data.
} 
Instrumenting will not alleviate the pathology since good instruments are correlated with the dependent variables, and therefore will mechanically be so as well with the residuals. The result is well known in theory, and a few applications have by now been developed in macroeconomics. ${ }^{15}$ The issue is particularly pressing in the present case, and not only because modeling inflation dynamics is important in and of itself. First, in a multivariate setting, heterogeneity biases may have different signs and different magnitudes on different co-variates. The next section shows how the biases may indeed have different signs on $\lambda^{b}$, $\lambda^{f}$, and $\theta$. We then implement simulations exercises suggestive that they also have different magnitudes. Second, equation (5) involves an expected term, which complicates substantially the approach, especially when it comes to instrumenting these expectations.

The standard approach to account for the expected term in New Keynesian Phillips curves has been to implement Generalized Method of Moments (GMM) estimators. These impose orthogonality conditions on an amended version of equation (3), where expected inflation is replaced by the value effectively observed. In particular, identification requires an instrument set, correlated with expected (sectoral) inflation but not with the residuals $v_{j, t+1}=\varepsilon_{j, t}-$ $\lambda_{j}^{f}\left(\pi_{j, t+1}-E_{t} \pi_{j, t+1}\right)$ in

$$
\pi_{j, t}=\lambda_{j}^{b} \pi_{j, t-1}+\lambda_{j}^{f} \pi_{j, t+1}+\theta_{j} s_{j, t}+v_{j, t+1} .
$$

The necessity of this instrumentation fundamentally alters the properties of the heterogeneous estimators established in Swamy (1970), Pesaran and Smith (1995) or Hsiao and Pesaran (2004). Heterogeneous estimators rest on the property that an average (weighted or not, depending on the stochastic nature of heterogeneity) of unit specific coefficients provides a consistent estimate of the aggregate effects, in our case $\lambda^{b}, \lambda^{f}$, and $\theta$. This holds because the stacked system of unit specific estimations can be rewritten in a panel form, since heterogeneity is assumed to enter linearly as unit-specific differences from the average of interest exactly as we have assumed here. The panel can then be estimated consistently, provided the specific type of heteroskedasticity caused by heterogeneity is accounted for, e.g. using a Generalized Least Squares approach.

But in the GMM case, instrumentation is called for at the industry level, and no instruments are available for expected sectoral inflation in a panel version of stacked sectoral Phillips curves. A term in $\tilde{\lambda}_{j}^{f} E_{t} \pi_{j, t+1}$ inevitably enters the panel residuals, and any variable uncorrelated with the residuals will not be correlated with expected inflation either. The panel simply cannot be estimated when instruments are needed. In other words, even though sector specific estimates of $\lambda_{j}^{b}, \lambda_{j}^{f}$, and $\theta_{j}$ may be obtained with GMM, no theory is available as to the properties of their average, weighted or not, and its connection with an unbiased aggregate estimate that accounts for heterogeneity. In general, we know how to account for heterogeneity by aggregating adequately unit-specific estimates, but we do not when instrumenting is necessary at the disaggregated level. As a result, we restrict our analysis to estimations of the Phillips curve that do not require a choice of instruments, and compare the results implied by

\footnotetext{
${ }^{15}$ Imbs et al. (2005) show heterogeneity biases the estimated persistence of the real exchange rate. Forni and Lippi (1997) and Canova (2007) review the relevance of the issue across a wide range of empirical applications in macroeconomics.
} 
estimators that allow for heterogeneity and those that do not. We also verify that the aggregate estimates implied by GMM are in line with established results, which confirms there is nothing anomalous to our dataset.

\subsection{A Two-Sector Example}

We illustrate the potential magnitude of heterogeneity biases in estimates of the New Keynesian Phillips Curve in the context of simulations based on a simple two-sector version of the model just described. For simplicity, we impose additional structure on the model and in particular assume marginal costs are driven by an autoregressive process of order two. ${ }^{16}$ In particular, in each sector $j$ we assume

$$
\begin{aligned}
\pi_{j, t} & =\lambda_{j}^{b} \pi_{j, t-1}+\lambda_{j}^{f} E_{t} \pi_{j, t+1}+\theta_{j} s_{j, t}+\varepsilon_{j, t} \\
s_{j, t} & =\rho_{1 j} s_{j, t-1}+\rho_{2 j} s_{j, t-2}+u_{j, t} .
\end{aligned}
$$

A word of caution is in order. Our empirical results are based on the assumption that the driving process underlying marginal costs is an autoregressive process of order two. This is to allow enough flexibility that the observed heterogeneous dynamics of marginal costs in our data can be accommodated, which an autoregressive process of order one is less able to do. Inasmuch as this section purports to offer a preview of our empirical results, we maintain the same assumption here. ${ }^{17}$

We have allowed for heterogeneity in $\lambda_{j}^{b}, \lambda_{j}^{f}$ and $\theta_{j}$, which the previous section showed is akin to assuming heterogeneous values for $\xi_{j}$ and $\alpha_{j}$. Appendix 1 shows this system implies a reduced form expression for sectoral inflation

$$
\pi_{j, t}=\xi_{j} \pi_{j, t-1}+\psi_{1 j} s_{j, t}+\psi_{2 j} s_{j, t-1}+\eta_{j, t}
$$

with

$$
\begin{aligned}
\psi_{1 j} & =\frac{1-\beta \alpha_{j}}{1-\beta \rho_{1 j}-\beta^{2} \rho_{2 j}} \frac{1-\alpha_{j}}{\alpha_{j}} \\
\psi_{2 j} & =\beta \psi_{1 j} \rho_{2 j} .
\end{aligned}
$$

We use simulation exercises with two sectors to evaluate the relative impact of dispersion in the sectoral values of $\xi_{j}$ and $\alpha_{j}$ on the aggregate structural parameters $\xi$ and $\alpha$, and the implied dynamics of aggregate inflation.

The parameters in both sectors are assumed to take the same initial values. Specifically, we choose $\xi_{j}=0.5, \alpha_{j}=0.7, \rho_{1}=1.1, \rho_{2}=-0.2$ and $V=\sigma_{\eta_{j}}^{2} / \sigma_{u_{j}}^{2}=1$, where $\sigma_{\eta_{j}}^{2}$ and $\sigma_{u_{j}}^{2}$ denote the variances of $\eta_{j, t}=\left(1+\beta \xi_{j}\right) \varepsilon_{j, t}$ and $u_{j, t}$ respectively. ${ }^{18}$ We only need to parameterize the ratio of volatilities, as we only seek to simulate the second moments of aggregate inflation,

\footnotetext{
${ }^{16}$ This is discussed and motivated in more details in Section 3.2, where we introduce the Maximum Likelihood estimator.

${ }^{17}$ We have checked that our empirical results continue to hold under higher order processes.

${ }^{18}$ These parameter values correspond to the unbiased estimates obtained from the French data used in this paper. The results are robust to alternative initial values.
} 
and in particular its persistence. The subjective discount factor is set at $\beta=0.99$. We introduce sector-level heterogeneity by drawing $\xi_{j}$ and $\alpha_{j}$ from ranges centered around their initial values. The extent of simulated heterogeneity increases with the range from which $\xi_{j}$ and $\alpha_{j}$ are drawn. ${ }^{19}$ Armed with sector-specific (and heterogeneous) structural parameters, we simulate inflation series according to the reduced form Phillips curve (and the assumed process for marginal costs) in each sector. We then aggregate them up, using equal weights, obtain a series for aggregate inflation and aggregate marginal costs, and use them to estimate the values of $\alpha$ and $\xi{ }^{20}$

Figure 1 reports the simulated values of $\xi$ and $\alpha$ for values of $\xi_{j}$ drawn from [0.25, 0.75], and values of $\alpha_{j}$ drawn from $[0.45,0.95]$. We draw all values of each parameter by increments of 0.05. The upper (lower) panel focuses on heterogeneity in $\xi_{j}\left(\alpha_{j}\right)$. Several results are worth mentioning. First, the Figure confirms the existence of a positive bias in the aggregate estimates of $\alpha$ and $\xi$. On most plots, the highest values of the aggregate structural parameters are obtained when the cross-sectoral dispersion of $\xi_{j}$ and $\alpha_{j}$ is maximal. Second, the plots suggest that aggregate estimates are most affected by the heterogeneity in $\alpha_{j}$. The dispersion in $\xi_{j}$ affects the estimates of $\xi$, but leaves $\alpha$ virtually unchanged. In contrast, the dispersion in $\alpha_{j}$ creates biases on both $\alpha$ and $\xi$. Further, the biases induced by the dispersion in $\alpha_{j}$ tend to be larger in magnitude.

In words, our simulations are suggestive of an asymmetry in the manner heterogeneity biases affect estimates of the New Keynesian Phillips curve. First, the heterogeneity in nominal rigidities affects both structural estimates in the Phillips curve, $\alpha$ and $\xi$. Second, a given dispersion in the extent of nominal rigidities has a substantially larger effect on $\alpha$ and $\xi$ than a comparable dispersion in $\xi_{j}$. Put differently, it is the heterogeneity in the Calvo parameter that is most likely to induce biases in aggregate estimations. On the basis of these simulations, heterogeneity biases tend to underestimate both the extent of forward-looking behavior $\left(\lambda^{f}\right)$ and the importance of nominal rigidities $(\theta)$.

\section{The Biases}

In this section, we describe analytically the biases that plague aggregate estimates of the New Keynesian Phillips Curve in the presence of unaccounted heterogeneity. We discuss the biases affecting both the coefficient on marginal costs and the coefficients on inflation and provide analytical expressions corresponding to a Phillips Curve estimated assuming marginal costs follow an autoregressive process of order one. This contrasts with our empirical sections, where we assume throughout marginal costs are best represented by an autoregressive process of order two, which has enough flexibility to accommodate the cross-sectional heterogeneity in our data. Unfortunately, our analytical results become considerably more complicated under autoregressive processes of orders higher than one, indeed at the cost of tractability. We

\footnotetext{
${ }^{19} \mathrm{We}$ also considered heterogeneity on the autoregressive parameters $\rho_{1 j}$ and $\rho_{2 j}$, and the ratio $\sigma_{\eta_{j}}^{2} / \sigma_{u_{j}}^{2}$. These alternative sources of heterogeneity played little role in the aggregate and the corresponding results are not reported for the sake of brevity.

${ }^{20}$ We also experimented with asymmetric sectors, with no sizable differences.
} 
conjecture there is no fundamental reason why the intuition developed in this section should not generalize. We close the section with simulation exercises that confirm our conjectures and decompose the biases into the components we obtain analytically.

\subsection{Analytics}

The GMM estimator requires an instrument set for expected inflation, which forbids the use of heterogeneous estimators. An alternative, introduced by Fuhrer and Moore (1995), Sbordone (2001) or Kurmann (2007) assumes a data generating process for marginal costs and implements a Maximum Likelihood estimator (ML) to estimate the model. Under the additional hypothesis, it becomes possible to solve future expected inflation out of the Phillips curve, and obtain a model that can be brought to the data directly. We now consider the role of heterogeneity under this estimation approach.

The full model of inflation rests on the following system

$$
\begin{aligned}
\pi_{j, t} & =\lambda_{j}^{b} \pi_{j, t-1}+\lambda_{j}^{f} E_{t} \pi_{j, t+1}+\theta_{j} s_{j, t}+\varepsilon_{j, t} \\
s_{j, t} & =\rho_{j} s_{j, t-1}+u_{j, t}
\end{aligned}
$$

where $u_{j, t}$ denotes an independent and identically distributed shock to real marginal costs in sector $j,\left|\rho_{j}\right|<1, \sigma_{\varepsilon_{j}}^{2}=E\left(\varepsilon_{j, t}^{2}\right)$ and $\sigma_{u_{j}}^{2}=E\left(u_{j, t}^{2}\right)$. Appendix 1 shows how the dynamics of inflation rewrite

$$
\pi_{j, t}=\xi_{j} \pi_{j, t-1}+\psi_{j} s_{j, t}+\eta_{j, t}
$$

with

$$
\psi_{j}=\frac{1-\beta \alpha_{j}}{1-\beta \rho_{j}} \frac{1-\alpha_{j}}{\alpha_{j}} \quad \text { and } \quad \eta_{j, t}=\left(1+\beta \xi_{j}\right) \varepsilon_{j, t} .
$$

Imposing homogeneity on an aggregated Phillips curve will force heterogeneity into the residual, and thus result in inconsistency in parameter estimates. ${ }^{21}$ We continue to assume that aggregation preserves the linearity property in heterogeneity; in particular, we assume the aggregate Phillips curve is true on average whenever $\xi_{j}=\xi+\tilde{\xi}_{j}, \alpha_{j}=\alpha+\tilde{\alpha}_{j}$, and $\rho_{j}=\rho+\tilde{\rho}_{j}$. Then we have

$$
\begin{gathered}
\pi_{t}=\xi \pi_{t-1}+\psi s_{t}+\bar{\eta}_{t} \\
s_{t}=\rho s_{t-1}+\bar{u}_{t}
\end{gathered}
$$

where $\psi=\frac{1-\beta \alpha}{1-\beta \rho} \frac{1-\alpha}{\alpha}$. In particular, we have $\psi_{j}=\psi+\tilde{\psi}_{j}$ and

$$
\tilde{\psi}_{j}=\frac{-\left(1-\beta \alpha \alpha_{j}\right)(1-\beta \rho) \tilde{\alpha}_{j}+\beta(1-\alpha) \alpha_{j} \tilde{\rho}_{j}}{\left(1-\beta \rho_{j}\right)(1-\beta \rho) \alpha \alpha_{j}} .
$$

\footnotetext{
${ }^{21}$ In fact, Carvalho (2006) finds a similar result in his theory. His equation (13) involves a term in $g_{t}$, which is akin to the perturbation in the residuals we build upon.
} 
As before, the residuals embed the dependent variables, since

$$
\begin{aligned}
& \bar{\eta}_{t}=\sum_{j=1}^{J} w_{j} \eta_{j, t}+\sum_{j=1}^{J} w_{j} \tilde{\xi}_{j} \pi_{j, t-1}+\sum_{j=1}^{J} w_{j} \tilde{\psi}_{j} s_{j, t} \\
& \bar{u}_{t}=\sum_{j=1}^{J} w_{j} u_{j, t}+\sum_{j=1}^{J} w_{j} \tilde{\rho}_{j} s_{j, t-1} .
\end{aligned}
$$

Orthogonality conditions impose that the residuals should verify

$$
\begin{aligned}
E\left[\left(\pi_{t}-\xi_{M L} \pi_{t-1}-\psi_{M L} s_{t}\right) \pi_{t-1}\right] & =0 \\
E\left[\left(\pi_{t}-\xi_{M L} \pi_{t-1}-\psi_{M L} s_{t}\right) s_{t}\right] & =0
\end{aligned}
$$

where $\xi_{M L}$ and $\psi_{M L}$ denote maximum likelihood estimates. The nature of $\bar{\eta}_{t}$ under heterogeneity will induce biases in potentially all the coefficients in the Phillips curve. In probability limits as $T$ becomes large, these biases write

$$
\begin{aligned}
\widetilde{\Lambda} \operatorname{plim}\left(\xi_{M L}-\xi\right) & =E\left(s_{t}^{2}\right) E\left(\pi_{t-1} \bar{\eta}_{t}\right)-E\left(s_{t} \pi_{t-1}\right) E\left(s_{t} \bar{\eta}_{t}\right) \\
\widetilde{\Lambda} \operatorname{plim}\left(\psi_{M L}-\psi\right) & =E\left(\pi_{t-1}^{2}\right) E\left(s_{t} \bar{\eta}_{t}\right)-E\left(s_{t} \pi_{t-1}\right) E\left(\pi_{t-1} \bar{\eta}_{t}\right) \\
\operatorname{plim}\left(\rho_{M L}-\rho\right) & =E\left(s_{t-1} \bar{u}_{t}\right) / E\left(s_{t-1}^{2}\right)
\end{aligned}
$$

where

$$
\widetilde{\Lambda}=E\left(s_{t}^{2}\right) E\left(\pi_{t-1}^{2}\right)-\left(E\left(s_{t} \pi_{t-1}\right)\right)^{2} .
$$

Since $\widetilde{\Lambda}>0$, the signs of the asymptotic biases are given by the right-hand side expressions. We maintain five simplifying assumptions. (H1) Heterogeneity is deterministic. (H2) The weights of all sectors in the economy are exogenous and uncorrelated with the magnitude of sectorspecific estimates of the Phillips curve. (H3) Sector-specific shocks are independent. (H4) Marginal costs follow a (potentially sector-specific) autoregressive process of order one. Our estimations later relax all four hypotheses; our purpose now is to obtain tractable expressions for all biases, at the cost of relatively benign assumptions. Under these hypotheses, the sign of the bias affecting estimates for $\xi$ and $\psi$ are given in Proposition 1

\section{Proposition 1 Under $\mathrm{H}_{1}-\mathrm{H}_{4}$,}

- The asymptotic bias of $\left(\xi_{M L}-\xi\right)$ can be decomposed into the sum of two terms:

$$
\begin{aligned}
& C_{1}=C_{11}+C_{12}=\frac{E\left(s_{t}^{2}\right)}{\widetilde{\Lambda}} \sum_{j=1}^{J} w_{j} \tilde{\xi}_{j} E\left(\pi_{t-1} \pi_{j, t-1}\right)-\frac{E\left(s_{t} \pi_{t-1}\right)}{\widetilde{\Lambda}} \sum_{j=1}^{J} w_{j} \tilde{\xi}_{j} E\left(s_{t} \pi_{j, t-1}\right) \\
& C_{2}=C_{21}+C_{22}=\frac{E\left(s_{t}^{2}\right)}{\widetilde{\Lambda}} \sum_{j=1}^{J} w_{j} \tilde{\psi}_{j} E\left(\pi_{t-1} s_{j, t}\right)-\frac{E\left(s_{t} \pi_{t-1}\right)}{\widetilde{\Lambda}} \sum_{j=1}^{J} w_{j} \tilde{\psi}_{j} E\left(s_{t} s_{j, t}\right)
\end{aligned}
$$

where

$$
\begin{aligned}
& C_{11}>0 \quad C_{12}<0 \\
& C_{21}>0
\end{aligned}
$$


- The asymptotic bias of $\left(\psi_{M L}-\psi\right)$ can be decomposed into the sum of two terms:

$$
\begin{aligned}
& D_{1}=D_{11}+D_{12}=\frac{E\left(\pi_{t-1}^{2}\right)}{\widetilde{\Lambda}} \sum_{j=1}^{J} w_{j} \tilde{\xi}_{j} E\left(s_{t} \pi_{j, t-1}\right)-\frac{E\left(s_{t} \pi_{t-1}\right)}{\widetilde{\Lambda}} \sum_{j=1}^{J} w_{j} \tilde{\xi}_{j} E\left(\pi_{t-1} \pi_{j, t-1}\right) \\
& D_{2}=D_{21}+D_{22}=\frac{E\left(\pi_{t-1}^{2}\right)}{\widetilde{\Lambda}} \sum_{j=1}^{J} w_{j} \tilde{\psi}_{j} E\left(s_{t} s_{j, t}\right)-\frac{E\left(s_{t} \pi_{t-1}\right)}{\widetilde{\Lambda}} \sum_{j=1}^{J} w_{j} \tilde{\psi}_{j} E\left(\pi_{t-1} s_{j, t}\right)
\end{aligned}
$$

where

$$
\begin{aligned}
& D_{11}>0 \quad D_{12}<0 \text {, } \\
& D_{21}>0 \quad D_{22}<0 \text {. }
\end{aligned}
$$

- The asymptotic bias of $\left(\rho_{M L}-\rho\right)$, given by

$$
\rho_{M L}-\rho=\sum_{j=1}^{J} w_{j} \tilde{\rho}_{j} E\left(s_{t} s_{j, t}\right) / E\left(s_{t-1}^{2}\right),
$$

is positive.

\section{Proof: See Appendix 2.}

From our simple two-sector simulated economy, we know that a quantitatively important source of bias is the dispersion in $\alpha_{j}$. Translated into analytical terms, this suggests $C_{2}$ and $D_{2}$ should be the main sources of the biases. Indeed, in both cases, the biases decompose into correlation terms involving $\tilde{\xi}_{j}\left(C_{1}\right.$ and $\left.D_{1}\right)$, and terms involving $\tilde{\psi}_{j}\left(C_{2}\right.$ and $\left.D_{2}\right)$. By definition, $\tilde{\psi}_{j}$ is only affected by heterogeneity in $\alpha_{j}$.

Our simulations therefore suggest $C_{2}$ and $D_{2}$ should be the main source of the heterogeneity bias. In order to garner an intuition in economic terms, it is useful to think of heterogeneity across sectors in the terminology introduced by Angeloni et al. (2006). Industries with high extrinsic persistence (high realizations of $\tilde{\psi}_{j}$ ) will naturally tend to display high correlations between marginal costs and inflation. This acts to increase the value of $C_{21}$. In contrast, under our assumptions on marginal costs, there is not reason to expect extrinsic persistence to correlate in any systematic manner with the variance in marginal costs, which only depends on its autoregressive properties. Ceteris paribus $C_{22}$ should take low values. This accounts for the fact that $C_{2}$ will tend to take positive and large values when nominal rigidities are sector-specific and heterogeneous.

By virtue of exactly identical reasoning, it is likely that $D_{22}$ will take large and negative values, since again by definition the correlation between marginal costs and inflation tends to be high for high realizations of $\tilde{\psi}_{j}$. In contrast, $D_{21}$ measures whether sectors with high extrinsic persistence are also ones with volatile marginal costs, like $C_{22}$ did. There is no systematic reasons to expect $D_{21}$ to take high values. In other words, $D_{2}$ should tend to take high negative values in the presence of heterogeneity in $\alpha_{j}$. 
It is straightforward to follow the same line of reasoning and show that $C_{1}$ and $D_{1}$ will tend to reinforce these biases when there is heterogeneity in indexation. Sectors with high levels of intrinsic persistence (high realizations of $\tilde{\xi}_{j}$ ) tend to display high inflation volatility, which results in high positive values for $C_{11}$ and negative values for $D_{12}$. A contrario, the correlation between marginal costs and inflation does not depend systematically on intrinsic persistence, and there is no reason to expect the values of $C_{12}$ and $D_{11}$ significantly away from zero. Taken together, these conjectures suggest positive values for $C_{1}$ and negative ones for $D_{1}$.

Put simply, our simulations suggest a positive bias on $\xi$ and a negative one on $\psi$. Estimates of the aggregate Phillips curve that ignore heterogeneity tend to over-estimate the extent of backward looking inflation, and under-estimate the response of prices to real marginal costs. ${ }^{22}$ The positive bias on the autoregressive properties of inflation is consistent with Granger (1980), who demonstrated the emergence of long-memory when aggregating heterogeneous autoregressive processes. The negative bias on $\psi$, the effect of marginal costs on pricing decisions is, in turn, consistent with the possibility that aggregate marginal costs are but an imperfect measure of sectoral costs, and their interactions. Equation (4) suggests the true measure of costs in the aggregate Phillips curve should involve $\sum_{j=1}^{J} w_{j} \theta_{j} s_{j t}$, which $\theta s_{t}$ may just approximate imperfectly. The attenuating bias on $\psi$ would then simply correspond to measurement error. We now turn to a simulation exercise that explores quantitatively the biases and their composition.

\subsection{Simulations}

We now perform some simulations that seek to confirm the analytical expressions just established, and in particular the signs and relative magnitudes of their various components. Our simulations now include sixteen sectors as in our French data. In addition, the simulations purport to perform the bias decompositions just discussed, and therefore are computed under the assumption that marginal costs follow an autoregressive process of order one as in the previous section. To facilitate comparison, we express all estimates in terms of the structural parameters $(\xi$ and $\alpha$ ), and infer the corresponding values for the reduced-form parameters.

The structural parameters $(\xi, \alpha$ and $\rho)$ are initially set at the values implied by heterogeneous estimations performed on our French data. Cross-industry heterogeneity in the structural parameters is drawn from a normal distribution with variances $\sigma_{\alpha}^{2}=\sigma_{\xi}^{2}=0.1{ }^{23} \mathrm{We}$ deduce sector-specific reduced-form estimates and simulate samples of 1000 observations on sectoral inflation and marginal cost. We use these artificial data to compute the corresponding aggregate inflation and marginal cost (using uniform weights), as well as the unbiased, sectorspecific estimates of $\xi_{j}$ and $\alpha_{j}$. We then estimate the aggregate Phillips Curve, using the ML

\footnotetext{
${ }^{22}$ In addition, the bias on $\rho_{M L}$ is unambiguously positive. The definition of $\psi_{j}$ suggests that high realizations of $\rho_{j}$ will be associated with high values of the reduced form coefficient on marginal costs. In other words, dispersion in $\rho_{j}$ acts to increase the heterogeneity in $\psi_{j}$. This is an aspect we have ignored in our simulations. Of course, the possibility is very much present in our empirical estimates.

${ }^{23}$ In order that we focus on the biases discussed analytically, and their composition, we impose homogeneity in $\rho_{j}$.
} 
estimator on simulated aggregate series. The resulting coefficient estimates are then used to back out the corresponding structural estimates $\xi$ and $\alpha$. We iterate the procedure, saving for each sample both the theoretical values of the structural parameters, and their empirical counterparts. We report the median value of the obtained estimates. ${ }^{24}$

Table 1 presents our baseline results. The homogeneous estimator unambiguously biases $\xi$ upwards and $\psi$ downward. Further, most of each bias originates in $C_{2}$ and $D_{2}$, which take by far the largest absolute values. It seems therefore that heterogeneity in the extent of nominal rigidities $\alpha_{j}$ drives most of the inconsistencies. The Table also reports the reduced form estimates of equation (5), and the biases on the structural parameters. As expected, we document a positive bias on $\lambda^{b}$ and a negative bias on $\theta$. As a result of this, homogeneous estimates of the duration of nominal rigidities are (slightly) biased upwards.

Our simulations largely confirm our analytics. We find sizable biases in all the coefficients of a reduced form Phillips curve, under rather restrictive hypotheses that do not necessarily hold in our data. We have imposed that marginal costs follow an autoregressive process of order one, constrained to be homogeneous across industries. We have assumed away any common influences on price across industries, and we have used uniform weights to aggregate industry-specific price dynamics. All four assumptions are likely to alter the magnitude of the biases we are concerned with. We now turn to real data, relax all hypotheses, and verify that heterogeneity continues to generate sizable inconsistencies.

\section{Econometric Methods}

We now introduce the estimators we use to account for sectoral heterogeneity. We discuss two estimators: the Mean Group (MG) and the Random Coefficient (RC) models, introduced by Swamy (1970, 1971) and Pesaran and Smith (1995). The main difference between the two estimators comes from their assumptions on the nature of heterogeneity. MG assumes sector-specific deviations from mean parameters are deterministic, whereas RC assumes they are random. As a result, MG implements a simple arithmetic averaging of sector specific estimates, whereas $\mathrm{RC}$ requires a generalized least squares procedure that optimally accounts for the stochastic nature of heterogeneity. ${ }^{25}$

The RC estimator relaxes assumption H1. In this section, we also relax the other constraints that afforded analytical expressions for the biases. In particular, some of our estimates use the industry weights directly implied by French data (H2), and we allow for cross-industry interdependence (H3). We do this in two ways. First, we implement the Seemingly Unrelated

\footnotetext{
${ }^{24}$ Reporting averages would render our simulation results quite sensitive to the odd extreme realization of heterogeneity. We choose instead to focus on median values, with the consequence that our decomposition will not hold perfectly.

${ }^{25}$ The difference is akin to that between fixed effect and random effect estimators, and can be tested accordingly. Hsiao and Pesaran (2004) shows that MG and RC estimators are equivalent in the limit. In other words, our analytical results, which were calculated on the basis of deterministic heterogeneity, become valid in the limit, even if heterogeneity is actually stochastic.
} 
Regression Estimation (SURE) correction to both heterogeneous estimators. ${ }^{26}$ Second, we introduce the common correlated effects Mean Group estimator (MG-CCE) and its random coefficient version (RC-CCE) introduced by Pesaran (2006). As already discussed, it is impossible to eschew assumption $\mathrm{H} 4$, since instrumentation is forbidden under heterogeneity. We allow for more flexible marginal costs, and model them as autoregressive processes of order two. We have verified that our empirical results stand under higher order processes.

\subsection{Mean Group}

The MG estimator introduced in Swamy $(1970,1971)$ simply consists in an arithmetic average of sector-specific parameter estimates. In particular, let $\Upsilon_{j}$ denote the vector of sector-specific parameters. The MG estimator $\hat{\Upsilon}_{M G}$ is given by

$$
\hat{\Upsilon}_{M G}=\frac{1}{J} \sum_{j=1}^{J} \hat{\Upsilon}_{j}
$$

A consistent estimator of the covariance matrix of $\hat{\Upsilon}_{M G}$ can be computed as

$$
V\left(\hat{\Upsilon}_{M G}\right)=\frac{1}{J(J-1)} \sum_{j=1}^{J}\left(\hat{\Upsilon}_{j}-\hat{\Upsilon}_{M G}\right)\left(\hat{\Upsilon}_{j}-\hat{\Upsilon}_{M G}\right)^{\prime}
$$

Two complications arise in our case. The arithmetic average of sector-specific inflation is not the object whose dynamics we are interested in. Aggregate inflation is given by a weighted average of sector-specific price changes, with weights $w_{j}$ corresponding to industry shares in the GDP deflator. We amend the MG estimator and introduce weights $w_{j}$ in computing aggregate estimates, which then indeed evaluate the dynamics of aggregate inflation as befits. Introducing these empirical weights does not affect the consistency of the MG estimator. ${ }^{27}$

Second, the parameters estimated by ML are not all structural. To preserve coherence, we obtain industry-level estimates of the reduced form coefficients $\xi_{j}, \psi_{1 j}, \psi_{2 j}, \rho_{1 j}$ and $\rho_{2 j}$, and perform the aggregation on the basis of these estimates. Then MG (or indeed RC) yields consistent estimates for the aggregate coefficients $\xi, \psi_{1}, \psi_{2}, \rho_{1}$ and $\rho_{2}$, which we use to back out the aggregate structural parameters. Thus we avoid aggregating non-linear estimates of $\alpha_{j}$. When evaluating the existence of a heterogeneity bias, we therefore compare homogeneous estimates of $\xi, \psi_{1}, \psi_{2}, \rho_{1}$ and $\rho_{2}$ to the corresponding weighted average of their industry level values. $^{28}$ The alternative would be to estimate the structural parameters $\xi$ and $\alpha$ at both levels of aggregation, infer the true aggregate estimates from a weighted average of disaggregated results, and compare homogeneous and heterogeneous estimates. But this might conflate the heterogeneity bias with one induced by aggregated non-linearities. We only present results that pertain to the former approach, which in fact is more in line with the initial insight in Pesaran and Smith (1995). This is true of all our heterogeneous estimations.

\footnotetext{
${ }^{26}$ This is directly applicable since we have sixteen sectors but 111 observations.

${ }^{27}$ This builds on the asymptotic result in Hsiao and Pesaran (2004) that RC and MG are equivalent in the limit.

${ }^{28}$ This is exactly the approach recommended in Stoker (1993).
} 


\subsection{Random Coefficients}

Following Swamy (1970, 1971), Pesaran and Smith (1995), and Hsiao and Pesaran (2004), we define the RC estimator as a weighted average of the least squares estimates, with weights inversely proportional to their covariance matrices. In particular, the best linear unbiased estimator of the mean coefficient vector is given by

$$
\hat{\Upsilon}_{R C}=\sum_{j=1}^{J} W_{j} \hat{\Upsilon}_{j}
$$

The weighting scheme is given by

$$
W_{j}=\left[\sum_{j=1}^{J}\left(\Delta+\Sigma_{\hat{\Upsilon}_{j}}\right)^{-1}\right]^{-1}\left(\Delta+\Sigma_{\hat{\Upsilon}_{j}}\right)^{-1}
$$

where

$$
\Delta=\frac{1}{J-1} \sum_{j=1}^{J}\left(\Upsilon_{j}-\Upsilon_{M G}\right)\left(\Upsilon_{j}-\Upsilon_{M G}\right)^{\prime}-\frac{1}{J} \sum_{j=1}^{J} \Sigma_{\hat{\Upsilon}_{j}}
$$

and $\Sigma_{\hat{\Upsilon}_{j}}=\sigma_{j}^{2}\left(X_{j}^{\prime} X_{j}\right)^{-1} \cdot X_{j, t}=\left(\pi_{j, t-1}, s_{j, t}\right)^{\prime}$ is the vector of regressors, and $\sigma_{j}^{2}$ is estimated by $\hat{\sigma}_{j}^{2}=\frac{1}{T-5} \pi_{j}^{\prime}\left(I_{T}-X_{j}\left(X_{j}^{\prime} X_{j}\right) X_{j}^{\prime}\right) \pi_{j}$. In words, $\Delta+\Sigma_{\hat{\Upsilon}_{j}}$ captures the dispersion of the industry-specific estimates, so that $W_{j}$ will optimally act to associate a large weight to sectors where the estimates are precise. The MG estimator is efficient when the optimal weights are not different from the arithmetic ones. ${ }^{29}$

A weighting issue arises when implementing RC for our purposes. The optimal weights $W_{j}$ are not necessarily aligned with the empirical sector shares, $w_{j}$. Although the exact pattern of weights does not matter in the limit, as exemplified by the asymptotic equivalence between RC and MG, we ascertain how much our results are affected by a particular patterns of industry weights. In what follows, we report RC estimates as implied by both optimal and observed weights. In particular, we constrain the weighing scheme used to compute $\hat{\Upsilon}_{M G}$ to be either uniform (which boils down to standard RC) or to entail observed weights (which boils down to our augmented version of MG, as discussed in the previous section).

\subsection{Cross-Industry Linkages}

It is eminently likely that shocks to sectoral inflation or marginal costs be correlated across sectors. This would happen for instance in the presence of macroeconomic aggregate shocks, or input-output linkages between industries. We now discuss how to deal econometrically with this possibility, while preserving a high level of generality in the nature of cross-industry linkages.

\footnotetext{
${ }^{29}$ Swamy (1970) includes the first term only in his suggested empirical estimates for $\hat{\Delta}$. This is not uncontroversial. More recent contributions recommend including both terms in the expression, as for instance in Hsiao and Pesaran (2004). We later report RC estimates corresponding to both hypotheses.
} 
We first apply a SURE correction to both our heterogeneous estimators. In particular, assume now $E\left[\varepsilon_{i, t} \varepsilon_{j, t}\right]=\sigma_{\varepsilon_{i} \varepsilon_{j}}, E\left[u_{i, t} u_{j, t}\right]=\sigma_{u_{i} u_{j}}$, and $E\left[\varepsilon_{i, t} u_{j, t}\right]=\sigma_{\varepsilon_{i} u_{j}}$, for $i \neq j$. Stacking all sectors,

$$
\left(\begin{array}{c}
Y_{1} \\
Y_{2} \\
\vdots \\
Y_{J}
\end{array}\right)=\left(\begin{array}{cccc}
X_{1} & 0 & \cdots & 0 \\
0 & X_{2} & \cdots & 0 \\
\vdots & \ddots & \ddots & \vdots \\
0 & \cdots & 0 & X_{J}
\end{array}\right)\left(\begin{array}{c}
\phi_{1} \\
\phi_{2} \\
\vdots \\
\phi_{J}
\end{array}\right)+\left(\begin{array}{c}
v_{1} \\
v_{2} \\
\vdots \\
v_{J}
\end{array}\right)
$$

where $Y_{j}=\left(\begin{array}{c}\pi_{j} \\ s_{j}\end{array}\right), X_{j}=\left(\begin{array}{ccccc}\pi_{j,-1} & s_{j} & s_{j,-1} & 0 & 0 \\ 0 & 0 & 0 & s_{j,-1} & s_{j,-2}\end{array}\right), v_{j}=\left(\begin{array}{l}\varepsilon_{j} \\ u_{j}\end{array}\right), \pi_{j}=\left(\pi_{j, t}\right)$, $\pi_{j,-1}=\left(\pi_{j, t-1}\right), s_{j}=\left(s_{j, t}\right), s_{j,-k}=\left(s_{j, t-k}\right)$, and $\phi_{j}=\left(\xi_{j}, \psi_{1 j}, \psi_{2 j}, \rho_{1 j}, \rho_{2 j}\right)^{\prime}$. The stacked disturbances $v_{j}$ have a covariance matrix $\Omega$ which standard ML techniques can account for. We correct both RC and MG accordingly.

The SURE correction requires the estimation of a large-dimensional covariance matrix, which may affect the finite-sample properties of the estimators. An alternative is proposed by Pesaran (2006), who introduced a correction technique to account for unobserved common factors potentially correlated with sector-specific regressors. The sector-specific estimations are filtered by means of cross-section aggregate regressors, which purge the differential effects of unobserved common factors. The approach is particularly appealing because of its simplicity. It merely requires the addition of an auxiliary regressor, given by the cross-sectional average of the regressors, which suffices to filter the common correlated effect (CCE) out. In particular, the model rewrites

$$
\begin{aligned}
\pi_{j, t} & =\xi_{j} \pi_{j, t-1}+\psi_{1 j} s_{j, t}++\psi_{2 j} s_{j, t-1}+f_{j, t}^{\prime} \gamma_{\pi, j}+\bar{\eta}_{j, t} \\
s_{j, t} & =\rho_{1 j} s_{j, t-1}+\rho_{2 j} s_{j, t-2}+f_{j, t}^{\prime} \gamma_{s, j}+\bar{u}_{j, t}
\end{aligned}
$$

where $f_{t}=\left(\bar{\pi}_{t}, \bar{\pi}_{t-1}, \bar{s}_{t}, \bar{s}_{t-1}, \bar{s}_{t-2}\right)^{\prime}, \bar{x}_{t}$ is the cross-sectional average of $x_{j, t}$, and $\bar{\eta}_{j, t}$ (resp. $\left.\bar{u}_{j, t}\right)$ denotes an independent and identically distributed shock to inflation (resp. real marginal costs) in sector $j$. We implement the CCE correction onto both our heterogeneous estimators. $^{30}$

\section{$5 \quad$ Results}

We first describe our sectoral data, which include production, prices, wages and employment in sixteen French sectors. We discuss some summary statistics. Next we present the industry specific estimates of the Phillips curve, and identify the main sources of heterogeneity in our data. Finally, we discuss the heterogeneity bias.

\footnotetext{
${ }^{30}$ A consistent estimator of $\Sigma_{\hat{\Upsilon}}$ is obtained using the Newey and West (1987) type procedure. The CCE estimator of sector-specific parameters are consistent as $J, T \rightarrow \infty$. As a result, the CCE correction of the MG (or RC) estimator is asymptotically unbiased as $J \rightarrow \infty$, for $T$ either fixed or $T \rightarrow \infty$. A rank condition is necessary regarding the factor loadings $f_{t}$. The asymptotic distribution can only be derived if $\sqrt{T} / J \rightarrow 0$ as $J, T \rightarrow \infty$.
} 


\subsection{Data}

Our data is constructed by INSEE, the French statistical institute. We have observations on output, prices, wages and employment for sixteen sectors of the French economy, comprising all activities and listed in Appendix 3. Coverage includes agriculture, manufacturing (six sectors) and services (nine sectors). For each industry, the inflation rate is computed as the quarteron-quarter growth rate of the value-added deflator. In computing a sector-specific measure of marginal costs, we follow Sbordone (2001) or Galí, Gertler, and López-Salido (2001). $s_{j, t}$ is the (logarithm) deviation of the share of labor income in value added from its sample mean, to which we apply the sector specific correction implied by $h_{j}$. From its definition, the correction itself is computed on the basis of the observed industry share of labor in production $a_{j}$, and a value for $\eta$ which is pinpointed by a level of markups calibrated at ten percent. ${ }^{31}$ Our data are quarterly from 1978:1 to 2005:3, for a total of 111 observations.

Table 2 presents some summary statistics. ${ }^{32}$ We report average inflation and average growth in real marginal costs, their serial correlations, and their contemporaneous correlation, at both industry and aggregate levels. There is extensive heterogeneity across sectors in both average measures. Annual inflation ranges between $0.2 \%$ and $5.5 \%$, and the average annual growth in real marginal costs ranges between $-3.6 \%$ and $0.1 \%$. The same is true of serial correlation in inflation, and the cross-correlation between $s_{j, t}$ and $\pi_{j, t}$. In contrast marginal costs are consistently highly serially correlated. Figures 2 and 3 plot sectoral inflation rates and real marginal costs. There is again considerable heterogeneity across sectors in the patterns of both variables, although they tend to track each other within each industry as testified in the industry-level Phillips curves we later estimate.

Table 2 also reveals that aggregate inflation and real marginal costs are highly serially correlated, and covary to an extent that is much larger than most industry-level series. Figure 4 plots both aggregate series, and illustrates that both series experienced a similar downward trend over the sample. Aggregate inflation and marginal costs track each other closely, quite reassuringly given the existing empirical support for aggregate Phillips curves.

\subsection{Industry Estimates}

Table 3 presents industry-level estimates of the New Keynesian Phillips curve on the basis of a Maximum Likelihood approach. We maintain the assumption that marginal costs are well characterized at the industry level by an autoregressive process of order two, and estimate the resulting reduced form equation. We focus on ML estimates of the Phillips curve at the industry level because the aggregation of heterogeneous coefficients obtained from GMM

\footnotetext{
${ }^{31}$ This follows directly from Sbordone (2001) or Galí, Gertler, and López-Salido (2001). The latter in particular argue that different markup values do not alter any of their results (in footnote 24). We checked that using a unique, aggregate measure of $a_{j}$ does not change any of our results either. Effectively, the correcting term $h_{j}$ affects identically homogeneous and heterogeneous estimates of the Phillips curve, and thus does not matter at all for the magnitude or existence of a heterogeneity bias.

${ }^{32}$ We subtracted its industry-specific mean from each series. We also experimented with filtering the data, with minimal end effects.
} 
estimations is uncharted territory. Our MG and RC heterogeneous estimators (and their corrections) are only equipped to aggregate industry-level estimates that arise from a ML estimator.

Several results stand out from Table 3. First, our data are supportive of inflation dynamics at the industry level that are consistent with the New Keynesian framework. In ten of the sixteen sectors, marginal costs affect significantly the pricing decisions of firms, to an extent that display substantial heterogeneity. Estimates of $\xi$ are adequately bounded, and marginal costs are unanimously persistent. Estimates of the reduced form Phillips curve given in equation (3) confirm large differences in the extent of backward looking behavior, with values of $\lambda^{b}$ ranging from zero to around a half. The heterogeneity carries through to sector-level estimates of the structural parameters. The extent of indexation $\xi$ varies between zero in Energy or Transportation to 0.8 or 0.9 in Agriculture, Real Estate or Government Services. Similarly we obtain estimates of $\alpha_{j}$ between zero and virtually one, with vastly different implied durations. These values, whose heterogeneity our simulations suggest is crucial in the aggregate, range from around one quarter in sectors like Agriculture, Food, Energy or Transportation, to more than five years in Real Estate and Business or Personal Services. On the whole, duration is found to take high values in virtually all service industries. ${ }^{33}$

Figure 5 plots observed inflation for each industry as against the path predicted by the estimated Phillips curve in that sector. The fit is remarkably close for as many as ten out of the sixteen industries with data. In fact, both series are virtually identical for eight of our sectors, including for instance Agriculture, Consumption Goods, Personal Services or Financial Services. Our results are broadly consistent with the estimates reported in Vermeulen et al. (2007), Fougère et al. (2005) or Baudry et al. (2005), also based on French data. ${ }^{34}$ For instance, Fougère et al. (2005) estimate long-lived nominal rigidities in services on average, but especially short ones in Food Manufacturing or Energy. The papers also document relatively homogeneous estimates within services and within manufactures, as we do. ${ }^{35}$ Interestingly, Vermeulen et al (2007) document similar patterns in other European countries.

\subsection{Heterogeneity Bias}

We now quantify the heterogeneity bias in our data, and compare estimates of the structural parameters implied by standard ML estimators performed on aggregated data, with the corre-

\footnotetext{
${ }^{33}$ We have implemented Fisher tests to investigate coefficient equality across sectors. We used the industrylevel estimates in Table 3, and found overwhelming rejection of the homogeneity assumption across all parameters $\xi, \alpha, \rho_{1}$ and $\rho_{2}$. When using instead (unreported) industry-level estimates that implement SURE to correct for cross-industry correlations, rejection becomes even stronger.

${ }^{34}$ These papers are not directly comparable because of different data sources, aggregation levels and modeling strategies. For instance, they use CPI data, and focus on consumption goods only, whereas we have information on producers goods as well. But all these papers find substantial heterogeneity, in particular between services and manufacturing industries. Vermeulen et al. (2007) also document the importance of labor costs in driving disaggregated price dynamics, a result entirely consistent with the existence of sectoral Phillips curves.

${ }^{35}$ In fact, we ran our heterogeneous estimators within both manufacturing industries and services, and in each case found barely any evidence of a heterogeneity bias. In contrast as will become clearer, the bias is large when considering the complete sample. In other words, the extent of heterogeneity in our data is largest between manufacturing industries and services.
} 
sponding estimates implied by heterogeneous estimators that make use of sectoral information. For completeness, we also report the estimates of an aggregate Phillips curve as implied by the standard (homogeneous) GMM approach. Our empirical results are based on the constraint that real marginal costs are well characterized by an autoregressive process of order two at the industry level. We therefore estimate a generalization of the system of equations (9), derived in Appendix 1, that accounts for the autoregressive properties of marginal costs, i.e.

$$
\begin{gathered}
\pi_{t}=\xi \pi_{t-1}+\psi_{1} s_{t}+\psi_{2} s_{t-1}+\bar{\eta}_{t} \\
s_{t}=\rho_{1} s_{t-1}+\rho_{2} s_{t-2}+\bar{u}_{t}
\end{gathered}
$$

with

$$
\begin{aligned}
\psi_{1} & =\frac{1-\beta \alpha}{1-\beta \rho_{1}-\beta^{2} \rho_{2}} \frac{1-\alpha}{\alpha} \\
\psi_{2} & =\beta \psi_{1} \rho_{2} .
\end{aligned}
$$

Table 4 reports our results. The first two columns report estimates for the aggregate New Keynesian Phillips curve, as implied by GMM and ML. The subsequent specifications correspond to the results that pertain to variants of our heterogeneous estimators, depending on what weighting pattern is used in aggregating. ${ }^{36}$

We find a large and positive heterogeneity bias on $\xi$. The homogeneous ML estimator implies a value of 0.666 , but accounting for heterogeneity, estimates range between 0.488 and 0.530, and all are significantly smaller. This implies estimates of firms backward looking behavior close to 0.33 when accounting for heterogeneity, as opposed to 0.40 from aggregate ML. Interestingly, the bias on $\lambda^{b}$ is smaller when comparing aggregate GMM estimates with heterogeneous results. ${ }^{37}$ The same is not true of the importance of marginal costs, which is systematically under-estimated when heterogeneity is ignored. GMM implies they are on the whole irrelevant in our data $(\theta=0)$, and ML implies a small and weakly significant role for $s_{t}(\theta=0.034)$. In contrast, the mean group estimator implies a value for $\theta$ close to 0.12 , and 0.31 when uniform weights are used in aggregating industry level estimates. ${ }^{38}$

How do these discrepancies in reduced form estimates translate into structural coefficients? Table 4 suggests the duration of nominal rigidities is seriously over-estimated by ML aggregate estimators, which imply prices remain unchanged for close to five quarters. This is close to the estimates obtained by Galí, Gertler, and López-Salido (2001) or Benigno and López-Salido

\footnotetext{
${ }^{36}$ To be precise, the use of different weights only matters for computing $\hat{\Upsilon}_{M G}$. The RC model continues to use the optimal weights $W_{j}$ when aggregating.

${ }^{37}$ But the comparison is somewhat diagonale, as heterogeneous estimators are based on assumptions on the process generating marginal costs, and make use of no instruments. It is however possible to use analytical expressions akin to what we developed in Section 3.1 to account for the smaller bias on $\lambda^{b}$ implied by a GMM estimator.

${ }^{38} \mathrm{RC}$ estimators, in contrast, imply values for $\theta$ that are still large, but not significantly different from zero. In unreported results, we have performed Hausman tests to ascertain whether MG or RC provided a better representation of our data, and have concluded MG results are to be preferred.
} 
(2006) who both use European data to estimate a duration of nominal rigidities upwards from one year. ${ }^{39}$

Our heterogeneous estimators, in contrast, all imply durations below three quarters, and a majority lies close to two quarters. These differences are also significant at standard confidence levels. A duration for price rigidities around two quarters is consistent with the estimates based on disaggregated data, documented among others in Bils and Klenow (2005). For instance, Bils and Klenow conclude that "the time between price changes remains under 5.5 months for half of consumption". Our aggregate estimates that account for heterogeneity are in that same vicinity, even though they also imply implausible (homogeneous) results. Heterogeneous estimators help translating short nominal durations up into aggregate data, and the heterogeneity bias explains away the anomaly. ${ }^{40}$

\subsection{Correcting for Cross-Industry Linkages}

We now implement two corrections to our heterogeneous estimators that allow for the possibility that shocks be correlated across industries. Our corrections are general enough to account for common macroeconomic shocks, input-output production linkages or indeed anything that would engender influences on sectoral prices or marginal costs that are contemporaneously correlated across industries.

In Appendix 4, we report various estimates that help quantifying cross-industry linkages in our data. Table A1 reports the cross-correlations between the residuals $\eta_{j, t}$ of each industryspecific Phillips curve estimate, as implied by equation (7). Table A2 focuses instead on the cross-industry correlations in $u_{j, t}$, the cost-push shock. On average, the values in Table A1 are positive, though relatively few are significant. This is consistent with price pressures affecting simultaneously several industries. We note significantly positive correlations tend to occur within manufactures, and within services. The same can be said of shocks to marginal costs in Table A2, providing support that cost-push shocks tend to affect more than one sector. This would characterize aggregate macroeconomic shocks, or perhaps production linkages across industries.

In short, shocks are correlated across sectors. Table 5 presents the two corrections we implement, SURE and CCE, along with the aggregate estimates from Table 4 for comparison purposes. The corrections only act to reinforce our conclusions. The corrected biases on $\xi$ become substantially larger, irrespective of the correcting approach, and heterogeneous estimates are as low as 0.348 under RC-CCE, as compared with 0.666 under homogeneity. This is a large bias, with considerable impact on the estimated role for backward looking

\footnotetext{
${ }^{39}$ For the Euro area as a whole, Galí, Gertler, and López-Salido (2001) report duration estimates equal to 4.7 quarters in their Table 2. Benigno and López-Salido (2006) present country-specific estimates in their Table 1. French nominal rigidities are estimated to last above 6 quarters.

${ }^{40}$ The GMM estimator implies a duration close to three quarters, but riddled with great uncertainty. Because of large standard errors, it is impossible to conclude whether the bias is significant in this case. But again, even if it were possible, the comparison would be diagonal, as heterogeneous estimators rely on fundamentally different hypotheses than GMM.
} 
pricing. Unbiased estimates of $\lambda^{b}$ are as low as 0.25 , as compared with 0.40 when imposing homogeneity. These differences are significant at any standard confidence level.

As in Table 4, the role of marginal costs in affecting prices is restored once heterogeneity is accounted for, especially as regards the MG estimator. Estimates of $\theta$ are up to five times larger when comparing aggregate ML results and heterogeneous estimates. This translates in significantly lower heterogeneous estimates for $\alpha$, ranging between 0.51 and 0.65 , as compared with 0.79 . The duration of nominal rigidities continues to range between two and 2.8 quarters, depending on which correction is implemented to account for correlated residuals. These differences are always significant. The durations we continue to obtain in the aggregate once heterogeneity is accounted for are consistent with existing studies concerned with disaggregated firm behavior. The durations that impose homogeneity are not.

\section{Robustness}

The results discussed so far rested on an indexation assumption to generate a hybrid Phillips curve. We have argued that heterogeneity in the extent of indexation is quantitatively unimportant in generating inconsistencies in aggregate estimates. In effect therefore, the justification for a term involving lagged inflation in the reduced form Phillips curve seems to be largely innocuous in terms of the implied aggregation biases. We now turn to an alternative, equally standard modeling of the hybrid Phillips curve.

Galí and Gertler (1999) introduced purely backward looking firms, assumed to obey a rule of thumb whereby the price in period $t$ depends only on information dated $t-1$ or earlier. In this section, we describe the sectoral Phillips curve this implies, which entails a different structural interpretation of the estimates of lagged inflation. We briefly introduce the implied inconsistencies, argue heterogeneity in the extent of backward looking behavior continues to be relatively innocuous in this model, and discuss the biases implied by French data.

The crucial difference with the model described in Section 2 rests on the assumption that a proportion $\omega_{j}$ of the firms that are allowed to adjust their prices do so in a pure backward looking manner. In particular, the sectoral $(\log )$ price level is given by

$$
p_{j, t}=\alpha_{j} p_{j, t-1}+\left(1-\alpha_{j}\right) p_{j, t}^{*}
$$

where $P_{j t}^{*}$ is an index of prices newly set at time $t$. By definition, newly set prices are given by

$$
p_{j, t}^{*}=\omega_{j} p_{j, t}^{b}+\left(1-\omega_{j}\right) p_{j, t}^{f}
$$

where $p_{j t}^{b}\left(p_{j t}^{f}\right)$ denote the price set by backward (forward) looking firms. Forward looking firms choose prices optimally as they would in the standard Calvo (1983) framework, i.e.

$$
p_{j, t}^{f}=\left(1-\beta \alpha_{j}\right) \sum_{k=0}^{\infty}\left(\beta \alpha_{j}\right)^{k} E_{t}\left(s_{j, t, t+k}+p_{t+k}\right) .
$$


In turn, backward looking firms merely adjust for inflation the prices they set the last time they could, i.e.

$$
p_{j, t}^{b}=p_{j, t-1}^{*}+\pi_{j, t-1}
$$

As is well known, these four conditions combine to imply a (linearized) hybrid Phillips curve:

$$
\pi_{j, t}=\underline{\lambda}_{j}^{b} \pi_{j, t-1}+\underline{\lambda}_{j}^{f} E_{t} \pi_{j, t+1}+\underline{\theta}_{j} s_{j, t}+\varepsilon_{j, t}
$$

with $\underline{\lambda}_{j}^{b}=\omega_{j} / \phi, \underline{\lambda}_{j}^{f}=\beta \alpha_{j} / \phi$, and $\underline{\theta}_{j}=\frac{\left(1-\omega_{j}\right)\left(1-\alpha_{j}\right)\left(1-\beta \alpha_{j}\right)}{\alpha_{j}+\omega_{j}\left[1-\alpha_{j}(1-\beta)\right]}$, and $\phi=\alpha_{j}+\omega_{j}\left[1-\alpha_{j}(1-\beta)\right]$. As before since marginal costs are heterogeneous ex post across firms, the corrected real marginal cost in sector $j$ writes $s_{j, t}=\left(s_{j, t}^{a v g}+p_{t}-p_{j, t}\right) /\left(1+h_{j}\right)$. Both models have an identical reduced form, but imply different interpretations of the structural parameters.

It continues to be impossible to estimate our model using the GMM approach, as no satisfactory instruments are available. We therefore continue to impose the additional assumption that marginal costs are well represented by an autoregressive process of order two. This also ensures the comparability of our estimates across models. The model we estimate is given by

$$
\pi_{t}=\underline{\delta}_{1} \pi_{t-1}+\underline{\psi}_{1} s_{t}+\underline{\psi}_{2} s_{t-1}+\bar{\eta}_{t}
$$

In results available upon request, we show analytically that the heterogeneity biases in this model have virtually identical properties to the ones described in Section 2. In particular, ML tends to bias estimates of both $\omega$ and $\alpha$ upwards. Imposing homogeneity increases both the apparent prevalence of backward looking behavior and the estimated duration of nominal rigidities in the aggregate. What is more, the bulk of these inconsistencies stems from heterogeneity in $\alpha_{j}$, rather than $\omega_{j}$.

We also estimated industry level Phillips curves as implied by the model in Galí and Gertler (1999). Since the model implies reduced form that are identical to Christiano, Eichenbaum, and Evans (2005), Figure 2 continues to illustrate the ability of this theory to fit price dynamics at the industry level. The interpretation of the structural estimates is however fundamentally different. We find values for $\omega_{j}$ ranging from zero in Energy, Transportation and Business Services to 0.8 in Personal and Government Services. ${ }^{41}$ The duration of nominal rigidities, in turn, ranges from a few days in Food Manufacturing, around one quarter in Agriculture, Energy or Transportation, to two years and above in the Car industry, Business Services, Health or Education. As far as nominal rigidities are concerned, these results are in line with those obtained in Section 5.

Table 6 illustrates how heterogeneity continues to generate sizable inconsistencies in the context of an alternative model. ${ }^{42}$ In particular, estimates of $\underline{\lambda}^{b}$ continue to suffer from

\footnotetext{
${ }^{41}$ These results are available upon request.

${ }^{42}$ The aggregate Phillips curve is estimated as follows. The reduced form is written in terms of the structural parameters $\alpha$ and $\omega$, and it is this expression that is used to impose restrictions on $\underline{\delta}_{1}, \underline{\psi}_{1}$, and $\underline{\psi}_{2}$.
} 
an upwards bias, and on the contrary $\underline{\theta}$ is kept artificially low. We obtain heterogeneous estimates of $\underline{\lambda}^{b}$ around 0.33 , as opposed to 0.40 under homogeneity. This corresponds to striking differences in the estimated proportion of backward looking firms, close to a half under ML, to 0.4 under GMM, and down to 0.23 under the Mean Group estimator. The duration of nominal rigidities, in turn, range from 1.9 to 2.5 quarters allowing for heterogeneity, while it is closer to 3 to 3.5 quarters under the standard approach.

Table 7 repeats the exercise allowing for correlated residuals, which strengthens all our results. Heterogeneous estimates of $\underline{\lambda}^{b}$ are now down to 0.25 , and those of $\omega$ as low as $0.17-$ almost three times smaller than the homogeneous ML value of 0.47 , and twice smaller than the GMM estimate. Nominal rigidities continue to last less than 2.5 quarters in all cases, down to less than 2 under MG-CCE. All these discrepancies are significant at standard confidence levels. These suggest our conclusions do not hinge on the use of a particular device when modeling a hybrid Phillips curve. What changes is the interpretation of the structural estimates, but not the magnitude nor the sign of the inconsistencies we document. In particular, it continues to be true that backward looking behavior and nominal rigidities are both magnified when homogeneity is imposed on the data.

\section{Conclusion}

We show estimates of the aggregate Phillips Curve are biased in the presence of heterogeneity in firms pricing behavior. We consider two archetypical models of a hybrid Phillips curve, amended to allow for differences in nominal rigidities and price setting behavior across industries. We provide the expressions for the inconsistencies that plague Phillips curve estimates in the presence of heterogeneity, and argue the biases do not all have the same sign, nor the same magnitude. We show analytically that an approach imposing homogeneity is likely to underestimate the role of (aggregate) marginal costs in affecting (aggregate) prices, and overestimate the apparent (aggregate) backward looking behavior in prices. Simulations suggest both inconsistencies tend to originate from differences across industries in the duration of nominal rigidities, and not from differences in the degree of indexation, or ad hoc backward looking behavior.

We investigate these analytics in French sectoral data, and verify they hold under less restrictive assumptions. In particular, we implement a battery of heterogeneous estimators, allowing for deterministic or stochastic heterogeneity, and for the possibility that prices and marginal costs be correlated across industries. Comparing our results and those implied by standard homogeneous approaches confirms our analysis. Prices respond to marginal costs and are more forward looking when firms' pricing strategies are allowed to differ across industries. The reduced form coefficient on marginal costs is up to ten times larger when heterogeneity is permitted, and the proportion of backward looking behavior is around a quarter, as compared with 0.4 to a half otherwise. Concomitantly our heterogeneous estimates imply an aggregate duration of nominal rigidities in the vicinity of two quarters, as compared with four to five when standard homogeneous approaches are implemented on our data. The difference is significant, and accounts for the discrepancy between the type of nominal rigidities documented in recent 
studies based on disaggregated data, and those that arise from standard aggregate estimates. The latter simply do not allow for heterogeneity.

Our results are based on French data, and it is thus difficult to ascertain their generality. To our knowledge, it has so far proved elusive to construct similar datasets elsewhere, that include quarterly measures of prices and real marginal costs at a disaggregated level. Given the current interest in disaggregated price dynamics, it is our hope the present exercise provides but a first step on the way. Whether our conclusions continue to be true elsewhere is an open question.

Ours is an empirical exercise. We set out to investigate the relevance of heterogeneity in explaining some of the anomalous results obtained when estimating aggregate Phillips curves. We have therefore assumed throughout the very shape of a hybrid Phillips curve continues to hold true on average even in the presence of heterogeneity. We have discussed how standard estimates ought to be corrected, rather than introducing an altogether novel structural expression for inflation dynamics. We view this alternative as complementary, and indeed liable to shed light on the economics behind our results. For instance, our conclusions are consistent with the presence of strategic complementarities in firms' pricing across industries, where price changes are triggered in part by decisions taken in other sectors. There, inaction is contagious and aggregate prices may appear to barely respond to changes in marginal costs. The importance of such complementarities is destined to remain a conjecture until a tractable model of heterogeneous pricing is proposed and estimated. 
Appendix 1: Derivation of the reduced form (Equation (7) in Section 2.3)

The full model of (sectoral) inflation rests on the following system

$$
\begin{aligned}
\pi_{j, t} & =\lambda_{j}^{b} \pi_{j, t-1}+\lambda_{j}^{f} E_{t} \pi_{j, t+1}+\theta_{j} s_{j, t}+\varepsilon_{j, t} \\
s_{j, t} & =\rho_{1 j} s_{j, t-1}+\rho_{2 j} s_{j, t-2}+u_{j, t} .
\end{aligned}
$$

Using the companion form of the second equation, we have

$$
\begin{aligned}
\pi_{j, t} & =\lambda_{j}^{b} \pi_{j, t-1}+\lambda_{j}^{f} E_{t} \pi_{j, t+1}+\left(\begin{array}{ll}
\theta_{j} & 0
\end{array}\right)\left(\begin{array}{c}
s_{j, t} \\
s_{j, t-1}
\end{array}\right)+\varepsilon_{j, t} \\
\left(\begin{array}{c}
s_{j, t} \\
s_{j, t-1}
\end{array}\right) & =\Lambda_{j}\left(\begin{array}{c}
s_{j, t-1} \\
s_{j, t-2}
\end{array}\right)+\left(\begin{array}{c}
u_{j, t} \\
0
\end{array}\right)
\end{aligned}
$$

where

$$
\Lambda_{j}=\left(\begin{array}{cc}
\rho_{1 j} & \rho_{2 j} \\
1 & 0
\end{array}\right)
$$

The characteristic equation of the Phillips Curve writes

$$
\left(1-\lambda_{j}^{b} L-\lambda_{j}^{f} L^{-1}\right) \pi_{j, t}=\left(\begin{array}{cc}
\theta_{j} & 0
\end{array}\right)\left(\begin{array}{c}
s_{j, t} \\
s_{j, t-1}
\end{array}\right)+\varepsilon_{j, t}
$$

where $L$ denotes the lag operator. The two roots are $\xi_{j}<1$ and $\frac{1}{\beta}>1$. The dynamics of inflation therefore rewrite

$$
\frac{1}{\beta}\left(1-\xi_{j} L\right)\left(1-\beta L^{-1}\right) \pi_{j, t}=\frac{1}{\lambda_{j, f}}\left(\begin{array}{cc}
\theta_{j} & 0
\end{array}\right)\left(\begin{array}{c}
s_{j, t} \\
s_{j, t-1}
\end{array}\right)+\frac{\varepsilon_{j, t}}{\lambda_{j, f}} .
$$

After some manipulations, this implies

$$
\pi_{j, t}=\xi_{j} \pi_{j, t-1}+\frac{\beta}{\lambda_{j}^{f}}\left(\begin{array}{ll}
\theta_{j} & 0
\end{array}\right) E_{t} \sum_{k=0}^{\infty} \beta^{k}\left(\begin{array}{c}
s_{j, t+k} \\
s_{j, t+k-1}
\end{array}\right)+\eta_{j, t}
$$

where $\eta_{j, t}=\left(1+\beta \xi_{j}\right) \varepsilon_{j, t}$.

Using

$$
E_{t}\left(\begin{array}{c}
s_{j, t+k} \\
s_{j, t+k-1}
\end{array}\right)=\Lambda_{j}^{k}\left(\begin{array}{c}
s_{j, t} \\
s_{j, t-1}
\end{array}\right)
$$

we have

$$
\begin{aligned}
\pi_{j, t} & =\xi_{j} \pi_{j, t-1}+\frac{\beta}{\lambda_{j}^{f}}\left(\begin{array}{ll}
\theta_{j} & 0
\end{array}\right) \sum_{k=0}^{\infty}\left(\beta \Lambda_{j}\right)^{k}\left(\begin{array}{c}
s_{j, t} \\
s_{j, t-1}
\end{array}\right)+\eta_{j, t} \\
& =\xi_{j} \pi_{j, t-1}+\frac{\beta}{\lambda_{j}^{f}}\left(\begin{array}{ll}
\theta_{j} & 0
\end{array}\right)\left(I_{2}-\beta \Lambda_{j}\right)^{-1}\left(\begin{array}{c}
s_{j, t} \\
s_{j, t-1}
\end{array}\right)+\eta_{j, t}
\end{aligned}
$$

where $I_{2}$ is the identity matrix of dimension two, and

$$
\left(I_{2}-\beta \Lambda_{j}\right)^{-1}=\frac{1}{\Delta_{j}}\left(\begin{array}{cc}
1 & \beta \rho_{2 j} \\
\beta & 1-\beta \rho_{1 j}
\end{array}\right)
$$


with $\Delta_{j}=1-\beta \rho_{1 j}-\beta^{2} \rho_{2 j}$.

The sectoral reduced-form can thus be expressed as

$$
\pi_{j, t}=\xi_{j} \pi_{j, t-1}+\psi_{1 j} s_{j, t}+\psi_{2 j} s_{j, t-1}+\eta_{j, t}
$$

with

$$
\begin{aligned}
\psi_{1 j} & =\frac{1-\beta \alpha_{j}}{1-\beta \rho_{1 j}-\beta^{2} \rho_{2 j}} \frac{1-\alpha_{j}}{\alpha_{j}} \\
\psi_{2 j} & =\beta \psi_{1 j} \rho_{2 j} .
\end{aligned}
$$

Under the assumption that the aggregate Phillips Curve is true on average, aggregate dynamics are then given by

$$
\begin{aligned}
\pi_{t} & =\xi \pi_{t-1}+\psi_{1} s_{t}+\psi_{2} s_{t-1}+\bar{\eta}_{t} \\
s_{t} & =\rho_{1} s_{t-1}+\rho_{2} s_{t-2}+\bar{u}_{t}
\end{aligned}
$$

where the residuals are defined in the text and

$$
\begin{aligned}
\psi_{1} & =\frac{1-\beta \alpha}{1-\beta \rho_{1}-\beta^{2} \rho_{2}} \frac{1-\alpha}{\alpha} \\
\psi_{2} & =\beta \psi_{1} \rho_{2} .
\end{aligned}
$$




\section{Appendix 2: Proof of Proposition 1}

We first establish two lemmas.

Lemma 1 Let $X$ be a random variable and, $f$ and $g$ be two increasing functions, then

$$
\operatorname{cov}(f(X), g(X)) \geq 0 .
$$

Proof: Assume two independent draws, $X_{i}$ and $X_{j}(i \neq j)$, from the distribution of $X$. Since $f$ and $g$ are increasing, we have

$$
\left[f\left(X_{i}\right)-f\left(X_{j}\right)\right]\left[g\left(X_{i}\right)-g\left(X_{j}\right)\right] \geq 0 .
$$

Using the expectation operator, we obtain

$$
E\left(\left[f\left(X_{i}\right)-f\left(X_{j}\right)\right]\left[g\left(X_{i}\right)-g\left(X_{j}\right)\right]\right) \geq 0
$$

which, since $X_{i}$ and $X_{j}$ are independent, is equivalent to

$$
E\left[f\left(X_{i}\right) g\left(X_{i}\right)\right]-E f\left(X_{j}\right) E g\left(X_{i}\right)-E f\left(X_{i}\right) E g\left(X_{j}\right)+E\left[f\left(X_{j}\right) g\left(X_{j}\right)\right] \geq 0
$$

or equivalently, since $X_{i}$ and $X_{j}$ have the same distribution,

$$
2(E[f(X) g(X)]-E f(X) E g(X)) \geq 0
$$

Thus

$$
\operatorname{cov}(f(X), g(X)) \geq 0
$$

Lemma 2 Consider the following reduced form

$$
\begin{aligned}
\pi_{t} & =\xi \pi_{t-1}+\psi s_{t}+\bar{\eta}_{t} \\
s_{t} & =\rho_{j} s_{t-1}+\bar{u}_{t}
\end{aligned}
$$

where $\psi=\frac{1-\beta \alpha}{1-\beta \rho} \frac{1-\alpha}{\alpha}$. Then,

$$
\begin{aligned}
E\left(s_{j, t}^{2}\right) & =\frac{\sigma_{u_{j}}^{2}}{1-\rho_{j}^{2}}=\sigma_{S_{j}}^{2} \\
E\left(\pi_{j, t} s_{j, t}\right) & =\frac{\psi_{j}}{1-\xi_{j} \rho_{j}} \sigma_{S_{j}}^{2} \\
E\left(\pi_{j, t-1} s_{j, t}\right) & =\frac{\psi_{j} \rho_{j}}{1-\xi_{j} \rho_{j}} \sigma_{S_{j}}^{2} \\
E\left(\pi_{j, t+1} s_{j, t}\right) & =\left(\frac{\xi_{j} \psi_{j}}{1-\xi_{j} \rho_{j}}+\psi_{j} \rho_{j}\right) \sigma_{S_{j}}^{2} \\
E\left(\pi_{j, t}^{2}\right) & =\frac{\sigma_{\eta_{j}}^{2}}{1-\xi_{j}^{2}}+\frac{1+\xi_{j} \rho_{j}}{\left(1-\xi_{j}^{2}\right)\left(1-\xi_{j} \rho_{j}\right)} \psi_{j}^{2} \sigma_{S_{j}}^{2} \\
E\left(\pi_{j, t+1} \pi_{j, t-1}\right) & =\xi_{j}^{2} \frac{\sigma_{\eta_{j}}^{2}}{1-\xi_{j}^{2}}+\left[\frac{\xi_{j}^{2}\left(1+\xi_{j} \rho_{j}\right)}{\left(1-\xi_{j}^{2}\right)\left(1-\xi_{j} \rho_{j}\right)}+\frac{\rho_{j}\left(\xi_{j}+\rho_{j}\right)}{\left(1-\xi_{j} \rho_{j}\right)}\right] \psi_{j}^{2} \sigma_{S_{j}}^{2}
\end{aligned}
$$


Proof: Assuming that all stochastic processes are weakly stationary, we have

$$
\begin{aligned}
E\left(\pi_{j, t} s_{j, t}\right) & =E\left(\xi_{j} \pi_{j, t-1}+\psi_{j} s_{j, t}+\eta_{j, t}, s_{j, t}\right)=\frac{\psi_{j}}{1-\xi_{j} \rho_{j}} \sigma_{S_{j}}^{2} \\
E\left(\pi_{j, t-1} s_{j, t}\right) & =E\left(\pi_{j, t-1}\left(\rho_{j} s_{j, t-1}+u_{j, t}\right)\right)=\frac{\psi_{j} \rho_{j}}{1-\xi_{j} \rho_{j}} \sigma_{S_{j}}^{2} \\
E\left(\pi_{j, t+1} s_{j, t}\right) & =E\left(\left(\xi_{j} \pi_{j, t}+\psi_{j} s_{j, t+1}+\eta_{j, t+1}\right) s_{j, t}\right)=\left(\frac{\xi_{j} \psi_{j}}{1-\xi_{j} \rho_{j}}+\psi_{j} \rho_{j}\right) \sigma_{S_{j}}^{2} \\
E\left(\pi_{j, t}^{2}\right) & =\xi_{j}^{2} E\left(\pi_{j, t-1}^{2}\right)+\psi_{j}^{2} E\left(s_{j, t}^{2}\right)+2 \xi_{j} \psi_{j} E\left(\pi_{j, t-1} s_{j, t}\right)+\sigma_{\eta_{j}}^{2} \\
& =\frac{1}{1-\xi_{j}^{2}}\left[\psi_{j}^{2} E\left(s_{j, t}^{2}\right)+2 \xi_{j} \psi_{j} E\left(\pi_{j, t-1} s_{j, t}\right)+\sigma_{\eta_{j}}^{2}\right] \\
& =\frac{\sigma_{\eta_{j}}^{2}}{1-\xi_{j}^{2}}+\frac{\left(1+\xi_{j} \rho_{j}\right.}{\left(1-\xi_{j}^{2}\right)\left(1-\xi_{j} \rho_{j}\right)} \psi_{j}^{2} \sigma_{S_{j}}^{2} \\
E\left(\pi_{j, t+1} \pi_{j, t-1}\right) & =E\left(\left(\xi_{j} \pi_{j, t}+\psi_{j} s_{j, t+1}+\eta_{j, t+1}\right) \pi_{j, t-1}\right) \\
& =\xi_{j} E\left(\left(\xi_{j} \pi_{j, t-1}+\psi_{j} s_{j, t}+\eta_{j, t}\right) \pi_{j, t-1}\right)+\psi_{j} E\left(\left(\rho_{j} S_{j, t}+u_{j, t+1}\right) \pi_{j, t-1}\right) \\
& =\xi_{j}^{2} E\left(\pi_{j, t}^{2}\right)+\xi_{j} \psi_{j} E\left(s_{j, t} \pi_{j, t-1}\right)+\psi_{j} \rho_{j} E\left(s_{j, t} \pi_{j, t-1}\right) \\
& =\xi_{j}^{2}\left[\frac{\sigma_{\eta_{j}}^{2}}{1-\xi_{j}^{2}}+\frac{1+\xi_{j} \rho_{j}}{\left(1-\xi_{j}^{2}\right)\left(1-\xi_{j} \rho_{j}\right)} \psi_{j}^{2} \sigma_{S_{j}}^{2}\right]+\frac{\rho_{j} \psi_{j}^{2}\left(\xi_{j}+\rho_{j}\right)}{1-\xi_{j} \rho_{j}} \sigma_{S_{j}}^{2} \\
& =\xi_{j}^{2} \frac{\sigma_{\eta_{j}}^{2}}{1-\xi_{j}^{2}}+\left[\frac{\xi_{j}^{2}\left(1+\xi_{j} \rho_{j}\right)}{\left(1-\xi_{j}^{2}\right)\left(1-\xi_{j} \rho_{j}\right)}+\frac{\rho_{j}\left(\xi_{j}+\rho_{j}\right)}{\left(1-\xi_{j} \rho_{j}\right)}\right] \psi_{j}^{2} \sigma_{S_{j}}^{2} .
\end{aligned}
$$

The ML estimator of $(\xi, \psi)^{\prime}$ is given by the two orthogonality conditions

$$
\begin{aligned}
E\left[\left(\pi_{t}-\xi_{M L} \pi_{t-1}-\psi_{M L} s_{t}\right) \pi_{t-1}\right] & =0 \\
E\left[\left(\pi_{t}-\xi_{M L} \pi_{t-1}-\psi_{M L} s_{t}\right) s_{t}\right] & =0
\end{aligned}
$$

The nature of $\bar{\eta}_{t}$ under heterogeneity will induce biases in potentially all the coefficients in the Phillips curve. In probability limits (when $T \rightarrow \infty$ ), these biases write

$$
\begin{aligned}
\widetilde{\Lambda} \operatorname{plim}\left(\xi_{M L}-\xi\right) & =E\left(s_{t}^{2}\right) E\left(\pi_{t-1} \bar{\eta}_{t}\right)-E\left(s_{t} \pi_{t-1}\right) E\left(s_{t} \bar{\eta}_{t}\right) \\
\widetilde{\Lambda} \operatorname{plim}\left(\psi_{M L}-\psi\right) & =E\left(\pi_{t-1}^{2}\right) E\left(s_{t} \bar{\eta}_{t}\right)-E\left(s_{t} \pi_{t-1}\right) E\left(\pi_{t-1} \bar{\eta}_{t}\right) \\
\operatorname{plim}\left(\rho_{M L}-\rho\right) & =E\left(s_{t-1} \bar{u}_{t}\right) / E\left(s_{t-1}^{2}\right)
\end{aligned}
$$

where

$$
\begin{aligned}
\widetilde{\Lambda} & =E\left(s_{t}^{2}\right) E\left(\pi_{t-1}^{2}\right)-\left(E\left(s_{t} \pi_{t-1}\right)\right)^{2} \\
\bar{\eta}_{t} & =\sum_{j=1}^{J} w_{j} \eta_{j, t}+\sum_{j=1}^{J} w_{j} \tilde{\xi}_{j} \pi_{j, t-1}+\sum_{j=1}^{J} w_{j} \tilde{\psi}_{j} s_{j, t} \\
\bar{u}_{t} & =\sum_{j=1}^{J} w_{j} u_{j, t}+\sum_{j=1}^{J} w_{j} \tilde{\rho}_{j} s_{j, t-1}
\end{aligned}
$$


Since $\widetilde{\Lambda}>0$, the signs of the asymptotic biases are given by the right-hand side expression. We suppose that (H1) heterogeneity is deterministic, (H2) the weights of all sectors in the economy are exogenous and uncorrelated with the magnitude of sector-specific estimates of the Phillips curve, (H3) sector-specific shocks are independent, and (H4) marginal costs follow a (potentially sector-specific) autoregressive process of order one.

Under H1, we have

$$
\begin{aligned}
\operatorname{plim}_{T \rightarrow \infty}\left(\xi_{M L}-\xi\right)= & \frac{E\left(s_{t}^{2}\right)}{\widetilde{\Lambda}} \sum_{j=1}^{J} w_{j} \tilde{\xi}_{j} E\left(\pi_{t-1} \pi_{j, t-1}\right)+\frac{E\left(s_{t}^{2}\right)}{\widetilde{\Lambda}} \sum_{j=1}^{J} w_{j} \tilde{\psi}_{j} E\left(\pi_{t-1} s_{j, t}\right) \\
& -\frac{E\left(s_{t} \pi_{t-1}\right)}{\widetilde{\Lambda}} \sum_{j=1}^{J} w_{j} \tilde{\xi}_{j} E\left(s_{t} \pi_{j, t-1}\right)-\frac{E\left(s_{t} \pi_{t-1}\right)}{\widetilde{\Lambda}} \sum_{j=1}^{J} w_{j} \tilde{\psi}_{j} E\left(s_{t} s_{j, t}\right)
\end{aligned}
$$

and

$$
\begin{aligned}
\operatorname{plim}_{T \rightarrow \infty}\left(\psi_{M L}-\psi\right)= & \frac{E\left(\pi_{t-1}^{2}\right)}{\widetilde{\Lambda}} \sum_{j=1}^{J} w_{j} \tilde{\xi}_{j} E\left(s_{t} \pi_{j, t-1}\right)+\frac{E\left(\pi_{t-1}^{2}\right)}{\widetilde{\Lambda}} \sum_{j=1}^{J} w_{j} \tilde{\psi}_{j} E\left(s_{t} s_{j, t}\right) \\
& -\frac{E\left(s_{t} \pi_{t-1}\right)}{\widetilde{\Lambda}} \sum_{j=1}^{J} w_{j} \tilde{\xi}_{j} E\left(\pi_{t-1} \pi_{j, t-1}\right)-\frac{E\left(s_{t} \pi_{t-1}\right)}{\widetilde{\Lambda}} \sum_{j=1}^{J} w_{j} \tilde{\psi}_{j} E\left(\pi_{t-1} s_{j, t}\right) .
\end{aligned}
$$

The expression for $\operatorname{plim}_{T \rightarrow \infty}\left(\xi_{M L}-\xi\right)$ can be written as the sum of two terms

$$
\begin{aligned}
& C_{1}=C_{11}+C_{12}=\frac{E\left(s_{t}^{2}\right)}{\widetilde{\Lambda}} \sum_{j=1}^{J} w_{j} \tilde{\xi}_{j} E\left(\pi_{t-1} \pi_{j, t-1}\right)-\frac{E\left(s_{t} \pi_{t-1}\right)}{\widetilde{\Lambda}} \sum_{j=1}^{J} w_{j} \tilde{\xi}_{j} E\left(s_{t} \pi_{j, t-1}\right) \\
& C_{2}=C_{21}+C_{22}=\frac{E\left(s_{t}^{2}\right)}{\widetilde{\Lambda}} \sum_{j=1}^{J} w_{j} \tilde{\psi}_{j} E\left(\pi_{t-1} s_{j, t}\right)-\frac{E\left(s_{t} \pi_{t-1}\right)}{\widetilde{\Lambda}} \sum_{j=1}^{J} w_{j} \tilde{\psi}_{j} E\left(s_{t} s_{j, t}\right) .
\end{aligned}
$$

Similarly, $\operatorname{plim}_{T \rightarrow \infty}\left(\psi_{M L}-\psi\right)$ can be decomposed into

$$
\begin{aligned}
& D_{1}=D_{11}+D_{12}=\frac{E\left(\pi_{t-1}^{2}\right)}{\widetilde{\Lambda}} \sum_{j=1}^{J} w_{j} \tilde{\xi}_{j} E\left(s_{t} \pi_{j, t-1}\right)-\frac{E\left(s_{t} \pi_{t-1}\right)}{\widetilde{\Lambda}} \sum_{j=1}^{J} w_{j} \tilde{\xi}_{j} E\left(\pi_{t-1} \pi_{j, t-1}\right) \\
& D_{2}=D_{21}+D_{22}=\frac{E\left(\pi_{t-1}^{2}\right)}{\widetilde{\Lambda}} \sum_{j=1}^{J} w_{j} \tilde{\psi}_{j} E\left(s_{t} s_{j, t}\right)-\frac{E\left(s_{t} \pi_{t-1}\right)}{\widetilde{\Lambda}} \sum_{j=1}^{J} w_{j} \tilde{\psi}_{j} E\left(\pi_{t-1} s_{j, t}\right) .
\end{aligned}
$$

Applying Lemma 2, $\mathrm{H} 4$ and $\mathrm{H} 5, C_{11}$ becomes

$$
C_{11}=\frac{E\left(s_{t}^{2}\right)}{\widetilde{\Lambda} J} \sum_{j=1}^{J} \tilde{\xi}_{j}\left(\frac{\sigma_{\eta_{j}}^{2}}{1-\xi_{j}^{2}}+\frac{1+\xi_{j} \rho_{j}}{\left(1-\xi_{j}^{2}\right)\left(1-\xi_{j} \rho_{j}\right)} \psi_{j}^{2} \sigma_{S_{j}}^{2}\right) .
$$

Under weak stationary, and assuming for simplicity $w_{j}=1 / J$ for all $j$, we have

$$
\lim _{J \rightarrow \infty} \frac{1}{J} \sum_{j=1}^{J} \tilde{\xi}_{j}\left(\frac{\sigma_{\eta_{j}}^{2}}{1-\xi_{j}^{2}}+\frac{1+\xi_{j} \rho_{j}}{\left(1-\xi_{j}^{2}\left(1-\xi_{j} \rho_{j}\right)\right.} \psi_{j}^{2} \sigma_{S_{j}}^{2}\right)=\operatorname{cov}\left(\tilde{\xi}_{j}, \tilde{C}_{11 j}\right)
$$


where we have defined $\tilde{C}_{11 j}=\frac{\sigma_{\eta_{j}}^{2}}{1-\xi_{j}^{2}}+\frac{1+\xi_{j} \rho_{j}}{\left(1-\xi_{j}^{2}\right)\left(1-\xi_{j} \rho_{j}\right)} \psi_{j}^{2} \sigma_{S_{j}}^{2}$. Therefore we have

$$
\lim _{J \rightarrow \infty} C_{11}=\frac{1}{\tilde{\Lambda}} E\left(s_{t}^{2}\right) \operatorname{cov}\left(\tilde{\xi}_{j}, \tilde{C}_{11 j}\right)
$$

whose sign we now seek to determine. Since $\tilde{\Lambda}$ and $E\left(s_{t}^{2}\right)$ are always positive, the sign of $C_{11}$ depends asymptotically on the sign of $\operatorname{cov}\left(\tilde{\xi}_{j}, \tilde{C}_{11 j}\right)$. It is straightforward to show that $\tilde{\xi}_{j}$ and $\tilde{C}_{11 j}$ both increase in $\xi_{j}$. Therefore a direct application of lemma 1 implies that $C_{11}$ is positive as $J \rightarrow \infty$.

Following a similar line of reasoning, one can show that

$$
\begin{aligned}
\lim _{J \rightarrow \infty} C_{12} & =-\frac{1}{\widetilde{\Lambda}} E\left(s_{t} \pi_{t-1}\right) \operatorname{cov}\left(\tilde{\xi}_{j}, \frac{\psi_{j} \rho_{j}}{1-\xi_{j} \rho_{j}} \sigma_{S_{j}}^{2}\right)<0 \\
\lim _{J \rightarrow \infty} C_{21} & =\frac{1}{\widetilde{\Lambda}} E\left(s_{t}^{2}\right) \operatorname{cov}\left(\tilde{\psi}_{j}, \frac{\psi_{j} \rho_{j}}{1-\xi_{j} \rho_{j}} \sigma_{S_{j}}^{2}\right)>0 \\
\lim _{J \rightarrow \infty} C_{22} & =-\frac{1}{\widetilde{\Lambda}} E\left(s_{t} \pi_{t-1}\right) \operatorname{cov}\left(\tilde{\psi}_{j}, \frac{\sigma_{u_{j}}^{2}}{1-\rho_{j}^{2}}\right)<0 .
\end{aligned}
$$

In other words, $C_{12}, C_{21}$ and $C_{22}$ all have signs unambiguously determined by covariance terms. A direct application of lemma 1 makes it possible to sign all three expressions. $C_{21}$ and $C_{22}$ involve covariance terms between functions that are both increasing in $\rho_{j}$, whereas they increase in $\xi_{j}$ as pertains to $C_{12}$.

Similarly, the asymptotic biases on $D_{i}$ s are given by

$$
\begin{aligned}
\lim _{J \rightarrow \infty} D_{11} & =\frac{1}{\widetilde{\Lambda}} E\left(\pi_{t-1}^{2}\right) \operatorname{cov}\left(\tilde{\xi}_{j}, \frac{\psi_{j} \rho_{j}}{1-\xi_{j} \rho_{j}} \sigma_{S_{j}}^{2}\right)>0 \\
\lim _{J \rightarrow \infty} D_{12} & =-\frac{1}{\widetilde{\Lambda}} E\left(s_{t} \pi_{t-1}\right) \operatorname{cov}\left(\tilde{\xi}_{j}, \frac{\sigma_{\eta_{j}}^{2}}{1-\xi_{j}^{2}}+\frac{1+\xi_{j} \rho_{j}}{\left(1-\xi_{j}^{2}\right)\left(1-\xi_{j} \rho_{j}\right)} \psi_{j}^{2} \sigma_{S_{j}}^{2}\right)<0 \\
\lim _{J \rightarrow \infty} D_{21} & =\frac{1}{\widetilde{\Lambda}} E\left(\pi_{t-1}^{2}\right) \operatorname{cov}\left(\tilde{\psi}_{j}, \frac{\sigma_{u_{j}}^{2}}{1-\rho_{j}^{2}}\right)>0 \\
\lim _{J \rightarrow \infty} D_{22} & =-\frac{1}{\widetilde{\Lambda}} E\left(s_{t} \pi_{t-1}\right) \operatorname{cov}\left(\tilde{\psi}_{j}, \frac{\psi_{j} \rho_{j}}{1-\xi_{j} \rho_{j}} \sigma_{S_{j}}^{2}\right)<0 .
\end{aligned}
$$

Again, all components of the bias have signs that are fully determined by covariance terms, and lemma 1 is sufficient to establish the signs of each element given unambiguous monotonicity properties of the functions whose covariances we seek to evaluate. Finally, the bias on $\rho_{M L}$ depends on the covariance between the persistence of the marginal cost $\tilde{\rho}_{j}=\left(\rho_{j}-\rho\right)$ and the parameters $\delta_{j}=w_{j} E\left(s_{t} s_{j, t}\right)$. Under (H2) and (H3), we have $\delta_{j}=$ $w_{j} \sigma_{u j}^{2} /\left(1-\rho_{j}^{2}\right)$, which increases in $\rho_{j}$. As a consequence, the asymptotic bias on $\rho_{M L}$ is positive. 


\section{Appendix 3: List of Industries}

- Agriculture [1]

- Manufacturing

- Food manufacturing [2]

- Consumption goods [3]

- Car industry [4]

- Equipment goods [5]

- Intermediary goods [6]

- Energy [7]

- Service

- Construction [8]

- Trade [9]

- Transportation [10]

- Financial activities [11]

- Real estate [12]

- Business services [13]

- Personal services [14]

- Education and health services [15]

- Government [16] 


\section{Appendix 4: Cross-Industry Linkages}

Table A1: Correlations of sectoral Phillips Curve residuals

\begin{tabular}{|c|c|c|c|c|c|c|c|c|}
\hline Industry & {$[1]$} & {$[2]$} & {$[3]$} & {$[4]$} & {$[5]$} & {$[6]$} & {$[7]$} & {$[8]$} \\
\hline$[1]$ & 1.000 & & & & & & & \\
\hline$[2]$ & 0.098 & 1.000 & & & & & & \\
\hline$[3]$ & $0.222^{*}$ & -0.019 & 1.000 & & & & & \\
\hline$[4]$ & -0.081 & 0.079 & $0.293^{*}$ & 1.000 & & & & \\
\hline$[5]$ & 0.094 & 0.113 & $0.333^{*}$ & $0.422^{*}$ & 1.000 & & & \\
\hline$[6]$ & 0.035 & 0.075 & -0.127 & 0.025 & 0.089 & 1.000 & & \\
\hline [7] & 0.044 & $0.256^{*}$ & -0.042 & -0.084 & $0.198^{*}$ & -0.059 & 1.000 & \\
\hline [8] & -0.017 & $0.202^{*}$ & 0.078 & 0.151 & 0.120 & 0.171 & 0.038 & 1.000 \\
\hline$[9]$ & -0.064 & 0.186 & -0.103 & $-0.229^{*}$ & $-0.206^{*}$ & 0.070 & -0.007 & -0.145 \\
\hline [10] & 0.191 & -0.021 & 0.193 & 0.091 & 0.004 & 0.173 & -0.016 & 0.121 \\
\hline [11] & 0.030 & -0.068 & 0.122 & 0.114 & 0.120 & $-0.217^{*}$ & 0.031 & -0.129 \\
\hline$[12]$ & -0.119 & 0.094 & 0.086 & -0.047 & 0.033 & -0.116 & $0.313^{*}$ & $0.213^{*}$ \\
\hline [13] & 0.112 & -0.062 & 0.048 & -0.068 & 0.033 & -0.009 & $-0.673^{*}$ & 0.034 \\
\hline [14] & 0.140 & 0.076 & $0.305^{*}$ & 0.152 & $0.260^{*}$ & 0.071 & 0.178 & $0.262^{*}$ \\
\hline [15] & -0.010 & 0.017 & $0.283^{*}$ & $0.216^{*}$ & $0.281^{*}$ & -0.031 & -0.023 & 0.142 \\
\hline [16] & -0.035 & 0.173 & 0.005 & 0.065 & 0.034 & 0.024 & 0.061 & 0.069 \\
\hline Industry & [9] & {$[10]$} & [11] & {$[12]$} & [13] & [14] & [15] & {$[16]$} \\
\hline [9] & 1.000 & & & & & & & \\
\hline [10] & -0.034 & 1.000 & & & & & & \\
\hline [11] & $-0.281^{*}$ & -0.034 & 1.000 & & & & & \\
\hline$[12]$ & -0.104 & 0.040 & -0.085 & 1.000 & & & & \\
\hline [13] & 0.067 & 0.022 & -0.025 & $-0.261^{*}$ & 1.000 & & & \\
\hline [14] & $-0.288^{*}$ & 0.111 & 0.027 & $0.439^{*}$ & -0.080 & 1.000 & & \\
\hline [15] & -0.116 & -0.013 & 0.018 & 0.167 & -0.052 & $0.235^{*}$ & 1.000 & \\
\hline [16] & 0.045 & -0.011 & -0.037 & 0.088 & 0.028 & 0.072 & $0.259^{*}$ & 1.000 \\
\hline
\end{tabular}

Note: The notation ${ }^{*}$ means that the correlation is statistically significant at $5 \%$ level. 
Table A2: Correlations of sectoral real marginal cost residuals

\begin{tabular}{|c|c|c|c|c|c|c|c|c|}
\hline Industry & $\overline{[1]}$ & $\overline{[2]}$ & $\overline{[3]}$ & $\overline{[4]}$ & $\overline{[5]}$ & {$[6]$} & $\overline{[7]}$ & $\overline{[8]}$ \\
\hline$[1]$ & 1.000 & & & & & & & \\
\hline$[2]$ & -0.008 & 1.000 & & & & & & \\
\hline$[3]$ & $0.209^{*}$ & -0.003 & 1.000 & & & & & \\
\hline [4] & $0.233^{*}$ & 0.092 & 0.177 & 1.000 & & & & \\
\hline$[5]$ & $0.247^{*}$ & -0.014 & 0.098 & $0.398^{*}$ & 1.000 & & & \\
\hline$[6]$ & $0.244^{*}$ & 0.109 & $0.289^{*}$ & $0.259^{*}$ & $0.309^{*}$ & 1.000 & & \\
\hline$[7]$ & -0.038 & 0.193 & -0.013 & -0.064 & 0.074 & 0.015 & 1.000 & \\
\hline [8] & 0.099 & 0.003 & $0.252^{*}$ & 0.188 & 0.088 & $0.349^{*}$ & -0.019 & 1.000 \\
\hline$[9]$ & 0.120 & $0.210^{*}$ & $0.311^{*}$ & $0.206^{*}$ & 0.076 & $0.346^{*}$ & -0.022 & 0.140 \\
\hline$[10]$ & 0.137 & 0.100 & 0.177 & 0.169 & 0.025 & $0.331^{*}$ & 0.070 & 0.095 \\
\hline [11] & 0.006 & -0.054 & 0.091 & 0.180 & 0.041 & 0.073 & -0.018 & 0.055 \\
\hline$[12]$ & -0.060 & 0.082 & 0.188 & -0.179 & 0.019 & $0.246^{*}$ & 0.152 & 0.106 \\
\hline [13] & 0.068 & -0.042 & $0.208^{*}$ & 0.078 & 0.070 & 0.056 & $-0.672^{*}$ & 0.066 \\
\hline [14] & 0.013 & 0.100 & 0.135 & 0.115 & -0.050 & -0.005 & 0.056 & $0.275^{*}$ \\
\hline [15] & -0.090 & -0.079 & 0.066 & 0.140 & 0.116 & 0.047 & -0.062 & 0.084 \\
\hline$[16]$ & 0.085 & -0.113 & -0.097 & 0.000 & 0.111 & -0.102 & -0.046 & -0.113 \\
\hline Industry & {$[9]$} & {$[10]$} & {$[11]$} & {$[12]$} & [13] & {$[14]$} & {$[15]$} & {$[16]$} \\
\hline$[9]$ & 1.000 & & & & & & & \\
\hline [10] & 0.191 & 1.000 & & & & & & \\
\hline [11] & -0.080 & 0.133 & 1.000 & & & & & \\
\hline$[12]$ & 0.145 & -0.056 & -0.005 & 1.000 & & & & \\
\hline [13] & 0.089 & -0.070 & 0.085 & 0.055 & 1.000 & & & \\
\hline [14] & 0.031 & 0.115 & 0.169 & -0.087 & 0.005 & 1.000 & & \\
\hline [15] & 0.054 & -0.011 & -0.026 & -0.047 & -0.032 & 0.198 & 1.000 & \\
\hline [16] & -0.101 & -0.086 & 0.162 & $-0.267^{*}$ & -0.023 & 0.159 & $0.493^{*}$ & 1.000 \\
\hline
\end{tabular}

Note: The notation ${ }^{*}$ means that the correlation is statistically significant at $5 \%$ level. 


\section{References}

[1] Altissimo, F., B. Mojon, and P. Zaffaroni (2007), Fast Micro and Slow Macro: Can Aggregation Explain the Persistence of Inflation, ECB Working paper, No. 729.

[2] Álvarez, L. J., P. Burriel, and I. Hernando (2005), Do Decreasing Hazard Functions for Price Changes Make any Sense?, ECB Working Paper Series, No. 461.

[3] Angeloni, I., L. Aucremanne, M. Ehrmann, J. Galí, A. Levin, and F. Smets (2006), New Evidence on Inflation Persistence and Price Stickiness in the Euro Area: Implications for Macro Modelling, Journal of the European Economic Association, 4(2-3), 562-574.

[4] Aoki, K. (2001), Optimal Monetary Policy Responses to Relative-Price Changes, Journal of Monetary Economics, 48(1), 55-80.

[5] Baudry, L., H. Le Bihan, P. Sevestre, and S. Tarrieu (2004), Price rigidity. Evidence from the French CPI micro-data, ECB Working Paper Series, No. 384.

[6] Benigno, P. (2004), Optimal Monetary Policy in a Currency Area, Journal of International Economics, 63(2), 293-320.

[7] Benigno, P., and D. López-Salido (2006), Inflation Persistence and Optimal Monetary Policy in the Euro Area, Journal of Money, Credit, and Banking, 38(3), 587-614.

[8] Bils, M., and P. Klenow (2005), Some Evidence on the Importance of Sticky Prices, Journal of Political Economy, 112(5), 947-985.

[9] Bouakez, H., E. Cardia, and F. J. Ruge-Murcia (2005), The Transmission of Monetary Policy in a Multi-Sector Economy, Working Paper, CIREQ, University of Montreal.

[10] Calvo, G. (1983), Staggered Prices in a Utility-Maximizing Framework, Journal of Monetary Economics, 12(3), 383-398.

[11] Canova, F. (2007), Applied Macroeconomic Research, Princeton University Press.

[12] Carlstrom, C. T., T. S. Fuerst, F. Ghironi, and K. Hernández (2006), Relative Price Dynamics and the Aggregate Economy, mimeo.

[13] Carvalho, C. (2006), Heterogeneity in Price Stickiness and the New Keynesian Phillips Curve, Working Paper, Princeton University.

[14] Chari, V., P. Kehoe, and E. McGrattan (2000), Sticky Price Models of The Business Cycle: Can The Contract Multiplier Solve the Persistence Problem?, Econometrica, 68(5), $1151-1179$.

[15] Christiano, L. J., M. Eichenbaum, and C. Evans (2005), Nominal Rigidities and the Dynamic Effects of a Shock to Monetary Policy, Journal of Political Economy, 113(1), $1-45$. 
[16] Dhyne, E., L. Alvarez, H. Le Bihan, G. Veronese, D. Dias, J. Hoffman, N. Jonker, P. Lünnemann, F. Rumler, and J. Vilmunen (2004), Price Setting in the Euro Area: Some Stylized Facts From Individual Consumer Price Data, ECB Working Paper Series, No. 524 .

[17] Dixon, H., and E. Kara (2005), Persistence and Nominal Inertia in a Generalized Taylor Economy: How Longer Contracts Dominate Shorter Contracts, ECB Working Paper Series, No. 489.

[18] Dufour, J.-M., L. Khalaf, and M. Kichian (2006), Inflation Dynamics and the New Keynesian Phillips Curve: An Identification-Robust Econometric Analysis, Journal of Economic Dynamics and Control, 30, 1707-1727.

[19] Dupor, B. (1999), Aggregation and Irrelevance in Multi-sector models, Journal of Monetary Economics, 43(2), 391-409.

[20] Erceg, C. J., and A. T. Levin (2002), Optimal Monetary Policy with Durable and nonDurable Goods, ECB Working Paper Series, No. 179.

[21] Forni, M., and M. Lippi (1997), Aggregation and the Microfoundations of Dynamic Macroeconomics, Clarendon Press, Oxford.

[22] Fougère, D., H. Le Bihan, and P. Sevestre (2005), Heterogeneity in Price Stickiness: A Microeconometric Investigation, CEPR Discussion Paper 5300.

[23] Fuhrer, J. C. (1997), The (Un)importance of Forward Looking Behavior in Price Specifications, Journal of Money, Credit, and Banking, 29(3), 338-350.

[24] Fuhrer, J. C., and G. R. Moore (1995), Inflation Persistence, Quarterly Journal of Economics, 110(1), 127-160.

[25] Fuhrer, J. C., G. R. Moore, S. D. Schuh (1995), Estimating the Linear Quadratic Inventory Model. Maximum Likelihood versus Generalized Method of Moments, Journal of Monetary Economics, 35, 115-157.

[26] Galí, J., and M. Gertler (1999), Inflation Dynamics: A Structural Econometrics Analysis, Journal of Monetary Economics, 44, 195-222.

[27] Galí, J., M. Gertler, and D. López-Salido (2001), European Inflation Dynamics. European Economic Review, 45, 1237-1270.

[28] Gertler, M., and J. Leahy (2006), A Phillips Curve with an Ss Foundation, NBER Working Paper, No. 11971.

[29] Granger, C. W. J. (1990), Aggregation of time-series variables - A Survey, in Barket, T., and M. H. Pesaran (eds), Disaggregation in Econometric Modelling, Routledge, London, $17-34$.

[30] Granger, C. W. J. (1987), Implications of Aggregation with Common Factors, Econometric Theory, 3, 209-222. 
[31] Granger, C. W. J. (1980), Long Memory Relationships and the Aggregation of Dynamic Models, Journal of Econometrics, 14, 227-238.

[32] Guay, A., and F. Pelgrin (2004), The U.S. Keynesian Phillips Curve: An Empirical Assessment, Bank of Canada Working Paper, No. 2004-35.

[33] Hsiao, C. (1986), Analysis of Panel Data, In Grandmont, J.-M., and C. F. Manski (eds.), Econometric Series Monographs (Vol. 11). Cambridge: Cambridge University Press.

[34] Hsiao, C., and M. H. Pesaran (2004), Random Coefficient Panel Data Models, CESifo Working Paper Series, No. 1233.

[35] Huang, K. X. D., and Z. Liu (2004), Input Output Structure and Nominal Rigidity: The Persistence Problem Revisited, Macroeconomic Dynamics, 8(2), 188-206.

[36] Imbs, J., H. Mumtaz, M. Ravn, and H. Rey (2005), PPP Strikes Back: Aggregation and the Real Exchange Rate, Quarterly Journal of Economics, 120(1), 1-43.

[37] Jondeau, E., and H. Le Bihan (2007), Examining Bias in Estimators of Linear Rational Expectations Models under Misspecification, forthcoming in Journal of Econometrics.

[38] Justiniano, A., M. Kumhof, and F. Ravenna (2006), Multi-Sectoral Cascading and Price Dynamics - A Bayesian Econometric Evaluation, mimeo.

[39] Kurmann, A. (2007), VAR-based Estimation of Euler Equations with an Application to New Keynesian Pricing, Journal of Economic Dynamics and Control, 31(3), 767-796.

[40] Leith, C., and J. Malley (2006), A Sectoral Analysis of Price-Setting Behaviour in US Manufacturing Industries, Review of Economics and Statistics, forthcoming.

[41] Lewbel, A. (1992), Aggregation with Log-Linear Models, Review of Economic Studies, $59(3), 635-642$.

[42] Lindé, J. (2005), Estimating New-Keynesian Phillips Curves: A Full Information Maximum Likelihood Approach, Journal of Monetary Economics, 52(6), 1135-1142.

[43] Mankiw, N. G., and R. Reiss (2002), Sticky Information versus Sticky Prices: A Proposal to Replace the New Keynesian Phillips Curve, Quarterly Journal of Economics, 117, $1295-1328$.

[44] Mavroeidis, S. (2004), Identification and Misspecification Issues in Forward Looking Monetary Models, Oxford Bulletin of Economics and Statistics, 66(s1), 609-636.

[45] Midrigan, V. (2006), Menu Costs, Multi-Product Firms, and Aggregate Fluctuations, Working Paper, Ohio State University.

[46] Nakamura, E., and J. Steinsson (2006), Five Facts About Prices: A Reevaluation of Menu Cost Models, mimeo, Harvard University.

[47] Nason, J. M., and G. W. Smith (2005), Identifying the New Keynesian Phillips Curve, Working Paper 2005-1, Federal Reserve Bank of Atlanta. 
[48] Newey, W. K., and K. D. West (1987), A Simple, Positive Definite, Heteroscedasticity and Autocorrelation Consistent Covariance Matrix, Econometrica, 55(3), 703-708.

[49] Pesaran, M. H. (2006), Estimation and Inference in Large Heterogeneous Panels with a Multifactor Error Structure, Econometrica, 74(4), 967-1012.

[50] Pesaran, M. H., R. G. Pierse, and M. S. Kumar (1989), Econometric Analysis of Aggregation in the Context of Linear Prediction Models, Econometrica, 57(4), 861-888.

[51] Pesaran, M. H., R. G. Pierse, and K. C. Lee (1994), Choice Between Disaggregate and Aggregate Specifications Estimated by Instrumental Variables Methods, Journal of Business and Economic Statistics, 12(1), 11-21.

[52] Pesaran, M. H., and R. Smith (1995), Estimation of Long-run Relationships from Dynamic Heterogenous Panels, Journal of Econometrics, 68(1), 79-114.

[53] Pesaran, M. H., R. Smith, and K. S. Im (1996), Dynamic Linear Models For Heterogeneous Panels, Chapter 8 in L. Mátyás and P. Sevestre (eds.), The Econometrics of Panel Data: A Handbook of the Theory With Applications, Kluwer Academic Publishers, 145-195.

[54] Robinson, P. M. (1978), Statistical Inference for a Random Coefficient Autoregressive Model, Scandinavian Journal of Statistics, 5, 163-168.

[55] Rudd, J., and K. Whelan (2005), New Tests of the New Keynesian Phillips Curve, Journal of Monetary Economics, 52(6), 1167-1181.

[56] Rudd, J., and K. Whelan (2003), Can Rational Expectations Sticky-Price Models Explain Inflation Dynamics?, Board of Governors of the Federal Reserve System, Finance and Economics Discussion Paper, No. 2003-46.

[57] Sbordone, A. (2001), Prices and Unit Labor Costs: A New Test of Price Stickiness, Journal of Monetary Economics, 49, 265-292.

[58] Stoker, T. J. (1993), Empirical Approaches to the Problem of Aggregation over Individuals, Journal of Economic Literature, 31(4), 1827-1874.

[59] Swamy, P. A. V. B. (1970), Efficient Inference in a Random Coefficient Regression Model, Econometrica, 38, 311-323.

[60] Swamy, P. A. V. B. (1971), Statistical Inference in Random Coefficient Regression Models, Berlin, Springer-Verlag.

[61] Vermeulem, P., D. Dias, M. Dossche, E. Gautier, I. Hernando, R. Sabbatini, and H. Stahl (2007), Price Setting in the Euro Area: Some Stylized Facts From Individual Producer Price Data, ECB Working Paper Series, No. 727.

[62] Woodford, M. (2003), Interest and Prices, Princeton University Press.

[63] Zaffaroni, P. (2004), Contemporaneous Aggregation of Linear Dynamic Models in Large Economies, Journal of Econometrics, 120, 75-102. 
Table 1: Simulations with 16 Sectors

\begin{tabular}{|c|c|c|c|c|}
\hline & True Value & $\mathrm{ML}$ & \multicolumn{2}{|c|}{ Decomposition } \\
\hline \multicolumn{5}{|c|}{ Reduced Form - Equation (9) } \\
\hline \multirow{3}{*}{$\xi$} & & & $C_{1}$ & $C_{2}$ \\
\hline & 0.489 & 0.786 & 0.041 & 0.250 \\
\hline & & & $D_{1}$ & $D_{2}$ \\
\hline$\psi$ & 3.637 & 2.114 & -0.197 & -1.310 \\
\hline$\rho$ & 0.935 & 0.934 & & \\
\hline \multicolumn{5}{|c|}{ Reduced Form - Equation (5) } \\
\hline$\lambda^{b}$ & 0.328 & 0.442 & & \\
\hline$\lambda^{f}$ & 0.668 & 0.556 & & \\
\hline$\theta$ & 0.182 & 0.089 & & \\
\hline \multicolumn{5}{|c|}{ Structural Estimates } \\
\hline$\xi$ & 0.489 & 0.786 & & \\
\hline$\alpha$ & 0.600 & 0.677 & & \\
\hline Duration & 2.503 & 3.092 & & \\
\hline
\end{tabular}

Note: The true values used for the simulations correspond to the random coefficient estimation of the aggregate Phillips Curve with an AR(1) dynamic for the real marginal cost (unreported estimates). The variances of the random parameters are set at 0.1 for $\xi$ and $\alpha$. There is no heterogeneity in $\rho$. Uniform weights are used to compute aggregate estimates. The sample size is $T=1000$. 
Table 2: Summary statistics

\begin{tabular}{lcccccc}
\hline \hline Industry & Weights & $\bar{\pi}$ & $\bar{s}$ & $\operatorname{corr}\left(\pi_{t-1}, \pi_{t}\right)$ & $\operatorname{corr}\left(s_{t-1}, s_{t}\right)$ & $\operatorname{corr}\left(\pi_{t}, s_{t}\right)$ \\
\hline \hline Aggregate & 100.00 & 3.996 & -0.095 & 0.921 & 0.984 & 0.887 \\
\hline Agriculture & 2.92 & 1.255 & -0.276 & 0.782 & 0.977 & -0.247 \\
Food Mfg & 2.33 & 3.477 & -0.102 & -0.075 & 0.778 & -0.320 \\
Cons. Goods & 3.02 & 2.639 & -0.087 & 0.620 & 0.939 & 0.367 \\
Car & 0.96 & 3.293 & -3.616 & 0.291 & 0.981 & 0.198 \\
Equip. Goods & 2.96 & 0.237 & -0.128 & 0.041 & 0.915 & -0.412 \\
Inter. Goods & 5.72 & 2.788 & -1.007 & 0.725 & 0.988 & 0.600 \\
Energy & 2.18 & 5.393 & -0.934 & -0.281 & 0.683 & -0.449 \\
Construction & 6.67 & 4.889 & -0.327 & 0.511 & 0.977 & 0.389 \\
Trade & 10.57 & 4.241 & -0.253 & 0.760 & 0.974 & 0.662 \\
Transportation & 3.76 & 2.935 & -0.112 & 0.027 & 0.777 & 0.034 \\
Finance & 5.01 & 3.366 & -0.410 & 0.600 & 0.971 & 0.143 \\
Real Estate & 11.82 & 5.023 & -0.272 & 0.864 & 0.983 & -0.683 \\
Business Serv. & 14.19 & 3.635 & -0.021 & -0.290 & 0.946 & -0.362 \\
Personal Serv. & 5.75 & 5.486 & 0.062 & 0.758 & 0.961 & -0.707 \\
Educ. \& Health & 13.94 & 5.542 & -0.261 & 0.933 & 0.986 & 0.848 \\
Govt. & 8.21 & 4.419 & -0.050 & 0.954 & 0.917 & 0.484 \\
\hline \hline
\end{tabular}


Table 3: Sectoral Phillips Curves

\begin{tabular}{|c|c|c|c|c|c|c|c|c|}
\hline Industry & Agriculture & Food & Cons. & Car & Equip. & Interm. & Energy & Construction \\
\hline & \multicolumn{8}{|c|}{ Reduced Form - Equation (7) } \\
\hline$\xi$ & $\begin{array}{c}0.776^{* * *} \\
(0.061)\end{array}$ & $\begin{array}{c}0.519^{* * *} \\
(0.085)\end{array}$ & $\begin{array}{c}0.612^{* * *} \\
(0.074)\end{array}$ & $\begin{array}{c}0.296^{* * *} \\
(0.077)\end{array}$ & $\begin{array}{c}0.149^{*} \\
(0.084)\end{array}$ & $\begin{array}{c}0.462^{* * *} \\
(0.066)\end{array}$ & $\begin{array}{l}0.082 \\
(0.114)\end{array}$ & $\begin{array}{c}0.503^{* * *} \\
(0.071)\end{array}$ \\
\hline$\psi_{1}$ & $\begin{array}{l}16.01 \\
(11.32)\end{array}$ & $\begin{array}{c}13.22^{* *} \\
(4.005)\end{array}$ & $\begin{array}{c}1.499^{* * *} \\
(0.528)\end{array}$ & $\begin{array}{c}0.228^{* * * *} \\
(0.081)\end{array}$ & $\begin{array}{l}0.010 \\
(0.168)\end{array}$ & $\begin{array}{c}0.851^{* * * *} \\
(0.162)\end{array}$ & $\begin{array}{l}21.08^{*} \\
(12.12)\end{array}$ & $\begin{array}{c}1.964^{* * * *} \\
(0.599)\end{array}$ \\
\hline$\psi_{2}$ & $\begin{array}{c}-12.01^{* * *} \\
(0.889)\end{array}$ & $\begin{array}{c}-3.535^{* * *} \\
(0.557)\end{array}$ & $\begin{array}{l}0.038 \\
(0.130)\end{array}$ & $\begin{array}{c}-0.063^{* *} \\
(0.019)\end{array}$ & $\begin{array}{l}0.010 \\
(0.033)\end{array}$ & $\begin{array}{c}-0.136^{* * *} \\
(0.064)\end{array}$ & $\begin{array}{l}-1.685 \\
(1.433)\end{array}$ & $\begin{array}{c}-0.422^{* * *} \\
(0.158)\end{array}$ \\
\hline$\rho_{1}$ & $\begin{array}{c}1.708^{* * *} \\
(0.058)\end{array}$ & $\begin{array}{c}0.916^{* * *} \\
(0.086)\end{array}$ & $\begin{array}{c}0.913^{* * *} \\
(0.088)\end{array}$ & $\begin{array}{c}1.249^{* * *} \\
(0.078)\end{array}$ & $\begin{array}{c}0.855^{* * *} \\
(0.088)\end{array}$ & $\begin{array}{c}1.134^{* * *} \\
(0.077)\end{array}$ & $\begin{array}{c}0.710^{* * * *} \\
(0.080)\end{array}$ & $\begin{array}{c}1.194^{* * * *} \\
(0.082)\end{array}$ \\
\hline \multirow[t]{2}{*}{$\rho_{2}$} & $\begin{array}{c}-0.758^{* * *} \\
(0.056)\end{array}$ & $\begin{array}{c}-0.270^{* * *} \\
(0.042)\end{array}$ & $\begin{array}{l}0.026 \\
(0.088) \\
\end{array}$ & $\begin{array}{c}-0.278^{* * *} \\
(0.077)\end{array}$ & $\begin{array}{l}0.009 \\
(0.087)\end{array}$ & $\begin{array}{c}-0.162^{* * *} \\
(0.075)\end{array}$ & $\begin{array}{c}-0.081 \\
(0.069)\end{array}$ & $\begin{array}{c}-0.217^{* * *} \\
(0.082)\end{array}$ \\
\hline & \multicolumn{8}{|c|}{ Reduced Form - Equation (3) } \\
\hline$\lambda^{b}$ & $\begin{array}{c}0.438^{* * *} \\
(0.019)\end{array}$ & $\begin{array}{c}0.343^{* * *} \\
(0.037)\end{array}$ & $\begin{array}{c}0.380^{* * *} \\
(0.029)\end{array}$ & $\begin{array}{c}0.229^{* * *} \\
(0.046)\end{array}$ & $\begin{array}{c}0.130^{* *} \\
(0.064)\end{array}$ & $\begin{array}{c}0.317^{* * *} \\
(0.031)\end{array}$ & $\begin{array}{l}0.076 \\
(0.098)\end{array}$ & $\begin{array}{c}0.336^{* * *} \\
(0.032)\end{array}$ \\
\hline$\lambda^{f}$ & $\begin{array}{c}0.560^{* * *} \\
(0.019)\end{array}$ & $\begin{array}{c}0.653^{* * *} \\
(0.036)\end{array}$ & $\begin{array}{c}0.617^{* * *} \\
(0.028)\end{array}$ & $\begin{array}{c}0.765^{* * *} \\
(0.045)\end{array}$ & $\begin{array}{c}0.862^{* * *} \\
(0.063)\end{array}$ & $\begin{array}{c}0.679^{* * *} \\
(0.030)\end{array}$ & $\begin{array}{c}0.916^{* * *} \\
(0.096)\end{array}$ & $\begin{array}{c}0.661^{* * *} \\
(0.031)\end{array}$ \\
\hline \multirow[t]{2}{*}{$\theta$} & $\begin{array}{l}0.466 \\
(0.400)\end{array}$ & $\begin{array}{c}3.126^{* *} \\
(1.381)\end{array}$ & $\begin{array}{l}0.066 \\
(0.047)\end{array}$ & $\begin{array}{l}0.006 \\
(0.005)\end{array}$ & $\begin{array}{l}0.001 \\
(0.021)\end{array}$ & $\begin{array}{c}0.021^{*} \\
(0.012)\end{array}$ & $\begin{array}{l}7.349 \\
(5.352)\end{array}$ & $\begin{array}{c}0.040^{* * * *} \\
(0.035)\end{array}$ \\
\hline & \multicolumn{8}{|c|}{ Structural Estimates } \\
\hline$\xi$ & $\begin{array}{c}0.776^{* * *} \\
(0.061)\end{array}$ & $\begin{array}{c}0.519^{* * *} \\
(0.084)\end{array}$ & $\begin{array}{c}0.612^{* * *} \\
(0.074)\end{array}$ & $\begin{array}{c}0.296^{* * *} \\
(0.077)\end{array}$ & $\begin{array}{l}0.149^{*} \\
(0.084)\end{array}$ & $\begin{array}{c}0.462^{* * *} \\
(0.066)\end{array}$ & $\begin{array}{l}0.082 \\
(0.114)\end{array}$ & $\begin{array}{c}0.503^{* * *} \\
(0.071)\end{array}$ \\
\hline$\alpha$ & $\begin{array}{c}0.416^{* * *} \\
(0.150)\end{array}$ & $\begin{array}{c}0.152^{* * *} \\
(0.052)\end{array}$ & $\begin{array}{c}0.727^{* * *} \\
(0.084)\end{array}$ & $\begin{array}{c}0.918^{* * * *} \\
(0.034)\end{array}$ & $\begin{array}{c}0.967^{* * * *} \\
(0.310)\end{array}$ & $\begin{array}{c}0.843^{* * *} \\
(0.040)\end{array}$ & $\begin{array}{l}0.102 \\
(0.066)\end{array}$ & $\begin{array}{c}0.786^{* * *} \\
(0.083)\end{array}$ \\
\hline Duration & $\begin{array}{c}1.712^{* * *} \\
(0.441)\end{array}$ & $\begin{array}{c}1.179^{* * *} \\
(0.072)\end{array}$ & $\begin{array}{c}3.663^{* * *} \\
(1.131)\end{array}$ & $\begin{array}{c}12.26^{* *} \\
(5.068)\end{array}$ & $\begin{array}{c}30.42^{* * *} \\
(28.69)\end{array}$ & $\begin{array}{c}6.378^{* * *} \\
(1.627)\end{array}$ & $\begin{array}{c}1.113^{* * *} \\
(0.082)\end{array}$ & $\begin{array}{c}4.673^{* *} \\
(1.810)\end{array}$ \\
\hline
\end{tabular}

\begin{tabular}{|c|c|c|c|c|c|c|c|c|}
\hline Industry & Trade & Transp. & Finance & Real Estate & Business & Pers. Serv. & Educ. Health & Govt \\
\hline & \multicolumn{8}{|c|}{ Reduced Form - Equation (7) } \\
\hline$\xi$ & $\begin{array}{c}0.531^{* * * *} \\
(0.066)\end{array}$ & $\begin{array}{l}0.049 \\
(0.084)\end{array}$ & $\begin{array}{c}0.577^{* * *} \\
(0.067)\end{array}$ & $\begin{array}{c}0.845^{* * * *} \\
(0.047)\end{array}$ & $\begin{array}{l}0.010 \\
(0.079)\end{array}$ & $\begin{array}{c}0.771^{* * *} \\
(0.066)\end{array}$ & $\begin{array}{c}0.718^{* * *} \\
(0.062)\end{array}$ & $\begin{array}{c}0.930^{* * *} \\
(0.034)\end{array}$ \\
\hline$\psi_{1}$ & $\begin{array}{c}2.306^{* * *} \\
(0.438)\end{array}$ & $\begin{array}{c}5.481^{* * * *} \\
(1.552)\end{array}$ & $\begin{array}{c}3.409^{* * *} \\
(1.047)\end{array}$ & $\begin{array}{l}0.010 \\
(0.100)\end{array}$ & $\begin{array}{l}0.010 \\
(0.010)\end{array}$ & $\begin{array}{l}0.010 \\
(0.411)\end{array}$ & $\begin{array}{c}0.694^{* * *} \\
(0.185)\end{array}$ & $\begin{array}{l}0.040 \\
(0.061)\end{array}$ \\
\hline$\psi_{2}$ & $\begin{array}{c}-0.582^{* *} \\
(0.179)\end{array}$ & $\begin{array}{l}0.479 \\
(0.422)\end{array}$ & $\begin{array}{c}-1.931^{* * *} \\
(0.192)\end{array}$ & $\begin{array}{c}-0.007 \\
(0.239)\end{array}$ & $\begin{array}{l}0.010 \\
(0.010)\end{array}$ & $\begin{array}{c}-0.002 \\
(0.112)\end{array}$ & $\begin{array}{c}0.137^{*} \\
(0.070)\end{array}$ & $\begin{array}{l}0.008 \\
(0.009)\end{array}$ \\
\hline$\rho_{1}$ & $\begin{array}{c}1.219^{* * *} \\
(0.081)\end{array}$ & $\begin{array}{l}0.704^{* * *} \\
(0.083)\end{array}$ & $\begin{array}{c}1.525^{* * *} \\
(0.060)\end{array}$ & $\begin{array}{c}1.664^{* * *} \\
(0.069)\end{array}$ & $\begin{array}{c}0.872^{* * *} \\
(0.074)\end{array}$ & $\begin{array}{c}1.129^{* * *} \\
(0.097)\end{array}$ & $\begin{array}{c}0.767^{* * *} \\
(0.101)\end{array}$ & $\begin{array}{c}0.733^{* * *} \\
(0.096)\end{array}$ \\
\hline \multirow[t]{2}{*}{$\rho_{2}$} & $\begin{array}{c}-0.255^{* * *} \\
(0.079)\end{array}$ & $\begin{array}{l}0.088 \\
(0.077)\end{array}$ & $\begin{array}{c}-0.572^{* * *} \\
(0.055)\end{array}$ & $\begin{array}{c}-0.701^{* * *} \\
(0.068)\end{array}$ & $\begin{array}{l}0.015 \\
(0.069)\end{array}$ & $\begin{array}{c}-0.202^{* *} \\
(0.096)\end{array}$ & $\begin{array}{c}0.199^{* *} \\
(0.099)\end{array}$ & $\begin{array}{c}0.207^{* *} \\
(0.097)\end{array}$ \\
\hline & \multicolumn{8}{|c|}{ Reduced Form - Equation (3) } \\
\hline$\lambda^{b}$ & $\begin{array}{c}0.348^{* * *} \\
(0.028)\end{array}$ & $\begin{array}{l}0.047 \\
(0.076)\end{array}$ & $\begin{array}{c}0.367^{* * *} \\
(0.027)\end{array}$ & $\begin{array}{c}0.460^{* * *} \\
(0.014)\end{array}$ & $\begin{array}{l}0.009 \\
(0.078)\end{array}$ & $\begin{array}{c}0.437^{* * *} \\
(0.021)\end{array}$ & $\begin{array}{c}0.419^{* * *} \\
(0.021)\end{array}$ & $\begin{array}{c}0.484^{* * *} \\
(0.009)\end{array}$ \\
\hline$\lambda^{f}$ & $\begin{array}{c}0.648^{* * *} \\
(0.028)\end{array}$ & $\begin{array}{l}0.943^{* * *} \\
(0.075)\end{array}$ & $\begin{array}{c}0.630^{* * *} \\
(0.027)\end{array}$ & $\begin{array}{c}0.539^{* * *} \\
(0.014)\end{array}$ & $\begin{array}{c}0.980^{* * * *} \\
(0.076)\end{array}$ & $\begin{array}{c}0.561^{* * *} \\
(0.021)\end{array}$ & $\begin{array}{c}0.579^{* * *} \\
(0.021)\end{array}$ & $\begin{array}{c}0.516^{* * *} \\
(0.009)\end{array}$ \\
\hline \multirow[t]{2}{*}{$\theta$} & $\begin{array}{c}0.065^{*} \\
(0.040) \\
\end{array}$ & $\begin{array}{c}1.132^{*} \\
(0.604)\end{array}$ & $\begin{array}{c}0.112^{*} \\
(0.066)\end{array}$ & $\begin{array}{l}0.001 \\
(0.008)\end{array}$ & $\begin{array}{c}0.001 \\
(0.026)\end{array}$ & $\begin{array}{l}0.001 \\
(0.019)\end{array}$ & $\begin{array}{c}0.018^{* *} \\
(0.009)\end{array}$ & $\begin{array}{l}0.002 \\
(0.002)\end{array}$ \\
\hline & \multicolumn{8}{|c|}{ Structural Estimates } \\
\hline$\xi$ & $\begin{array}{c}0.531^{* * *} \\
(0.066)\end{array}$ & $\begin{array}{l}0.049 \\
(0.084)\end{array}$ & $\begin{array}{c}0.577^{* * * *} \\
(0.067)\end{array}$ & $\begin{array}{c}0.845^{* * * *} \\
(0.047)\end{array}$ & $\begin{array}{l}0.010 \\
(0.010)\end{array}$ & $\begin{array}{c}0.771^{* * *} \\
(0.066)\end{array}$ & $\begin{array}{c}0.718^{* * *} \\
(0.062)\end{array}$ & $\begin{array}{c}0.930^{* * *} \\
(0.034)\end{array}$ \\
\hline$\alpha$ & $\begin{array}{c}0.734^{* * *} \\
(0.071)\end{array}$ & $\begin{array}{c}0.944^{* * *} \\
(0.075)\end{array}$ & $\begin{array}{c}0.663^{* * *} \\
(0.084)\end{array}$ & $\begin{array}{c}0.984^{* * *} \\
(0.344)\end{array}$ & $\begin{array}{c}0.970^{* * *} \\
(0.368)\end{array}$ & $\begin{array}{c}0.976^{*} \\
(0.560)\end{array}$ & $\begin{array}{c}0.842^{* * *} \\
(0.034)\end{array}$ & $\begin{array}{c}0.952^{* * *} \\
(0.040)\end{array}$ \\
\hline Duration & $\begin{array}{c}3.762^{* * * *} \\
(1.011)\end{array}$ & $\begin{array}{c}1.547^{* * *} \\
(0.218)\end{array}$ & $\begin{array}{c}2.966^{* * *} \\
(0.737)\end{array}$ & $\begin{array}{c}64.30^{* * *} \\
(21.49)\end{array}$ & $\begin{array}{c}33.50^{* * *} \\
(12.26)\end{array}$ & $\begin{array}{l}42.60 \\
(101.2)\end{array}$ & $\begin{array}{c}3.326^{* * *} \\
(1.349)\end{array}$ & $\begin{array}{l}21.06 \\
(17.66)\end{array}$ \\
\hline
\end{tabular}

Note: Standard deviation in parentheses. Marginal costs are allowed to follow an autoregressive process of order two. The estimates are obtained using a Maximum Likelihood procedure. 
Table 4: Aggregate Phillips Curves

\begin{tabular}{|c|c|c|c|c|c|c|c|c|}
\hline & GMM & ML & MG & $\mathrm{MG}^{*}$ & $\mathrm{RC}$ & $\mathrm{RC}^{*}$ & $\mathrm{RC}_{2}$ & $\mathrm{RC}_{2}^{*}$ \\
\hline & \multicolumn{8}{|c|}{ Reduced Form - Equation (10) } \\
\hline$\xi$ & \multirow[t]{5}{*}{$\begin{array}{c}0.467^{* *} \\
(0.119)\end{array}$} & $\begin{array}{c}0.666^{* * *} \\
(0.065)\end{array}$ & $\begin{array}{c}0.530^{* * *} \\
(0.025)\end{array}$ & $\begin{array}{c}0.489^{* * * *} \\
(0.018)\end{array}$ & $\begin{array}{c}0.488^{* * *} \\
(0.076)\end{array}$ & $\begin{array}{c}0.488^{* * * *} \\
(0.075)\end{array}$ & $\begin{array}{c}0.496^{* * * *} \\
(0.085)\end{array}$ & $\begin{array}{c}0.497^{* * * *} \\
(0.084)\end{array}$ \\
\hline$\psi_{1}$ & & $\begin{array}{c}1.513^{* * *} \\
(0.363)\end{array}$ & $\begin{array}{c}2.171^{* * * *} \\
(0.205)\end{array}$ & $\begin{array}{c}4.176^{* * *} \\
(0.398)\end{array}$ & $\begin{array}{l}2.714 \\
(1.792)\end{array}$ & $\begin{array}{l}2.669 \\
(1.715)\end{array}$ & $\begin{array}{l}2.834^{*} \\
(1.584)\end{array}$ & $\begin{array}{c}2.790^{* *} \\
(1.425)\end{array}$ \\
\hline$\psi_{2}$ & & $\begin{array}{l}0.006 \\
(0.159)\end{array}$ & $\begin{array}{c}-0.334^{* * *} \\
(0.051)\end{array}$ & $\begin{array}{c}-0.762^{* * *} \\
(0.073)\end{array}$ & $\begin{array}{c}-0.523^{* *} \\
(0.201)\end{array}$ & $\begin{array}{c}-0.515^{* *} \\
(0.197)\end{array}$ & $\begin{array}{c}-0.564^{* *} \\
(0.232)\end{array}$ & $\begin{array}{c}-0.556^{* *} \\
(0.228)\end{array}$ \\
\hline$\rho_{1}$ & & $\begin{array}{c}0.969^{* * *} \\
(0.106)\end{array}$ & $\begin{array}{c}1.080^{* * *} \\
(0.025)\end{array}$ & $\begin{array}{c}1.081^{* * *} \\
(0.020)\end{array}$ & $\begin{array}{c}1.099^{* * *} \\
(0.085)\end{array}$ & $\begin{array}{c}1.100^{* * *} \\
(0.085)\end{array}$ & $\begin{array}{c}1.101^{* * *} \\
(0.095)\end{array}$ & $\begin{array}{c}1.102^{* * *} \\
(0.095)\end{array}$ \\
\hline \multirow[t]{2}{*}{$\rho_{2}$} & & $\begin{array}{l}0.004 \\
(0.106)\end{array}$ & $\begin{array}{c}-0.155^{* * *} \\
(0.024)\end{array}$ & $\begin{array}{c}-0.184^{* * *} \\
(0.018)\end{array}$ & $\begin{array}{c}-0.195^{* * *} \\
(0.076)\end{array}$ & $\begin{array}{c}-0.195^{* * *} \\
(0.075)\end{array}$ & $\begin{array}{c}-0.201^{* *} \\
(0.084)\end{array}$ & $\begin{array}{c}-0.201^{* *} \\
(0.083)\end{array}$ \\
\hline & \multicolumn{8}{|c|}{ Reduced Form - Equation (5) } \\
\hline$\lambda^{b}$ & $\begin{array}{c}0.319^{* * *} \\
(0.056)\end{array}$ & $\begin{array}{c}0.402^{* * *} \\
(0.024)\end{array}$ & $\begin{array}{c}0.347^{* * *} \\
(0.011)\end{array}$ & $\begin{array}{c}0.329^{* * *} \\
(0.008)\end{array}$ & $\begin{array}{c}0.329^{* * * *} \\
(0.035)\end{array}$ & $\begin{array}{c}0.329^{* * * *} \\
(0.034)\end{array}$ & $\begin{array}{c}0.333^{* * * *} \\
(0.038)\end{array}$ & $\begin{array}{c}0.333^{* * * *} \\
(0.038)\end{array}$ \\
\hline$\lambda^{f}$ & $\begin{array}{c}0.680^{* * *} \\
(0.057)\end{array}$ & $\begin{array}{c}0.597^{* * *} \\
(0.024)\end{array}$ & $\begin{array}{c}0.659^{* * *} \\
(0.017)\end{array}$ & $\begin{array}{c}0.667^{* * *} \\
(0.008)\end{array}$ & $\begin{array}{c}0.667^{* * *} \\
(0.034)\end{array}$ & $\begin{array}{c}0.667^{* * *} \\
(0.034)\end{array}$ & $\begin{array}{c}0.664^{* * * *} \\
(0.037)\end{array}$ & $\begin{array}{c}0.664^{* * *} \\
(0.037)\end{array}$ \\
\hline \multirow[t]{2}{*}{$\theta$} & $\begin{array}{l}0.098 \\
(0.071)\end{array}$ & $\begin{array}{c}0.034^{*} \\
(0.019)\end{array}$ & $\begin{array}{c}0.118^{* * * *} \\
(0.015)\end{array}$ & $\begin{array}{c}0.311^{* * * *} \\
(0.047)\end{array}$ & $\begin{array}{l}0.187 \\
(0.169) \\
\end{array}$ & $\begin{array}{l}0.183 \\
(0.161) \\
\end{array}$ & $\begin{array}{l}0.203 \\
(0.173) \\
\end{array}$ & $\begin{array}{r}0.199 \\
(0.161) \\
\end{array}$ \\
\hline & \multicolumn{8}{|c|}{ Structural Estimates } \\
\hline$\xi$ & $\begin{array}{c}0.467^{* *} \\
(0.119)\end{array}$ & $\begin{array}{c}0.666^{* * *} \\
(0.065)\end{array}$ & $\begin{array}{c}0.530^{* * *} \\
(0.025)\end{array}$ & $\begin{array}{c}0.489^{* * * *} \\
(0.018)\end{array}$ & $\begin{array}{c}0.488^{* * * *} \\
(0.076)\end{array}$ & $\begin{array}{c}0.488^{* * * *} \\
(0.075)\end{array}$ & $\begin{array}{c}0.496^{* * * *} \\
(0.085)\end{array}$ & $\begin{array}{c}0.497^{* * * *} \\
(0.084)\end{array}$ \\
\hline$\alpha$ & $\begin{array}{c}0.688^{* * *} \\
(0.197)\end{array}$ & $\begin{array}{c}0.794^{* * *} \\
(0.058)\end{array}$ & $\begin{array}{c}0.659^{* * * *} \\
(0.017)\end{array}$ & $\begin{array}{c}0.515^{* * *} \\
(0.024)\end{array}$ & $\begin{array}{c}0.593^{* * * *} \\
(0.136)\end{array}$ & $\begin{array}{c}0.599^{* * * *} \\
(0.131)\end{array}$ & $\begin{array}{c}0.583^{* * * *} \\
(0.128)\end{array}$ & $\begin{array}{c}0.585^{* * * *} \\
(0.120)\end{array}$ \\
\hline Duration & $\begin{array}{l}3.201 \\
(2.028) \\
\end{array}$ & $\begin{array}{c}4.843^{* * *} \\
(1.364)\end{array}$ & $\begin{array}{c}2.931^{* * * *} \\
(0.143)\end{array}$ & $\begin{array}{c}2.060^{* * * *} \\
(0.102)\end{array}$ & $\begin{array}{c}2.477^{* * * *} \\
(0.832)\end{array}$ & $\begin{array}{c}2.496^{* * * *} \\
(0.815)\end{array}$ & $\begin{array}{c}2.396^{* *} \\
(0.733)\end{array}$ & $\begin{array}{c}2.411^{* * * *} \\
(0.699)\end{array}$ \\
\hline
\end{tabular}

Note: Standard deviation in parentheses. All estimators use observed industry weights, except those denoted by an asterisk where uniform weights are used instead. RC denotes the estimator proposed by Swamy (1970), and $\mathrm{RC}_{2}$ denotes the alternative where both terms in $\hat{\Delta}$ are included. 
Table 5: Aggregate Phillips Curves - Correlated Effects

\begin{tabular}{|c|c|c|c|c|c|c|}
\hline & & & \multicolumn{2}{|c|}{ SURE } & \multicolumn{2}{|c|}{$\mathrm{CCE}$} \\
\hline & GMM & ML & MG & $\mathrm{RC}$ & MG & $\mathrm{RC}$ \\
\hline & \multicolumn{6}{|c|}{ Reduced Form - Equation (10) } \\
\hline$\xi$ & $\begin{array}{c}0.467^{* * *} \\
(0.119)\end{array}$ & $\begin{array}{c}0.666^{* * *} \\
(0.065)\end{array}$ & $\begin{array}{c}0.470^{* * *} \\
(0.020)\end{array}$ & $\begin{array}{c}0.403^{* * *} \\
(0.067)\end{array}$ & $\begin{array}{c}0.405^{* * *} \\
(0.021)\end{array}$ & $\begin{array}{c}0.348^{* * *} \\
(0.071)\end{array}$ \\
\hline$\psi_{1}$ & & $\begin{array}{c}1.513^{* * *} \\
(0.363)\end{array}$ & $\begin{array}{c}1.920^{* * *} \\
(0.213)\end{array}$ & $\begin{array}{l}1.921 \\
(1.646)\end{array}$ & $\begin{array}{c}1.975^{* * *} \\
(0.216)\end{array}$ & $\begin{array}{l}3.125^{*} \\
(1.756)\end{array}$ \\
\hline$\psi_{2}$ & & $\begin{array}{c}0.006^{* * *} \\
(0.159)\end{array}$ & $\begin{array}{c}-0.550^{* * *} \\
(0.032)\end{array}$ & $\begin{array}{c}-0.494^{* * *} \\
(0.111)\end{array}$ & $\begin{array}{c}-0.180^{* * *} \\
(0.054)\end{array}$ & $\begin{array}{c}-0.054 \\
(0.189)\end{array}$ \\
\hline$\rho_{1}$ & & $\begin{array}{c}0.969^{* * *} \\
(0.106)\end{array}$ & $\frac{1.197^{* * *}}{(0.018)}$ & $\begin{array}{c}1.154^{* * *} \\
(0.072)\end{array}$ & $\begin{array}{c}0.983^{* * *} \\
(0.029)\end{array}$ & $\begin{array}{c}0.887^{* * *} \\
(0.125)\end{array}$ \\
\hline \multirow[t]{2}{*}{$\rho_{2}$} & & $\begin{array}{c}0.004^{* * *} \\
(0.106)\end{array}$ & $\begin{array}{c}-0.290^{* * *} \\
(0.017)\end{array}$ & $\begin{array}{c}-0.260^{* * *} \\
(0.060)\end{array}$ & $\begin{array}{c}-0.093^{* * *} \\
(0.028)\end{array}$ & $\begin{array}{c}-0.028 \\
(0.097)\end{array}$ \\
\hline & \multicolumn{6}{|c|}{ Reduced Form - Equation (5) } \\
\hline$\lambda^{b}$ & $\begin{array}{c}0.319^{* * *} \\
(0.056)\end{array}$ & $\begin{array}{c}0.402^{* * *} \\
(0.024)\end{array}$ & $\begin{array}{c}0.321^{* * *} \\
(0.009)\end{array}$ & $\begin{array}{c}0.288^{* * *} \\
(0.034)\end{array}$ & $\begin{array}{c}0.289^{* * *} \\
(0.011)\end{array}$ & $\begin{array}{c}0.258^{* * *} \\
(0.039)\end{array}$ \\
\hline$\lambda^{f}$ & $\begin{array}{c}0.680^{* * * *} \\
(0.057)\end{array}$ & $\begin{array}{c}0.597^{* * *} \\
(0.024)\end{array}$ & $\begin{array}{c}0.675^{* * *} \\
(0.009)\end{array}$ & $\underset{(0.033)}{0.708^{* * *}}$ & $\begin{array}{c}0.707^{* * * *} \\
(0.030)\end{array}$ & $\begin{array}{c}0.736^{* * *} \\
(0.038)\end{array}$ \\
\hline \multirow[t]{2}{*}{$\theta$} & $\begin{array}{c}0.098^{* * * *} \\
(0.071)\end{array}$ & $\begin{array}{c}0.034^{*} \\
(0.019)\end{array}$ & $\begin{array}{c}0.129^{* * *} \\
(0.017)\end{array}$ & $\begin{array}{l}0.154 \\
(0.143) \\
\end{array}$ & $\begin{array}{c}0.166^{* * *} \\
(0.022)\end{array}$ & $\begin{array}{l}0.345 \\
(0.251) \\
\end{array}$ \\
\hline & \multicolumn{6}{|c|}{ Structural Estimates } \\
\hline$\xi$ & $\begin{array}{c}0.467^{* * *} \\
(0.119)\end{array}$ & $\begin{array}{c}0.666^{* * *} \\
(0.065)\end{array}$ & $\begin{array}{c}0.470^{* * * *} \\
(0.020)\end{array}$ & $\begin{array}{c}0.403^{* * *} \\
(0.067)\end{array}$ & $\begin{array}{c}0.405^{* * *} \\
(0.021)\end{array}$ & $\begin{array}{c}0.348^{* * *} \\
(0.071)\end{array}$ \\
\hline$\alpha$ & $\begin{array}{c}0.688^{* * * *} \\
(0.197)\end{array}$ & $\begin{array}{c}0.794^{* * * *} \\
(0.058)\end{array}$ & $\begin{array}{c}0.652^{* * *} \\
(0.019)\end{array}$ & $\begin{array}{c}0.633^{* * *} \\
(0.133)\end{array}$ & $\begin{array}{c}0.623^{* * *} \\
(0.018)\end{array}$ & $\begin{array}{c}0.513^{* * *} \\
(0.120)\end{array}$ \\
\hline Duration & $\begin{array}{l}3.209 \\
(2.028)\end{array}$ & $\begin{array}{c}4.843^{* * *} \\
(1.364)\end{array}$ & $\begin{array}{c}2.872^{* * *} \\
(0.152)\end{array}$ & $\begin{array}{c}2.726^{* * *} \\
(0.992)\end{array}$ & $\begin{array}{c}2.650^{* * * *} \\
(0.128)\end{array}$ & $\begin{array}{c}2.055^{* * *} \\
(0.508)\end{array}$ \\
\hline
\end{tabular}

Note: Standard deviation in parentheses. All estimators use observed industry weights. 
Table 6: Aggregate Phillips Curves - Galí and Gertler (1999)

\begin{tabular}{|c|c|c|c|c|c|c|c|c|}
\hline & GMM & $\mathrm{ML}$ & MG & $\mathrm{MG}^{*}$ & $\mathrm{RC}$ & $\mathrm{RC}^{*}$ & $\mathrm{RC}_{2}$ & $\mathrm{RC}_{2}^{*}$ \\
\hline & \multicolumn{8}{|c|}{ "Reduced Form - Equation (12) } \\
\hline$\underline{\delta}_{1}$ & \multirow[t]{5}{*}{$\begin{array}{c}0.538^{* * *} \\
(0.094)\end{array}$} & $\begin{array}{c}0.666^{* * *} \\
(0.064)\end{array}$ & $\begin{array}{c}0.531^{* * *} \\
(0.025)\end{array}$ & $\begin{array}{c}0.491^{* * *} \\
(0.018)\end{array}$ & $\begin{array}{c}0.492^{* * *} \\
(0.077)\end{array}$ & $\begin{array}{c}0.492^{* * *} \\
(0.076)\end{array}$ & $\begin{array}{c}0.520^{* * *} \\
(0.074)\end{array}$ & $\begin{array}{c}0.531^{* * *} \\
(0.073)\end{array}$ \\
\hline$\underline{\psi}_{1}$ & & $\begin{array}{c}1.514^{* * *} \\
(0.424)\end{array}$ & $\begin{array}{c}2.122^{* * *} \\
(0.199)\end{array}$ & $\begin{array}{c}4.082^{* * *} \\
(0.390)\end{array}$ & $\begin{array}{l}2.664 \\
(1.737)\end{array}$ & $\begin{array}{l}2.632^{*} \\
(1.615)\end{array}$ & $\begin{array}{c}2.927^{* *} \\
(1.352)\end{array}$ & $\begin{array}{c}2.913^{* *} \\
(1.248)\end{array}$ \\
\hline$\underline{\psi_{2}}$ & & $\begin{array}{l}0.006 \\
(0.146)\end{array}$ & $\begin{array}{c}-0.582^{* * *} \\
(0.088)\end{array}$ & $\begin{array}{c}-1.148^{* * *} \\
(0.167)\end{array}$ & $\begin{array}{c}-0.620 \\
(0.726)\end{array}$ & $\begin{array}{c}-0.611^{* *} \\
(0.711)\end{array}$ & $\begin{array}{c}-0.746^{*} \\
(0.421)\end{array}$ & $\begin{array}{c}-0.765^{*} \\
(0.456)\end{array}$ \\
\hline$\rho_{1}$ & & $\begin{array}{c}0.969^{* * * *} \\
(0.098)\end{array}$ & $\begin{array}{c}1.080^{* * *} \\
(0.025)\end{array}$ & $\begin{array}{c}1.081^{* * *} \\
(0.020)\end{array}$ & $\frac{1.102^{* * *}}{(0.085)}$ & $\frac{1.100^{* * *}}{(0.085)}$ & $\begin{array}{c}1.115^{* * *} \\
(0.082)\end{array}$ & $\underbrace{1.117^{* * * *}}_{(0.082)}$ \\
\hline \multirow[t]{2}{*}{$\rho_{2}$} & & $\begin{array}{l}0.004 \\
(0.099) \\
\end{array}$ & $\begin{array}{c}-0.155^{* * *} \\
(0.024)\end{array}$ & $\begin{array}{c}-0.185^{* * *} \\
(0.018)\end{array}$ & $\begin{array}{c}-0.195^{* * *} \\
(0.076)\end{array}$ & $\begin{array}{c}-0.195^{* * *} \\
(0.075)\end{array}$ & $\begin{array}{c}-0.217^{* * *} \\
(0.072)\end{array}$ & $\begin{array}{c}-0.220^{* *} \\
(0.072)\end{array}$ \\
\hline & \multicolumn{8}{|c|}{ Reduced Form - Equation (11) } \\
\hline$\underline{\lambda}^{b}$ & $\begin{array}{c}0.351^{* * *} \\
(0.064)\end{array}$ & $\begin{array}{c}0.402^{* * * *} \\
(0.024)\end{array}$ & $\begin{array}{c}0.349^{* * *} \\
(0.011)\end{array}$ & $\begin{array}{c}0.331^{* * *} \\
(0.008)\end{array}$ & $\begin{array}{c}0.331^{* * *} \\
(0.035)\end{array}$ & $\begin{array}{c}0.331^{* * *} \\
(0.035)\end{array}$ & $\begin{array}{c}0.344^{* * * *} \\
(0.032)\end{array}$ & $\begin{array}{c}0.349^{* * * *} \\
(0.032)\end{array}$ \\
\hline$\underline{\lambda}^{f}$ & $\begin{array}{c}0.645^{* * *} \\
(0.065)\end{array}$ & $\begin{array}{c}0.595^{* * *} \\
(0.024)\end{array}$ & $\begin{array}{c}0.647^{* * *} \\
(0.011)\end{array}$ & $\begin{array}{c}0.664^{* * *} \\
(0.008)\end{array}$ & $\begin{array}{c}0.664^{* * *} \\
(0.035)\end{array}$ & $\begin{array}{c}0.664^{* * *} \\
(0.035)\end{array}$ & $\begin{array}{c}0.651^{* * *} \\
(0.033)\end{array}$ & $\begin{array}{c}0.647^{* * * *} \\
(0.032)\end{array}$ \\
\hline \multirow[t]{2}{*}{$\underline{\theta}$} & $\begin{array}{c}0.080^{*} \\
(0.042)\end{array}$ & $\begin{array}{c}0.039^{*} \\
(0.022)\end{array}$ & $\begin{array}{c}0.119^{* * *} \\
(0.012)\end{array}$ & $\begin{array}{c}0.314^{* * *} \\
(0.030)\end{array}$ & $\begin{array}{l}0.187 \\
(0.124)\end{array}$ & $\begin{array}{c}0.184^{*} \\
(0.112)\end{array}$ & $\begin{array}{c}0.218^{*} \\
(0.104)\end{array}$ & $\begin{array}{c}0.219^{* *} \\
(0.093)\end{array}$ \\
\hline & \multicolumn{8}{|c|}{ Structural Estimates } \\
\hline$\omega$ & $\begin{array}{c}0.368^{* * *} \\
(0.037)\end{array}$ & $\begin{array}{c}0.475^{* * *} \\
(0.064)\end{array}$ & $\begin{array}{c}0.320^{* * *} \\
(0.015)\end{array}$ & $\begin{array}{c}0.231^{* * *} \\
(0.011)\end{array}$ & $\begin{array}{c}0.270^{* * *} \\
(0.066)\end{array}$ & $\begin{array}{c}0.271^{* * *} \\
(0.062)\end{array}$ & $\begin{array}{c}0.270^{* * *} \\
(0.057)\end{array}$ & $\begin{array}{c}0.275^{* * *} \\
(0.054)\end{array}$ \\
\hline$\alpha$ & $\begin{array}{c}0.684^{* * *} \\
(0.097)\end{array}$ & $\begin{array}{c}0.708^{* * *} \\
(0.059)\end{array}$ & $\begin{array}{c}0.600^{* * *} \\
(0.014)\end{array}$ & $\begin{array}{c}0.469^{* * *} \\
(0.014)\end{array}$ & $\begin{array}{c}0.546^{* * *} \\
(0.095)\end{array}$ & $\begin{array}{c}0.548^{* * * *} \\
(0.088)\end{array}$ & $\begin{array}{c}0.518^{* * *} \\
(0.066)\end{array}$ & $\begin{array}{c}0.515^{* * *} \\
(0.059)\end{array}$ \\
\hline Duration & $\begin{array}{c}3.165^{* * *} \\
(0.094) \\
\end{array}$ & $\begin{array}{c}3.430^{* * * *} \\
(0.690)\end{array}$ & $\begin{array}{c}2.502^{* * *} \\
(0.085) \\
\end{array}$ & $\begin{array}{c}1.881^{* * *} \\
(0.050)\end{array}$ & $\begin{array}{c}2.073^{* * *} \\
(0.408) \\
\end{array}$ & $\begin{array}{c}2.061^{* * *} \\
(0.375) \\
\end{array}$ & $\begin{array}{c}2.073^{* *} \\
(0.283) \\
\end{array}$ & $\begin{array}{c}2.062^{* * *} \\
(0.250)\end{array}$ \\
\hline
\end{tabular}

Note: Standard deviation in parentheses. All estimators use observed industry weights, except those denoted by an asterisk where uniform weights are used instead. RC denotes the estimator proposed by Swamy (1970), and $\mathrm{RC}_{2}$ denotes the alternative where both terms in $\hat{\Delta}$ are included. 
Table 7: Aggregate Phillips Curves - Correlated Effects, Galí and Gertler (1999)

\begin{tabular}{|c|c|c|c|c|c|c|}
\hline & & & \multicolumn{2}{|c|}{ SURE } & \multicolumn{2}{|c|}{$\mathrm{CCE}$} \\
\hline & GMM & ML & MG & $\mathrm{RC}$ & MG & $\mathrm{RC}$ \\
\hline & \multicolumn{6}{|c|}{ Reduced Form - Equation (12) } \\
\hline$\underline{\delta}_{1}$ & $\begin{array}{c}0.538^{* * * *} \\
(0.094)\end{array}$ & $\begin{array}{c}0.666^{* * *} \\
(0.064)\end{array}$ & $\begin{array}{c}0.470^{* * * *} \\
(0.007)\end{array}$ & $\begin{array}{c}0.411^{* * * *} \\
(0.067)\end{array}$ & $\begin{array}{c}0.346^{* * *} \\
(0.017)\end{array}$ & $\begin{array}{c}0.347^{* * *} \\
(0.070)\end{array}$ \\
\hline$\underline{\psi}_{1}$ & & $\begin{array}{c}1.514^{* * * *} \\
(0.424)\end{array}$ & $\begin{array}{c}1.895^{* * *} \\
(0.650)\end{array}$ & $\begin{array}{l}1.923 \\
(1.600)\end{array}$ & $\begin{array}{c}3.095^{* * *} \\
(0.406)\end{array}$ & $\begin{array}{c}3.009^{*} \\
(1.692)\end{array}$ \\
\hline$\underline{\psi}_{2}$ & & $\begin{array}{l}0.006 \\
(0.146)\end{array}$ & $\begin{array}{c}-0.756^{*} \\
(0.422)\end{array}$ & $\begin{array}{c}-0.723 \\
(0.979)\end{array}$ & $\begin{array}{c}-1.150^{* * *} \\
(0.274)\end{array}$ & $\begin{array}{l}-1.426 \\
(1.151)\end{array}$ \\
\hline$\rho_{1}$ & & $\begin{array}{c}0.969^{* * * *} \\
(0.098)\end{array}$ & $\begin{array}{c}1.197^{* * * *} \\
(0.018)\end{array}$ & $\frac{1.165^{* * *}}{(0.072)}$ & $\begin{array}{c}0.975^{* * *} \\
(0.022)\end{array}$ & $\begin{array}{c}0.975^{* * * *} \\
(0.092)\end{array}$ \\
\hline \multirow[t]{2}{*}{$\rho_{2}$} & & $\begin{array}{l}0.004 \\
(0.099) \\
\end{array}$ & $\begin{array}{c}-0.290^{* * *} \\
(0.017)\end{array}$ & $\begin{array}{c}-0.267^{* * *} \\
(0.060)\end{array}$ & $\begin{array}{c}-0.101^{* * *} \\
(0.019)\end{array}$ & $\begin{array}{c}-0.101^{* * *} \\
(0.079)\end{array}$ \\
\hline & \multicolumn{6}{|c|}{ Reduced Form - Equation (11) } \\
\hline$\underline{\lambda}^{b}$ & $\begin{array}{c}0.351^{* * * *} \\
(0.064)\end{array}$ & $\begin{array}{c}0.402^{* * *} \\
(0.024)\end{array}$ & $\begin{array}{c}0.321^{* * *} \\
(0.003)\end{array}$ & $\begin{array}{c}0.292^{* * * *} \\
(0.034)\end{array}$ & $\begin{array}{c}0.258^{* * *} \\
(0.009)\end{array}$ & $\begin{array}{c}0.258^{* * * *} \\
(0.039)\end{array}$ \\
\hline$\underline{\lambda}^{f}$ & $\begin{array}{c}0.645^{* * *} \\
(0.065)\end{array}$ & $\begin{array}{c}0.595^{* * * *} \\
(0.024)\end{array}$ & $\begin{array}{c}0.674^{* * *} \\
(0.009)\end{array}$ & $\begin{array}{c}0.702^{* * * *} \\
(0.034)\end{array}$ & $\begin{array}{c}0.736^{* * *} \\
(0.009)\end{array}$ & $\begin{array}{c}0.736^{* * * *} \\
(0.038)\end{array}$ \\
\hline \multirow[t]{2}{*}{$\underline{\theta}$} & $\begin{array}{c}0.080^{*} \\
(0.042)\end{array}$ & $\begin{array}{c}0.039^{*} \\
(0.022)\end{array}$ & $\begin{array}{c}0.130^{* * *} \\
(0.045)\end{array}$ & $\begin{array}{l}0.150 \\
(0.126) \\
\end{array}$ & $\begin{array}{c}0.312^{* * *} \\
(0.040)\end{array}$ & $\begin{array}{c}0.304^{*} \\
(0.164) \\
\end{array}$ \\
\hline & \multicolumn{6}{|c|}{ Structural Estimates } \\
\hline$\omega$ & $\begin{array}{c}0.368^{* * * *} \\
(0.037)\end{array}$ & $\begin{array}{c}0.475^{* * * *} \\
(0.064)\end{array}$ & $\begin{array}{c}0.284^{* * *} \\
(0.019)\end{array}$ & $\begin{array}{c}0.245^{* * *} \\
(0.056)\end{array}$ & $\begin{array}{c}0.173^{* * *} \\
(0.008)\end{array}$ & $\begin{array}{c}0.175^{* * * *} \\
(0.034)\end{array}$ \\
\hline$\alpha$ & $\begin{array}{c}0.684^{* * * *} \\
(0.097)\end{array}$ & $\begin{array}{c}0.708^{* * * *} \\
(0.059)\end{array}$ & $\begin{array}{c}0.602^{* * *} \\
(0.049)\end{array}$ & $\begin{array}{c}0.594^{* * *} \\
(0.121)\end{array}$ & $\begin{array}{c}0.499^{* * *} \\
(0.021)\end{array}$ & $\begin{array}{c}0.503^{* * *} \\
(0.091)\end{array}$ \\
\hline Duration & $\begin{array}{c}3.165^{* * *} \\
(0.094)\end{array}$ & $\begin{array}{c}3.430^{* * * *} \\
(0.690)\end{array}$ & $\begin{array}{c}2.512^{* * *} \\
(0.307) \\
\end{array}$ & $\begin{array}{c}2.466^{* * *} \\
(0.889) \\
\end{array}$ & $\begin{array}{c}1.995^{* * *} \\
(0.085) \\
\end{array}$ & $\begin{array}{c}2.013^{* * *} \\
(0.369) \\
\end{array}$ \\
\hline
\end{tabular}

Note: Standard deviation in parentheses. All estimators use observed industry weights. 
Figure 1: Two-Sector Simulations
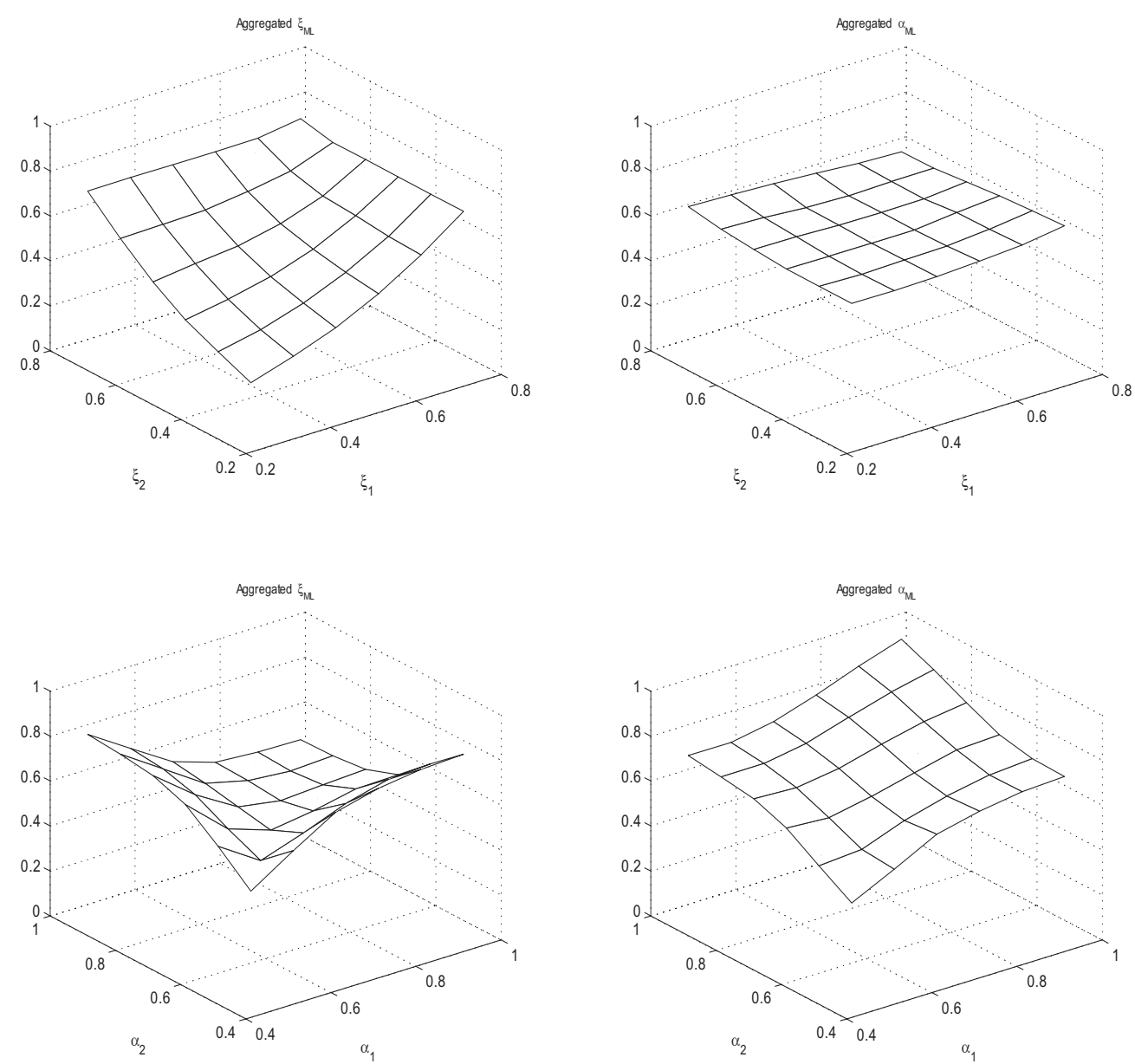
Figure 2: Sectoral Inflation Rates (unfiltered)
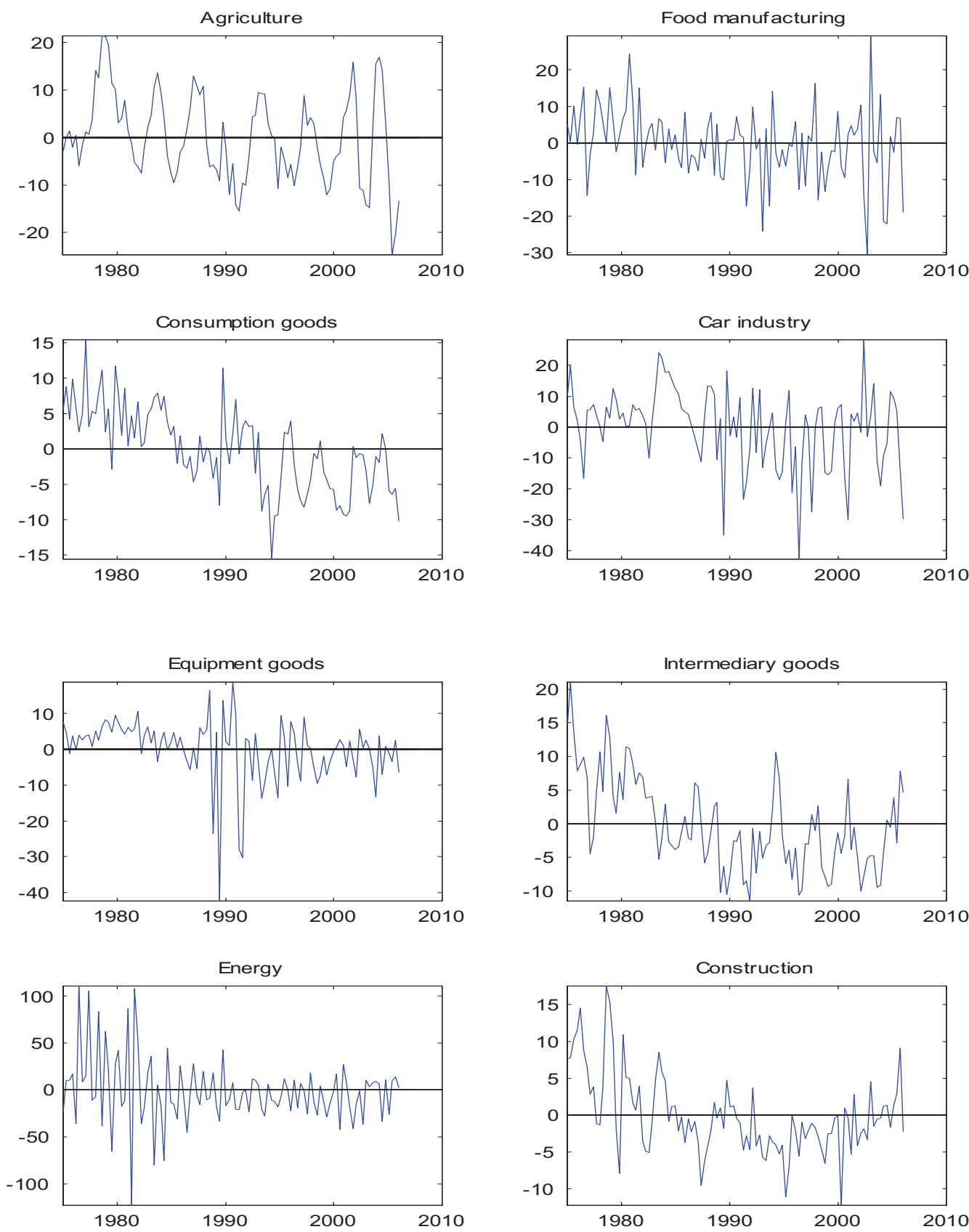
Figure 2: Sectoral Inflation Rates (unfiltered) - Continued
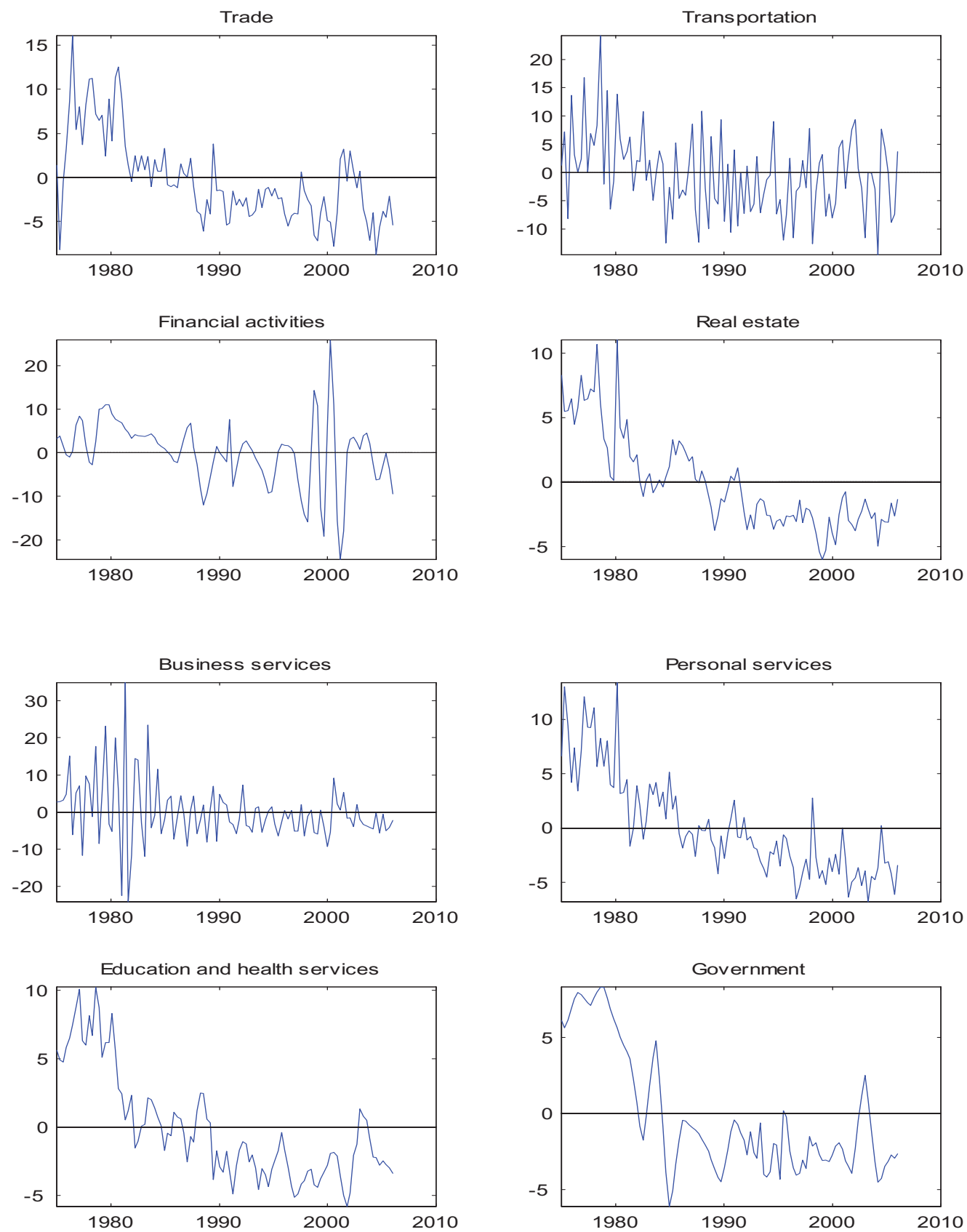
Figure 3: Sectoral Marginal Costs (unfiltered)
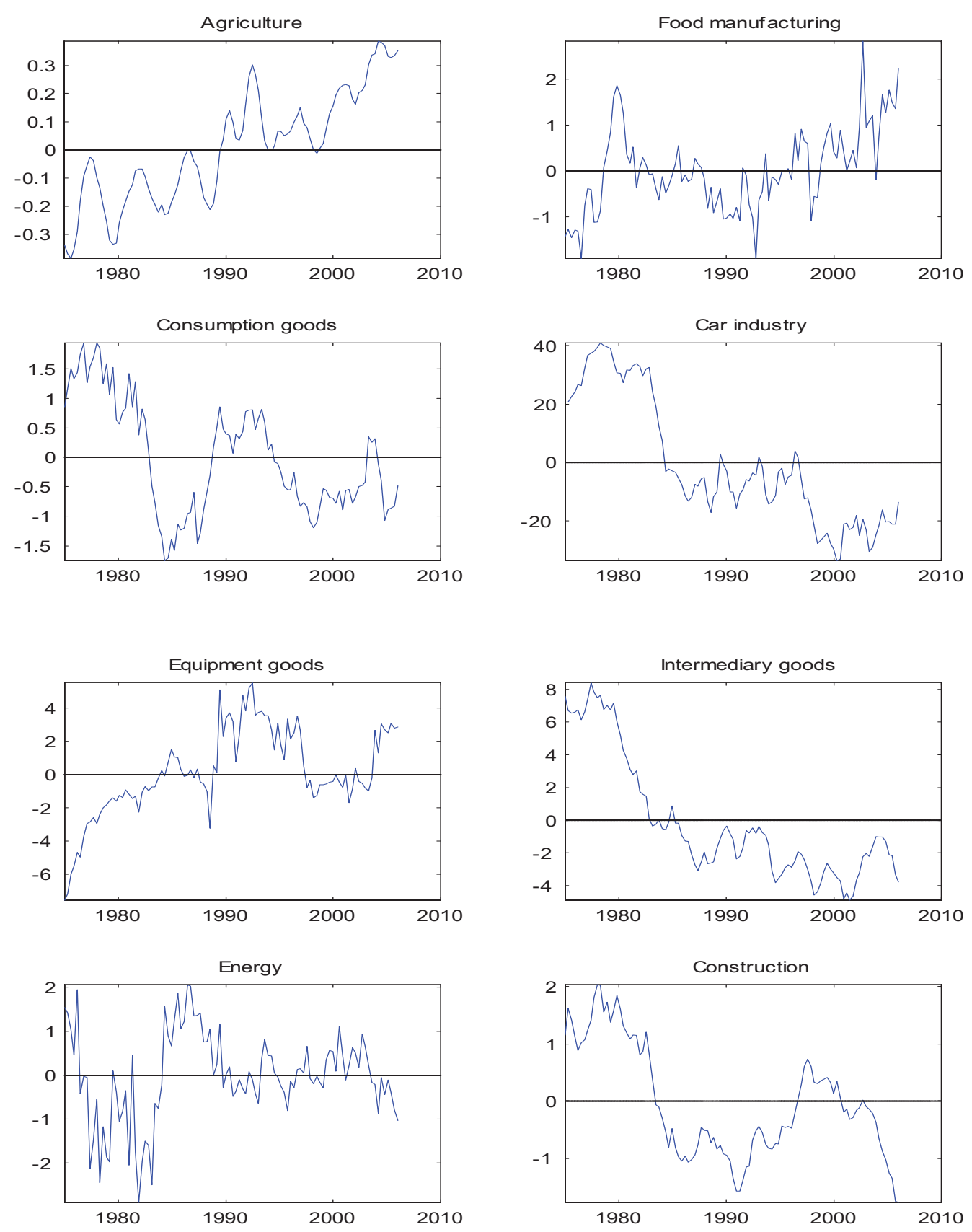
Figure 3: Sectoral Marginal Costs (unfiltered) - Continued
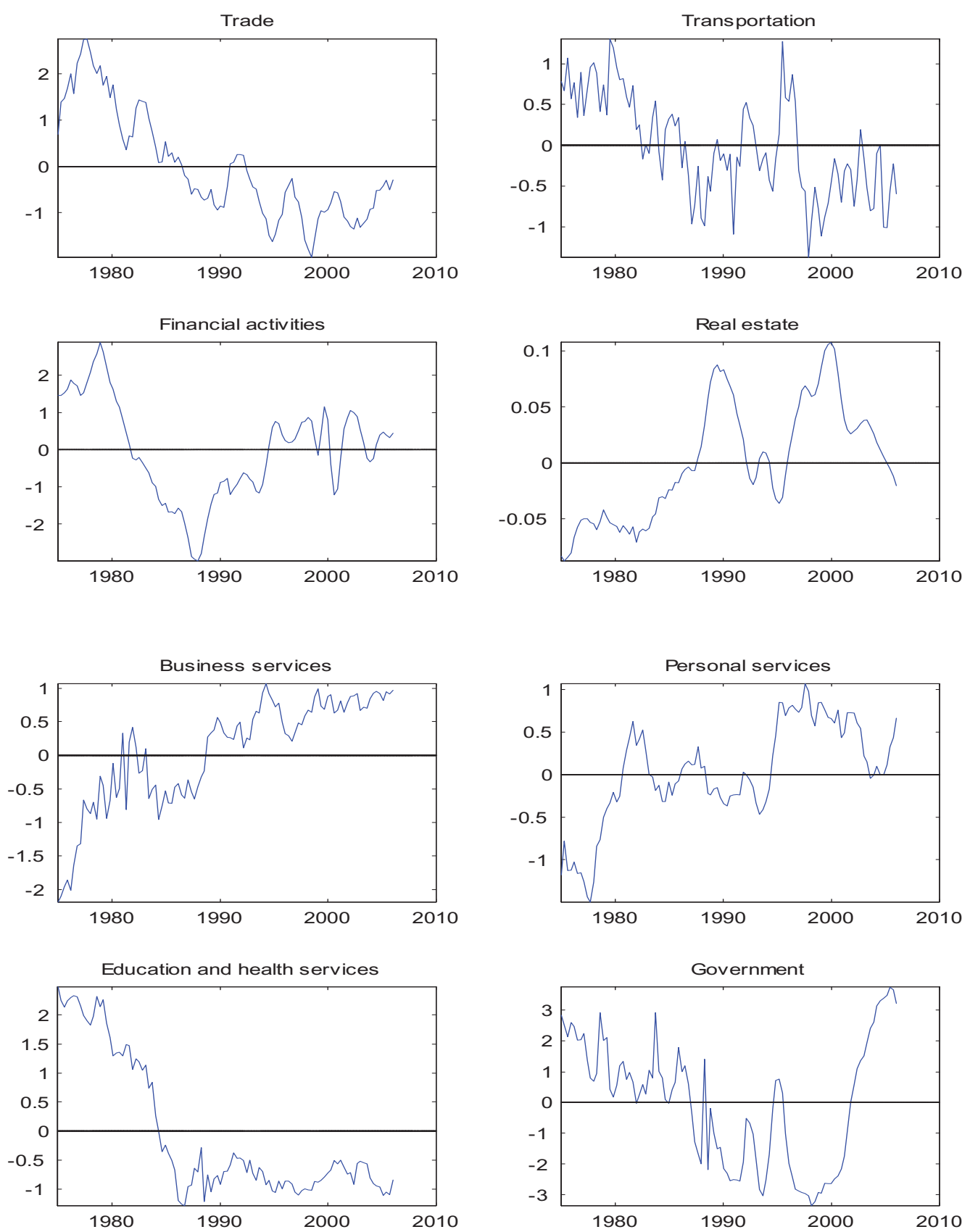
Figure 4: Aggregate Inflation and Marginal Costs (unfiltered)

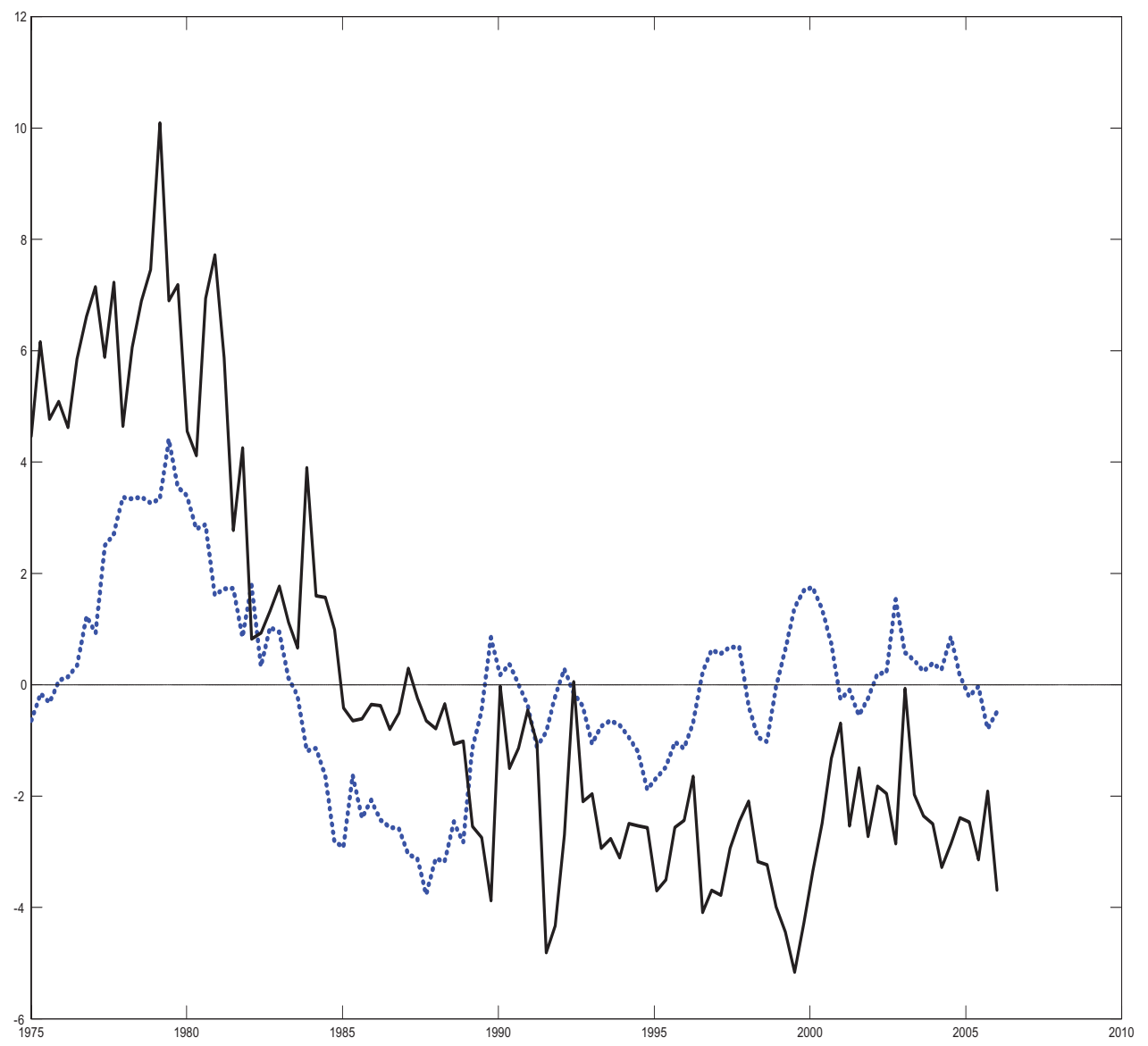

Note: Plain line denotes observed inflation and dotted line is the real marginal cost. 
Figure 5: Industry Phillips Curves
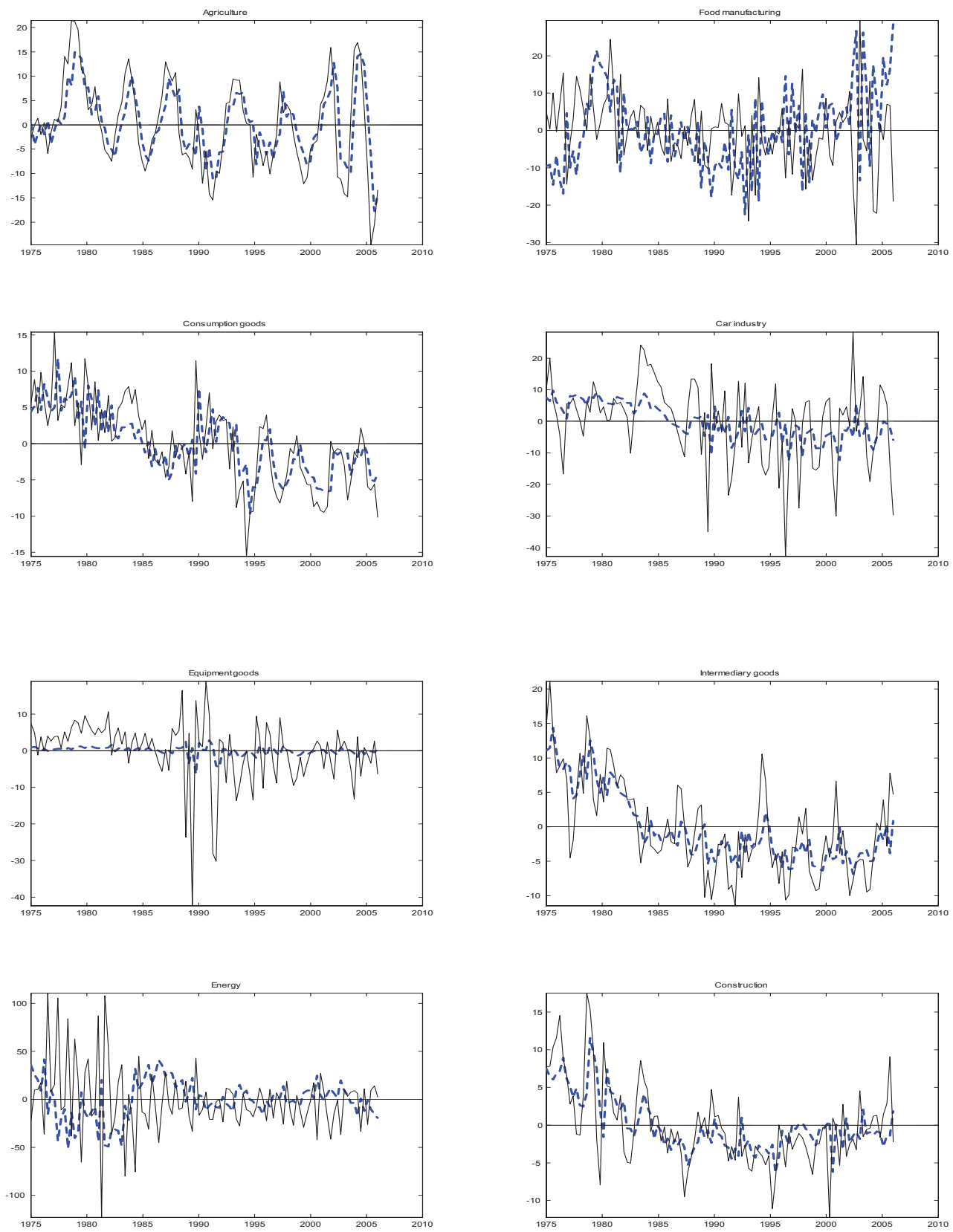

Note: Plain line denotes observed inflation and dotted line is fitted inflation. 


\section{European Central Bank Working Paper Series}

For a complete list of Working Papers published by the ECB, please visit the ECB's website (http://www.ecb.int)

745 "Market discipline, financial integration and fiscal rules: what drives spreads in the euro area government bond market?" by S. Manganelli and G.Wolswijk,April 2007.

746 "U.S. evolving macroeconomic dynamics: a structural investigation" by L. Benati and H. Mumtaz,April 2007.

747 "Tax reform and labour-market performance in the euro area: a simulation-based analysis using the New Area-Wide Model" by G. Coenen, P. McAdam and R. Straub,April 2007.

748 "Financial dollarization: the role of banks and interest rates" by H. S. Basso, O. Calvo-Gonzalez and M. Jurgilas, May 2007.

749 "Excess money growth and inflation dynamics" by B. Roffia and A. Zaghini, May 2007.

750 "Long run macroeconomic relations in the global economy" by S. Dees, S. Holly, M. H. Pesaran and L.V. Smith, May 2007.

75I "A look into the factor model black box: publication lags and the role of hard and soft data in forecasting GDP” by M. Bańbura and G. Rünstler, May 2007.

752 "Econometric analyses with backdated data: unified Germany and the euro area" by E.Angelini and M. Marcellino, May 2007.

753 “Trade credit defaults and liquidity provision by firms" by F. Boissay and R. Gropp, May 2007.

754 "Euro area inflation persistence in an estimated nonlinear DSGE model" by G.Amisano and O.Tristani, May 2007.

755 "Durable goods and their effect on household saving ratios in the euro area" by J.Jalava and I. K. Kavonius, May 2007.

756 "Maintaining low inflation: money, interest rates, and policy stance" by S. Reynard, May 2007.

757 "The cyclicality of consumption, wages and employment of the public sector in the euro area" by A. Lamo, J.J. Pérez and L. Schuknecht, May 2007.

758 "Red tape and delayed entry" by A. Ciccone and E. Papaioannou, June 2007.

759 "Linear-quadratic approximation, external habit and targeting rules" by P. Levine, J. Pearlman and R. Pierse, June 2007.

760 "Modelling intra- and extra-area trade substitution and exchange rate pass-through in the euro area" by A. Dieppe and T.Warmedinger, June 2007.

761 "External imbalances and the US current account: how supply-side changes affect an exchange rate adjustment" by P. Engler, M. Fidora and C. Thimann, June 2007.

762 "Patterns of current account adjustment: insights from past experience" by B.Algieri and T. Bracke, June 2007. 
763 "Short- and long-run tax elasticities: the case of the Netherlands" by G.Wolswijk, June 2007.

764 "Robust monetary policy with imperfect knowledge" by A. Orphanides and J. C.Williams, June 2007.

765 “Sequential optimization, front-loaded information, and U.S. consumption” by A.Willman, June 2007.

766 "How and when do markets tip? Lessons from the Battle of the Bund" by E. Cantillon and P.-L.Yin, June 2007.

767 “Explaining monetary policy in press conferences” by M. Ehrmann and M. Fratzscher, June 2007.

768 "A new approach to measuring competition in the loan markets of the euro area" by M. van Leuvensteijn, J.A. Bikker,A. van Rixtel and C. Kok Sørensen, June 2007.

769 “The ‘Great Moderation’ in the United Kingdom” by L. Benati, June 2007.

770 “Welfare implications of Calvo vs. Rotemberg pricing assumptions” by G. Lombardo and D. Vestin, June 2007.

77I "Policy rate decisions and unbiased parameter estimation in typical monetary policy rules" by J. Podpiera, June 2007.

772 "Can adjustment costs explain the variability and counter-cyclicality of the labour share at the firm and aggregate level?" by P. Vermeulen, June 2007.

773 "Exchange rate volatility and growth in small open economies at the EMU periphery" by G. Schnabl, July 2007.

774 "Shocks, structures or monetary policies? The euro area and US after 200 I" by L. Christiano, R. Motto and M. Rostagno, July 2007.

775 "The dynamic behaviour of budget components and output" by A. Afonso and P. Claeys, July 2007.

776 “Insights gained from conversations with labor market decision makers” by T. F. Bewley, July 2007.

777 "Downward nominal wage rigidity in the OECD" by S. Holden and F.Wulfsberg, July 2007.

778 “Employment protection legislation and wages” by M. Leonardi and G. Pica, July 2007.

779 “On-the-job search and the cyclical dynamics of the labor market” by M. U. Krause and T.A. Lubik, July 2007.

780 "Dynamics and monetary policy in a fair wage model of the business cycle" by D. de la Croix, G. de Walque and R.Wouters, July 2007.

781 "Wage inequality in Spain: recent developments” by M. Izquierdo and A. Lacuesta, July 2007.

782 "Panel data estimates of the production function and product and labor market imperfections" by S. Dobbelaere and J. Mairesse, July 2007.

783 "The cyclicality of effective wages within employer-employee matches: evidence from German panel data" by S.Anger, July 2007.

784 "Understanding the dynamics of labor shares and inflation” by M. Lawless and K. Whelan, July 2007

785 “Aggregating Phillips curves” by J. Imbs, E. Jondeau and F. Pelgrin, July 2007. 


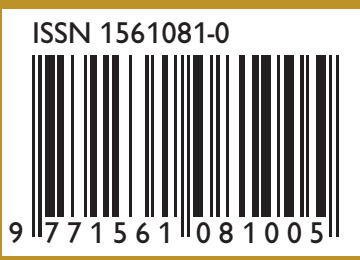

